\title{
LUNG VOLUMES AND FORCED VENTILATORY FLOWS
}

\author{
REPORT WORKING PARTY \\ STANDARDIZATION OF LUNG FUNCTION TESTS \\ EUROPEAN COMMUNITY FOR STEEL AND COAL
}

\author{
OFFICIAL STATEMENT OF THE EUROPEAN RESPIRATORY SOCIETY \\ हू. \\ Ph.H Quanjer, G.J. Tammeling, J.E. Cótes, O.F. Pedersen, R. Peslin, J-C. Yernault
}

\begin{abstract}
1 Introduction
1.1 Static lung volumes and capacities

. .5

1.2 Dynamic lung volumes and forced ventilatory flows ....... 6

1.3 Application of tests ...

2 Indices and definitions

2.1 Static lung volumes

2.2 Forced expiration ............................................................. 11

2.3 Forced inspiration ............................................................ 12

2.4 Maximal voluntary ventilation ...................................... 12

3 Methods

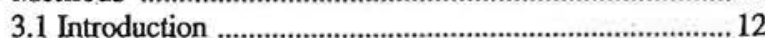

3.2 Measurement variability ............................................ 12

3.3 Correcting to standard conditions ....................................13

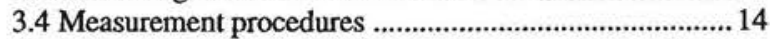

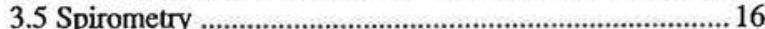

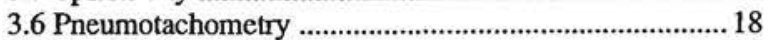

3.7 Gas dilution methods ..................................................... 18

3.8 Whole body plethysmography .......................................21

3.9 Radiographic determination of lung volumes ................2 24

4 Bronchodilator response and serial measurements ........2 24

4.1 Assessment of response to bronchodilator drugs............ 24

4.2 Serial measurements

CONTENTS

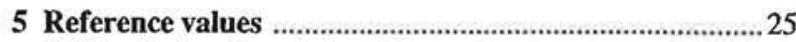

5.1 Predictions for adults of Caucasian descent ..................25

5.2 Other ethnic groups and other factors .............................26

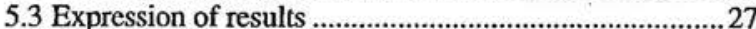

6 Summary of recommendations ...........................................2 27

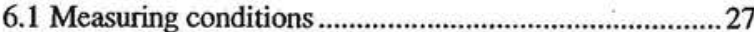

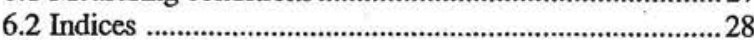

6.3 Reference values ...........................................................29

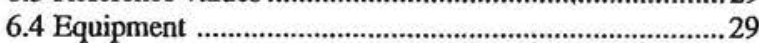

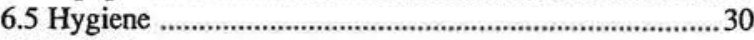

APPENDIX

A Factors affecting measurements of gas flow by pneumo-

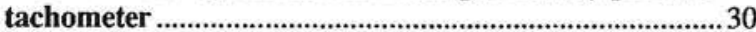

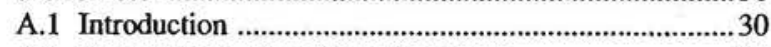

A.2 Temperature, viscosity and volume ............................30

A.3 Conclusions ................................................................. 31

B Measuring lung volume by the helium dilution method 32

B.1 Sources of error .............................................................32

B.2 Heat conductivity meter ................................................ 32

B.3 Solubility of helium ……........................................... 32

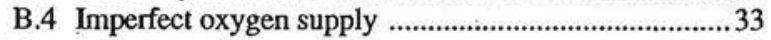

References

\section{Introduction}

Lung volumes are subdivided into static and dynamic lung volumes. Static lung volumes are measured by methods which are based on the completeness of respiratory manoeuvres, so that the velocity of the manoeuvres should be adjusted accordingly. The measurements taken during fast breathing movements are described as dynamic lung volumes and as forced inspiratory and expiratory flows.

\subsection{Static lung volumes and capacities}

The volume of gas in the lung and intrathoracic airways is determined by the properties of lung parenchyma and surrounding organs and tissues, surface tension, the force exerted by respiratory muscles, by lung reflexes and by the properties of airways. The gas volumes of thorax and lung are the same except in the case of a pneumothorax. If two or more subdivisions of the total lung capacity are taken together, the sum of the constituent volumes is described as a lung capacity. Lung volumes and capacities are described in more detail in $\S 2$.

\subsubsection{Determinants}

Factors which determine the size of the normal lung include stature, age, sex, body mass, posture, habitus, ethnic group, reflex factors and daily activity pattern. The level of maximal inspiration (total lung capacity, TLC) is influenced by the force developed by the inspiratory muscles (disorders include e.g. muscular dystrophy), the 


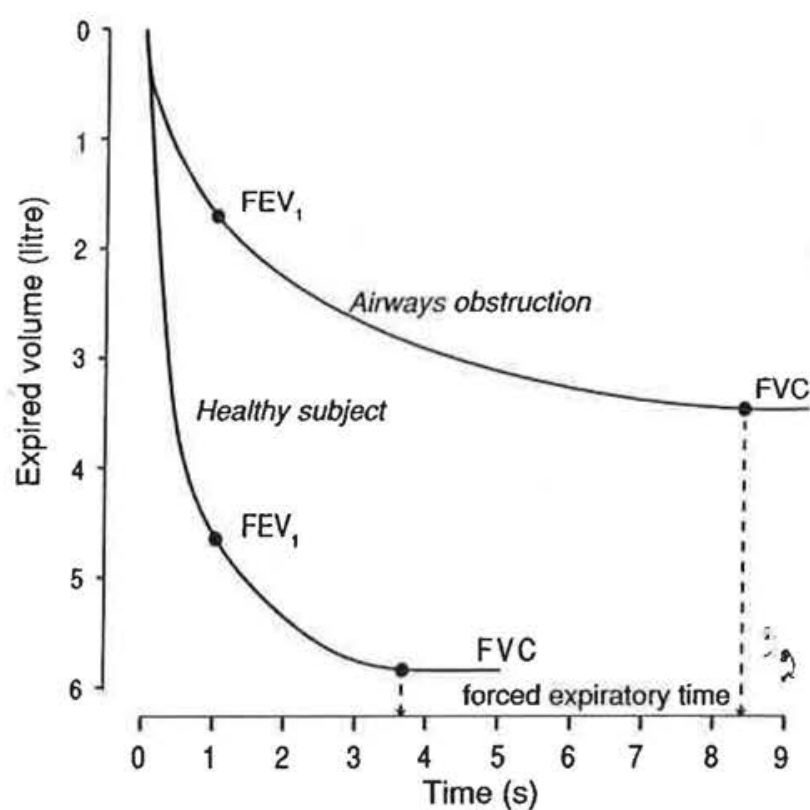

Fig. 1. - Idealized forced expiratory spirograms (volume-time curves) of patients with airflow limitation and healthy subjects breathing air.

elastic recoil of the lung (disorders include e.g. pulmonary fibrosis and emphysema) and the elastic properties of the thorax and adjacent structures (disorders include e.g. ankylosis of joints). The level of maximal expiration (residual volume, RV) is determined by the force exerted by respiratory muscles (disorders include $e . g$. muscle paralysis), obstruction, occlusion and compression of small airways (disorders include e.g. emphysema) and by the mechanical properties of lung and thorax (disorders include diffuse fibrosis, kyphoscoliosis).

Assessing the total lung capacity is indispensable in establishing a restrictive ventilatory defect or in diagnosing abnormal lung distensibility, as may occur in patients with emphysema. Measurements of lung volumes are also essential in interpreting data on lung elastic recoil pressure, instantaneous ventilatory flows, airways resistance, and the transfer factor of the lung, since these are all volume dependent.

\subsubsection{Restrictive ventilatory defects}

Static lung volumes may be diminished by disorders which restrict lung expansion (restrictive ventilatory defects), such as neuromuscular disorders, diseases of the chest wall and abdomen, disorders of the pleural space, increase in lung stiffness, and decrease in the number of available alveolar units (lung resection, atelectasis, scars).

A restrictive ventilatory defect is best described on the basis of a reduced TLC rather than from vital capacity measurements. The vital capacity, i.e. the volume change between RV and TLC, may be diminished by both restrictive and obstructive ventilatory defects; in the latter case it is due to an increase in residual volume due to (premature) airways closure (gas trapping) and airflow limitation at low lung volumes $[1,2]$, leading to incomplete lung emptying. However, in small airways disease the RV is increased with no change in TLC; accordingly the VC is reduced (with a proportionate decrease in FEV, [3]). Hence the vital capacity alone is of little use in discriminating between restrictive, obstructive and mixed ventilatory defects. In some cases of cystic fibrosis, which primarily affects the airways, temporary decreases in TLC have been described, possibly due to partial atelectasis [4].

\subsubsection{Hyperinflation}

The total lung capacity may be abnormally large in acromegaly and in the case of increased lung distensibility. In the latter situation RV and the functional residual capacity (FRC) are also increased, whereas TLC tends to decrease. The term hyperinflation has been proposed to describe the increase in FRC [5]; however, it is also frequently used to describe increases in TLC or RV. Hyperinflation is usually associated with an obstructive ventilatory defect (see $\S 1.2 .2$ ), but the relationship between the increased FRC and the lowered FEV, is weak [6].

\subsection{Dynamic lung volumes and forced ventilatory flows}

\section{1:2.1 Determinants}

The ability to move air rapidly in and out of the lungs is essential for normal activity, and any diminution of more than minimal extent will usually cause breathlessness on exertion and hence reduce the capacity for exercise. Ventilatory impairment can arise from changes in the nervous system, the skeleto-muscular system, the skin and subcutaneous tissues, the lungs or the inhaled gas. However the commonest cause is narrowing of the airways. The impairment can be detected by dynamic spirometry, which constitutes the first stage in the assessment of respiratory function. Subsequent stages include consideration of mechanisms, the amount of function which remains, the cause of the condition and the means for its alleviation.

Dynamic lung volumes and flows are assessed during forced inspiration or expiration, or during forced breathing when maximal effort is applied throughout the respiratory manoeuvre. In this it differs from the measurement of static lung volumes where the maximal effort is generated only at the beginning and end of the manoeuvre. The results of dynamic spirometry are usually expressed in terms of the relationships of inspired or expired volume to time as described by the volume-time curve (spirogram: fig. 1). They are also expressed as the relationship of maximal flow to lung volume described by the flowvolume curve (fig. 2).

\subsubsection{Obstructive ventilatory defect}

The obstructive ventilatory defect is defined as a decrease in FEV, (the volume exhaled in 1 second during a forced expiration started at the level of TLC) out of proportion of any decrease in VC, i.e. a decrease in the FEV,/VC ratio. The flows during a forced expiration are reduced concomitantly. 


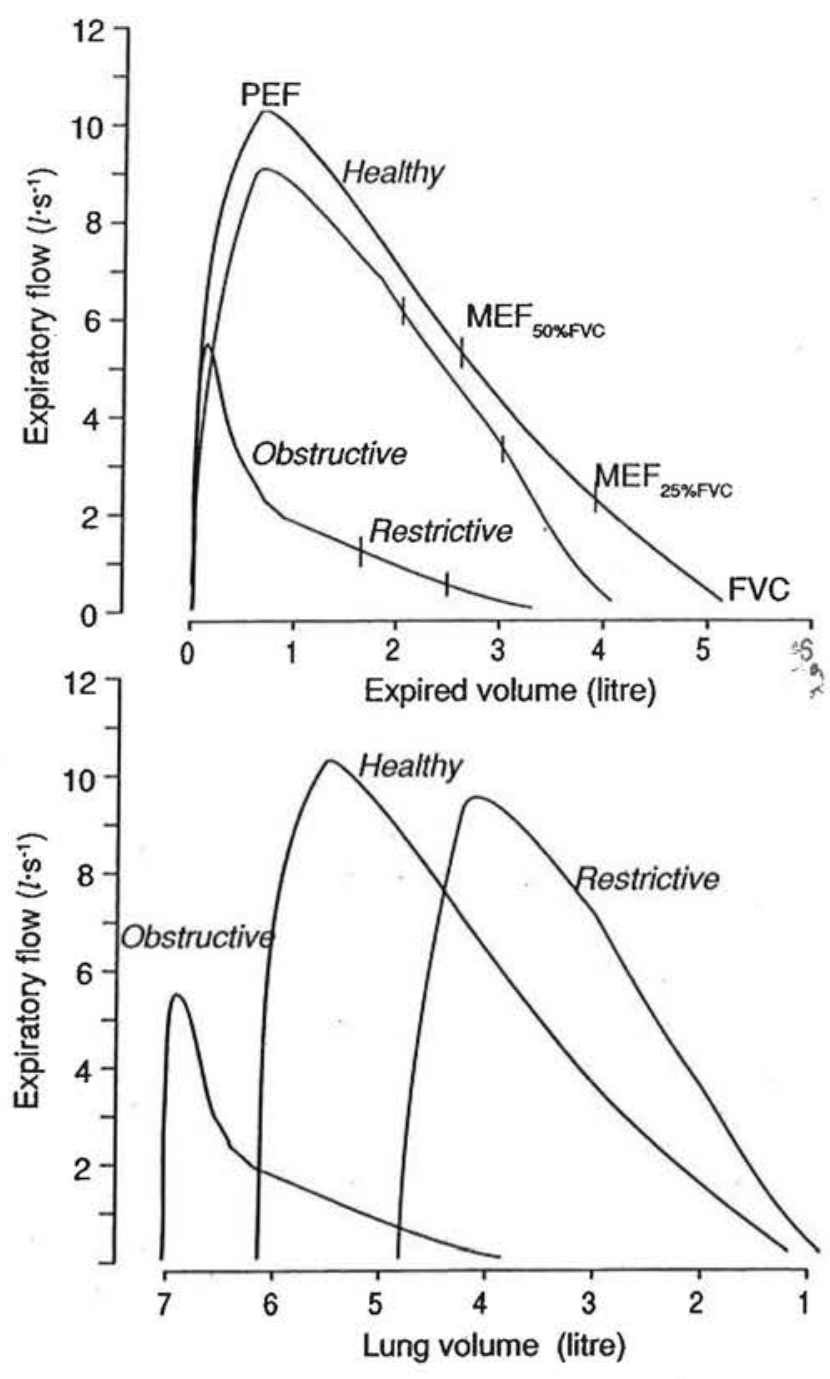

Fig. 2. - Maximal expiratory flow-volume curves of healthy subjects and in patients with an obstructive and restrictive ventilatory defect. In the top panel the curves are superimposed at TLC, the lower panel shows maximal expiratory flow as a function of absolute lung volume.

The determinants of expiratory flow during a forced expiration are complex. During the forced expiration both the pleural and alveolar pressures are greatly increased above pressure at the mouth. However, after a brief effort dependent phase, which includes the peak expiratory flow, the pressure drop from alveoli to the mouth causes pressure in intrathoracic airways to become less than the surrounding pleural pressure; hence these airways are dynamically compressed and act as flow limiting segments, causing forced expiratory flows to be effort independent. At this stage the forced expiratory flow is determined by a complex interplay between lung elastic recoil pressure, the resistance to airflow of airways upstream of the flow limiting segment, and the elastic properties of the compressed airway «tube law» [7]. In healthy, young subjects near residual volume the high intrathoracic pressures and hence airway compression cannot be maintained, so that expiratory flows may become effort dependent once more. The elastic properties of the extrathoracic airways vary with the stretch to which they are subjected, such as with flexion and extension of the neck [8]. Within an individual the lung elastic recoil pressure varies with volume and hence with the level of lung inflation. During a forced expiration, the effect of reduction in lung volume due to gas compression is more pronounced in a patient with obstructive lung disease than in a healthy subject; this is because the absolute volume may be increased and hence the volume compressed greater, and with a limited VC this represents a greater proportion of VC. Thus the patient's lung is at a lower point on its pressure-volume curve and hence at a lower elastic recoil pressure. This pressure would be higher if less expiratory force were to be applied. Since the recoil pressure determines the expiratory flow the latter can sometimes be increased by the patient exerting less expiratory sffort. Under these circumstances the volume expired in 1 second $\left(\mathrm{FEV}_{1}\right)$ is larger than during a maximal effort [9-12].

\subsubsection{Site of expiratory flow limitation}

The (forced) vital capacity and instantaneous flows can be obtained from both volume-time and flow-volume curves. Time averaged flows or forced expiratory times are derived from volume-time curves. In healthy subjects, maximal flows at large lung volumes reflect mainly the flow characteristics of the trachea and central bronchi, whilst those at small lung volumes are usually held to reflect more the characteristics of the smaller intrathoracic airways $[13,14]$. In the latter the flow is laminar, whilst in the large airways it is at least partly turbulent. The turbulent component of the airway resistance but not the laminar component is reduced by replacing the respired air with gas of low density, for example, helium with $20 \%$ oxygen. However, the reduction in gas density also has other effects which make interpretation difficult. On this account the procedure is not recommended for routine assessment $[15,16]$.

In lung diseases including asthma, which cause acute changes in ventilatory capacity, the larger «central» intrathoracic airways are supposed to be the principal site of reversible airflow limitation. The smaller «peripheral» airways contribute to the limitation when there is bronchiolitis as can occur with infection, asthma or chronic exposure to fumes, fibrosis of the respiratory bronchioles as in asbestosis, or reduced lung elasticity; the latter is a feature of emphysema. In patients with emphysema the site of flow limitation moves peripherally $[13,14]$. Intravenous administration of histamine in dogs similarly moves the flow limiting segment towards the periphery, but this is overruled by adding a central obstruction [17]. In heart-lung transplant patients who develop bronchiolitis obliterans the first physiological abnormality is a decrease of flows at low lung volumes with a progressive increase in convexity towards the volume axis of the terminal part of the flow-volume curve [18].

A progressive deviation from normal ventilatory capacity can be detected by longitudinal measurements (§ 4.2); the principal constraints are then the appropriateness and reproducibility of the tests. For measurements at one point in time an additional constraint is what 
constitutes normal function for the individual in question. The estimate of normal lung function is called the reference value ( $\$ 5$ ).

\subsubsection{Extrathoracic ainway obstruction}

During a forced expiration the extrathoracic airways are subjected to a positive transmural pressure, whereas during forced inspiratory manoeuvres their calibre decreases due to the negative transmural pressure. Accordingly extrathoracic airway obstruction is best detected during a forced inspiration (see $\S 2.3$ ).

\subsection{Application of tests}

Assessments of lung volumes and forced ventilatory flows described in this report are usually the first to be applied in clinical and non-clinical work. They are used in:

1 The diagnosis of subjects with known or suspected lung disease, e.g. to identify intra- or extrathoracic airflow limitation or a restrictive ventilatory defect.

2 The treatment of patients with lung disease, to monitor the effect of preventive measures (e.g. allergen avoidance, therapeutic interventions (effects of drugs), or diagnostic procedures (e.g. the use of the $\mathrm{FEV}_{1}$ in tests of bronchial responsiveness).

3 Establishing a prognosis, based on e.g. the severity and extent of respiratory impairment, on the effectiveness of therapeutic interventions, or the rate of deterioration over a period of time.

4 Making a pre-operative assessment with a view to estimating the risk from respiratory complications and optimising the patient's condition pre-operatively.

5 Evaluating pulmonary disablement.

Table 1. - Selected SI base and derived units, and nonSI units retained.

\begin{tabular}{|c|c|c|c|c|}
\hline Name of quantity & $\begin{array}{l}\text { Name } \\
\text { of unit }\end{array}$ & $\begin{array}{l}\text { Symbol } \\
\text { for unit }\end{array}$ & $\begin{array}{l}\text { Definition } \\
\text { of unit }\end{array}$ & \\
\hline length & metre & $\mathrm{m}$ & & \\
\hline mass & kilogramme & $\mathrm{kg}$ & & \\
\hline time & second & $s$ & & \\
\hline $\begin{array}{c}\text { thermodynamic } \\
\text { temperature }\end{array}$ & kelvin & $\mathbf{K}$ & - & \\
\hline $\begin{array}{l}\text { amount of } \\
\text { substance }\end{array}$ & mole & $\mathrm{mol}$ & & \\
\hline frequency & hertz & $\mathrm{Hz}$ & $\mathrm{s}^{-1}$ & \\
\hline force & newton & $\mathrm{N}$ & $\mathrm{m} \cdot \mathrm{kg} \cdot \mathrm{s}^{-2}$ & \\
\hline pressure & pascal & $\mathrm{Pa}$ & $\mathrm{N} \cdot \mathrm{m}^{-2}$ & \\
\hline dynamic viscosity & poise & $\mathbf{P}$ & $10^{-1} \mathrm{~Pa} \cdot \mathrm{s}$ & \\
\hline Celsius temperature & degree & ${ }^{\circ} \mathrm{C}$ & $*$ & \\
\hline \multirow[t]{4}{*}{ time } & minute & $\min$ & $60 \mathrm{~s}$ & \\
\hline & hour & h & $3600 \mathrm{~s}$ & \\
\hline & day & d & $86400 \mathrm{~s}$ & \\
\hline & year & a & $365 \mathrm{~d}$ & \\
\hline volume & litre. & $l$ & $10^{-3}$ & $\mathrm{~m}^{3}$ \\
\hline
\end{tabular}

6 Monitoring the respiratory health of populations in epidemiological studies and by monitoring at the workplace.

7 Aiding in the interpretation of other lung function tests which are volume dependent, e.g. the transfer factor etc

Positive test results reveal functional patterns rather than a particular disease. For example, the VC and the FEV, may be reduced by a restrictive and by an obstructive ventilatory defect, and these conditions may occur concurrently (see $\S 2.1 .10$ ). The tests contribute information which can complement that obtained in other ways.

\section{Iñices and definitions}

A schematic representation of static lung volumes is given in figure 3. The definitions of lung volumes and capacities given here are in agreement with those proposed by the European Society for Clinical Respiratory Physiology and the World Health Organization, Europe Branch [5]. Unless otherwise specified, volumes are expressed in $l$ BTPS (see $\S 3.3$ ) and flows in $l$ BTPS $\mathrm{s}^{-1}$. The units adopted are those of the Système international d'unités (SI-units), and based on recommendations for use of SI units in respiratory physiology [19-32]. The units relevant for this report, including, non-SI units retained and allowed within the European Community, are given in table 1 , while table 2 gives the conversion factors to go from conventional to SI units. In keeping with international recommendations in respiratory physiology the units for pressure and volume are $\mathrm{kPa}$ and litre respectively. A list of abbreviations, symbols and units, with a translation of terms into the languages of the European Community, is to be found elsewhere in this volume.

\subsection{Static lung volumes}

\subsubsection{Vital capacity}

The vital capacity (VC) is the volume change at the mouth between the positions of full inspiration and complete expiration. The measurement may be made in one of the following ways:

1 Inspiratory vital capacity (IVC): the measurement is performed in a relaxed manner, without undue haste or deliberately holding back, from a position of full expiration to full inspiration;

2 Expiratory vital capacity (EVC): the measurement is similarly performed from a position of full inspiration to full expiration;

3 Two-stage vital capacity: the vital capacity is determined in two steps as the sum of the inspiratory capacity (IC) and expiratory reserve volume (ERV);

4 Forced vital capacity (FVC): this denotes the volume of gas which is exhaled during a forced expiration starting from a possition of full inspiration and ending at complete expiration. 
Table 2. - Factors for converting conventional units to SI units.

\begin{tabular}{|c|c|c|}
\hline Name of quantity & Conventional to SI unit & SI to Conventional \\
\hline force & $1 \mathrm{kgf}=9.807 \mathrm{~N}$ & $1 \mathrm{~N}=0.102 \mathrm{kgf}$ \\
\hline pressure, & $1 \mathrm{cmH}_{2} \mathrm{O}=0.098 \mathrm{kPa}$ & $1 \mathrm{kPa}=10.2 \mathrm{cmH}_{2} \mathrm{O}$ \\
\hline \multirow[t]{3}{*}{ tension } & $1 \mathrm{mmHg}=0.133 \mathrm{kPa}$ & $1 \mathrm{kPa}=7.50 \mathrm{mmHg}$ \\
\hline & $1 \mathrm{bar}=100 \mathrm{kPa}$ & $1 \mathrm{kPa}=0.01 \mathrm{bar}$ \\
\hline & 1 dyn $\cdot \mathrm{cm}^{-2}=10^{-4} \mathrm{kPa}$ & $\begin{array}{l}1 \mathrm{kPa}=10^{4} \text { dyn } \cdot \mathrm{cm}^{-2} \\
1 \mathrm{kPa} \cdot l^{-1} \cdot \mathrm{s}=\end{array}$ \\
\hline resistance & $\begin{array}{c}1 \mathrm{cmH}_{2} \mathrm{O} \cdot l^{-1} \cdot \mathrm{s}= \\
0.098 \mathrm{kPa} \cdot l^{-1} \cdot \mathrm{s}\end{array}$ & $\begin{array}{l}1 \mathrm{kPa} \cdot l^{-1} \cdot \mathrm{s}= \\
10.2 \mathrm{cmH}_{2} \mathrm{O} \cdot l^{-1} \cdot \mathrm{s}\end{array}$ \\
\hline \multirow[t]{2}{*}{ conductance } & $1 \mathrm{l} \cdot \mathrm{cmH}_{2} \mathrm{O}^{-1} \cdot \mathrm{s}^{-1}=$ & $1 l \cdot \mathrm{kPa}^{-1} \cdot \mathrm{s}^{-1}=$ \\
\hline & $10.2 l \cdot \mathrm{kPa}^{-1} \cdot \mathrm{s}^{-1}$ & $0.098 \mathrm{l} \cdot \mathrm{cmH}_{2} \mathrm{O}^{-1} \cdot \mathrm{s}^{-1}$ \\
\hline gas exchange* & $1 \mathrm{ml} / \mathrm{min}=$ & $1 \mathrm{mmol} / \mathrm{min}=$ \\
\hline & $0.045 \mathrm{mmol} / \mathrm{min}$ & $22.4 \mathrm{ml} / \mathrm{min}$ \\
\hline \multirow[t]{2}{*}{ transfer factor } & $1 \mathrm{ml} \cdot \mathrm{min}^{-1} \cdot \mathrm{mmHg}^{-1}=$ & $1 \mathrm{mmol} \cdot \mathrm{min}^{-1} \cdot \mathrm{kPa}^{-1}=$ \\
\hline & $0.335 \mathrm{mmol} \cdot \mathrm{min}^{-1} \cdot \mathrm{kPa}^{-1}$ & $2.99 \mathrm{ml} \cdot \mathrm{min}^{-1} \cdot \mathrm{mmHg}^{-1}$ \\
\hline concentration* & $\begin{array}{l}1 \mathrm{ml} / 100 \mathrm{ml}= \\
0.45 \mathrm{mmol} / \mathrm{l}\end{array}$ & $\begin{array}{l}1 \mathrm{mmol} / \mathrm{l}= \\
2.24 \mathrm{ml} / 100 \mathrm{ml}\end{array}$ \\
\hline
\end{tabular}

Subdivisions of the vital capacity include the tidal volume (TV, $V_{\mathrm{T}}$ ), inspiratory reserve volume (IRV), expiratory reserve volume (ERV); the inspiratory capacity (IC) is the sum of IRV and $V_{T}$ (fig. 3).

The average within-subject standard deviation of repeated measurements of the vital capacity is between 90 and $200 \mathrm{ml}$, a weighted average being $148 \mathrm{ml}$ (see overview in [33]). The variability is also expressed as the coefficient of variation, which varies between 0.3 and 11.4 per cent within the same individual; this index assumes that the variability is proportional to the mean, which is most often not true for ventilatory indices. In healthy subjects differences between the FVC and IVC are minimal. The relaxed expiratory vital capacity, and particularly the forced vital capacity [34], may be considerably less than the IVC in patients with airflow limitation; therefore when the total lung capacity is computed as the sum of RV and VC it will be underestimated unless the IVC is used: TLC $=$ RV + IVC. Similarly the Tiffeneau index (FEV,\%VC) will be spuriously high in patients with airflow limitation unless the IVC is used in the denominator. Hence, where a measurement of VC is used, it shall normally be the IVC; if this is not feasible then the relaxed VC is a good alternative. The two-stage vital capacity is not recommended for routine use; its measurement may occasionally be useful in very dyspnoeic patients.

\subsubsection{Expiratory reserve volume}

The expiratory reserve volume (ERV) is the volume that can be maximally expired from the level of the functional residual capacity. It is less in the supine than in the sitting posture [33] and decreases in obesity [35-40]; ERV is rarely used as an independent index.

\subsubsection{Inspiratory reserve volume}

The inspiratory reserve volume (IRV) is the maximal volume that can be inspired from the mean endinspiratory level. It is of theoretical interest only.

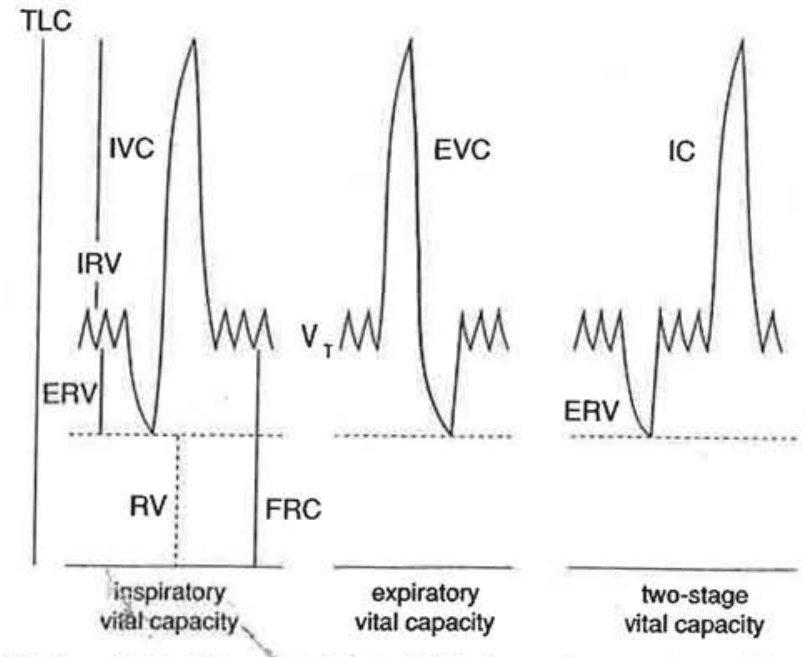

Fig. 3. - Schematic representation of static lung volumes and capacities. Modified with permission from [41]. See text for definitions.

\subsubsection{Inspiratory capacity}

The inspiratory capacity (IC) is the maximal volume that can be inspired from functional residual capacity; it is equal to the sum of tidal volume and inspiratory reserve volume. It is not different in the supine compared to the sitting position [42].

\subsubsection{Tidal volume}

The tidal volume $\left(V_{\mathrm{T}}, \mathrm{TV}\right)$ is the volume of gas which is inspired or expired during a respiratory cycle; although listed under static lung volumes, it is a dynamic lung volume, which varies with the level of physical activity. It is commonly measured at the mouth and varies with measuring conditions (rest, exercise, posture). The average value of at least six breaths should be used.

\subsubsection{Functional residual capacity}

The functional residual capacity (FRC) is the volume of gas present in the lung and airways at the average endexpiratory level. It is the sum of expiratory reserve and residual volume. The latter volume can only be measured indirectly; the method of measurement as well as the measuring conditions should be specified.

The functional residual capacity can be assessed by a "gas dilution" method, by body plethysmography or by radiography., In healthy subjects the three methods yield very similar results [43-50]. The coefficient of variation of repeated measurements on the same subject is usually less than $10 \%$ [51]. In patients with severe airflow limitation or emphysema the true lung volume is underestimated by the dilution method, unless mixing time is prolonged to at least $20 \mathrm{~min}[44,45,52,53]$. The gas dilution method is widely used because it is simple to perform and the equipment is relatively inexpensive. The plethysmograph method is mandatory for studies of instantaneous lung volume such as are required for interpretation of airways resistance and forced expiratory flow. The plethysmographic FRC includes non-ventilated as well as ventilated lung compartments. On this account 
in patients with gas trapping and lung cysts the method gives higher results than the gas dilution technique; the difference between plethysmographic and gas dilution measurements provides information about non-ventilated air spaces within the thorax. The plethysmographically assessed lung volume may be further increased by gas present in the abdomen [54-56]. In the case of severe air-flow limitation the lung volume may be systematically overestimated [47, 57-69] by the plethysmographic method when the measurement is performed at respiratory rates in excess of $1 \mathrm{~s}^{-1}$.

The FRC varies considerably with the level of physical activity and with posture, being smaller when lying down than when sitting or standing; it is also greatly influenced by the quantity of body fat. This is because gross obesity decreases total and chest wall compliance $[41,70]$ and diminishes the ERV and FRC [35-40].

\subsubsection{Residual volume}

The residual volume (RV) is the volume of gas remaining in the lung at the end of a full expiration. It is calculated by subtracting the expiratory reserve volume from the functional residual capacity: RV $=$ FRC - ERV, or RV = TLC - IVC. The coefficient of variation of repeated measurements on the same subject is about $8 \%$ [71].

\subsubsection{Total lung capacity}

The total lung capacity (TLC) is the volume of gas in the lung at the end of a full inspiration. It is either calculated from: TLC $=\mathrm{RV}+\mathrm{IVC}$, or from: TLC $=\mathrm{FRC}+\mathrm{IC}$; the latter is the preferred method in body plethysmography. It can also be measured directly by the radiologic technique. The method of measurement (gas dilution, body plethysmography, radiology) should be specified.

\subsubsection{Thoracic gas volume}

The thoracic gas volume (TGV) is the volume of gas in the thorax at any point in time and any level of thoracic compression. It is usually measured by the whole body plethysmograph method [55], which is the method of choice in patients with airflow limitation, in whom gas is often trapped behind occluded airways; however, when there is severe airways obstruction thoracic gas volume may be overestimated (see $\S 2.1 .6$ ) $[47,57-60$, 64-68].

The thoracic gas volume may be determined at any level of lung inflation; the level should be specified (e.g. FRC). Alternatively the TLC or RV can be obtained by adding to the TGV the volume which can be inhaled to total lung capacity, or by subtracting the volume that can be exhaled to residual volume. In the latter case, the inspiratory or expiratory manoeuvres should be performed immediately after the measurement of TGV.

\subsubsection{Clinical usefulness}

Measurements of VC have a well-established basis in assessing lung volumes in health and disease. However, the information provided by VC may be ambiguous, and clinically relevant information may be obtained only from considering additional indices. For instance, coexistence of an obstructive and restrictive ventilatory defect cannot be deduced from simple spirometric measurements; the diagnosis of a mixed ventilatory defect should be limited to the combination of a reduced TLC and $\mathrm{FEV}_{1} / \mathrm{VC}$ ratio. However, in patients with airflow limitation and emphysema, TLC is not very sensitive to processes usually associated with a restrictive pattem such as lobectomy [72] or cryptogenic fibrosing alveolitis [73].

A lowered RV is occasionally the sole physiological abnormality [74] in patients with chest wall problems (skeletal deformity, fibrothorax) or parenchymal disease (congestive heart failure, sarcoidosis, infections). RV measurentents are also useful in evaluating the interaction between smoking and interstitial lung disease. In smokers and ex-smokers with parenchymal sarcoidosis RV and FRC are lower than in nonsmokers [75], whereas in idiopathic pulmonary fibrosis RV is higher in smokers [76]; in these studies groups did not differ with respect to $\mathrm{VC}$ and $\mathrm{FEV}_{1}$. Increases in RV without changes in $\mathrm{FEV}_{1}$ and $\mathrm{FEV}_{1} / \mathrm{VC}$ are seen in patients at risk of developing chronic obstructive pulmonary disease, such as middle-aged women with heterozygous $\alpha_{1}$-antichymotrypsin deficiency [77]. A slight increase in RV is the most frequent functional abnormality in young patients after an episode of idiopathic spontaneous pneumothorax [78], in whom CT examination suggests centrilobular emphysema in upper lung zones [79]. Longitudinal studies over a mean interval of 3.5 years in middle-aged cigarette smokers without established lung disease demonstrated more consistent increases in RV and TLC than in decreases in $\mathrm{VC}$ or $\mathrm{FEV}_{1}$ [80].

Measurements of FRC unaccompanied by information about RV and TLC are of interest in patients with chest wall disorders. FRC and ERV are markedly reduced in persons with morbid obesity when $\mathrm{VC}$ and $\mathrm{FEV}$, are still within the normal range [40]. In subjects with the sleep apnoea syndrome with normal VC, RV and TLC the level of nocturnal hypoxaemia can be predicted from the decrease in FRC and ERV when changing from the sitting to the supine posture [81]. In other conditions FRC and RV are normal when VC and TLC are severely reduced, e.g. after surgical correction for funnel chest [82]. These examples illustrate the complex interactions between lung and chest wall [83], and underline the need for measuring several indices in addition to spirometric measurements.

Useful information can also be derived from assessing TLC by different methods in the same patient. In healthy subjects TLC assessed by the single breath helium dilution method (see $\S 3.7 .2$ ) is somewhat smaller (down to $83 \%$ ) than when assessed with the multi-breath technique $[71,84,85]$. The difference can be accentuated in patients with asthma even during a period when no airflow limitation is detected, indicating abnormal unevenness of ventilation distribution. Also the trapped gas volume ( $\S 3.8 .7)$ is of interest in patients with bullous emphysema in whom surgical correction is considered $[86,87]$. 


\subsubsection{Forced vital capacity}

The forced vital capacity (FVC) is the volume of gas delivered during an expiration made as forcefully and completely as possible starting from full inspiration (fig. 1, 2 and 4). The FVC is to be distinguished from the relaxed expiratory vital capacity and from the inspiratory vital capacity, where the emphasis is put only on the completeness of the manoeuvre, not on the speed. The FVC may be underestimated if not enough time is allowed for lung emptying at low lung volumes, where the emptying rate is determined by airflow limitation $[1,2]$.

\subsubsection{Time averaged maximal expiratory flow}

The timed forced expiratory volume (FEV) is the volume of gas exhaled in a specified time from the start of the forced vital capacity manoeuvre; conventionally, the time used is $1 \mathrm{~s}$, symbolized $\mathrm{FEV}_{1}$. It is an extensively used index with good reproducibility; the standard deviation of repeated measurements within healthy subjects in various studies varies from 60 to $270 \mathrm{ml}, 183$ $\mathrm{ml}$ being the weighted average (computed from overview in [33]). The FEV, can be standardized for the vital capacity, when it is called $\mathrm{FEV}_{1} \%\left(\mathrm{FEV}_{1} \% \mathrm{VC}\right.$, the VC needs to be specified). The use of the inspiratory, the relaxed expiratory or the two-stage vital capacity in the denominator yields a more sensitive index of airflow limitation; the first of these is the Tiffeneau index [88].

The maximal mid-expiratory flow (MMEF, $\mathrm{FEF}_{25-75 \%}$ ), also called forced mid-expiratory flow, is the mean forced expiratory flow during the middle half of the FVC [89]. It is extensively used and is reported to have a good sensitivity for diagnosing minimal airflow limitation, but interpretation is difficult if the vital capacity is abnormal. The index should not be used for assessing changes in airflow limitation, for example following inhalation of a bronchodilator drug (§ 4.1).

The forced late expiratory flow $\left(\mathrm{FEF}_{75-85 \%}\right)$ is the mean flow during exhalation from 75 to $85 \%$ of the FVC. The index has a poor reproducibility and is little used. Other indices have been suggested; they are poorly reproducible and have not been shown to provide information which is not provided by other indices.

\subsubsection{Instantaneous maximal expiratory flows}

The peak expiratory flow (PEF) is the maximal flow during a forced expiratory vital capacity manoeuvre starting from a position of full inspiration. In healthy subjects the index reflects the calibre of «central» airways and the force exerted by the expiratory muscles. The PEF is widely used in the management of patients with variable airflow limitation, in whom it is significantly influenced by the calibre of peripheral airways. The index is effort dependent. The results are influenced by the definition of peak flow which is adopted, for example with respect to its duration; in addition results using different equipment are not always comparable.
Thus further work is needed [90]. A working party of the EUROPEAN RESPIRATORY SOCIETY will shortly issue recommendations on peak expiratory flow, hence this item will not be addressed in great detail in this report.

The maximal expiratory flow at a specified lung volume $\left(V_{\max , \mathrm{x} \% V}, \mathrm{MEF}_{\mathrm{x} \% V}, \mathrm{FEF}_{\mathrm{x} \% V}\right)$ is the expiratory flow achieved at the designated lung volume during a forced expiratory manoeuvre starting from TLC [91]. Variations in lung volume are measured either at the mouth or from the chest using a whole body plethysmograph. The two methods can yield substantially different results, on account of the former making no allowance for the reduction in lung volume which occurs by compression of the alveolar gas during the forced expiratory manoeuvre. The reduction in turn reduces the lung elastic recoil and hence the calibre of lung airways ( $\$ 1.2 .2)$. In practice, the flow is determined at a volume defined in one of the following ways:

a. That obtained when a given percentage of the FVC remains to be expired (e.g. $\mathrm{MEF}_{25 \% \mathrm{FvC},} V_{\max , 25 \% \mathrm{FVC}}^{\prime}$ ). The flow was also expressed in terms of the proportion of FVC which has been exhaled (e.g. $\mathrm{FEF}_{75 \% \mathrm{FvC}}$ ). These indices are complementary, which easily leads to confusion; hence it is recommended to use only $\mathrm{MEF}_{\mathrm{xq} \mathrm{FVC}}$. b. That obtained when a given percentage of the actual or the predicted total lung capacity remains in the lung (for example $\mathrm{MEF}_{60 \% \mathrm{JLC}}, \mathrm{MEF}_{60 \% \text { pred } \mathrm{TC}}$ ).

The result is expressed either as a flow $\left(l \cdot \mathrm{s}^{-1}\right)$ to be compared to the reference value, or divided by an observed or a predicted lung volume (FVC or TLC). The former procedure is recommended.

The forced expiratory flows when $50 \%$ or $25 \%$ of the vital capacity remains in the lung are widely measured. However, the measurements are of only moderate reproducibility: [92] and are often subject to instrumental error, which contributes to differences in absolute values between laboratories. In addition interpretation is difficult if the vital capacity is abnormal, whilst incomplete expiratory effort can cause a large overestimation of $\mathrm{MEF}_{25 \% \mathrm{FVC}}$. For groups of healthy subjects, the results are poorly described by multiple linear regression equations on height and age. Thus these indices have not yet fulfilled early expectations as to their usefulness.

\subsubsection{Forced expiratory times}

The forced expiratory time $\left(\mathrm{FET}_{\mathrm{b}}\right)$ is the time required to exhale a specified portion b of the FVC; for example, the $\mathrm{FET}_{95 \% \mathrm{FVC}}$ is the time required to deliver the first $95 \%$ of the FVC. The test is seldom used.

The time constant of the upstream segment of intrathoracic airways is the reciprocal of the slope of the flowvolume curve over a specified range [93]. The index is reported to reflect the compliance of the airways at the choke point [94]. It is probably of limited usefulness.

The mean transit time is the mean time taken by gas molecules to leave the lung during the performance of the FVC manoeuvre. It is obtained by applying moment analysis to the volume-time curve, which is considered as a cumulative distribution of transit times; 
the analysis also yields the standard deviation of transit times and an index of skewness of their distribution (derived from the second and third moments respectively) [95]. Advantages claimed for this approach include a high signal-to-noise ratio and independence of lung volume; however, the methodology is not yet fully standardized $[96,97]$ and more information is needed on its usefulness.

\subsection{Forced inspiration}

The manoeuvre of forced inspiration is used to detect obstruction to flow in extrathoracic airways [98], such as in laryngeal or tracheal obstruction. The procedure is considered unpleasant by many subjects so is seldom used in other circumstances. However, it can be used to differentiate expiratory airflow limitation due to airways obstruction from that attributable solely to low elastic lung recoil from pulmonary emphysema; in the latter case inspiratory flows would be little affected [99]. Extra care should be given to hygienic measures with inspiratory measurements as compared with tests which entail expiratory manoeuvres only.

Inspiratory flows are also useful in distinguishing between extrathoracic and intrathoracic airways obstruction; thus a ratio of $\mathrm{MEF}_{\text {sorfve }} \mathrm{MIF}_{\text {sos }}>1.0$, but similarly a ratio of FEV $(\mathrm{ml})$ to PEF $\left(l \cdot \mathrm{min}^{-1}\right)>10.0$ and a ratio of $\mathrm{FEV}_{1}$ to $\mathrm{FEV}_{0.5}$ of 1.5 or more are all compatible with upper airway obstruction [100-103]; such ratios should be accompanied with reproducible inspiratory flow plateaus.

\subsubsection{Forced inspiratory vital capacity}

The forced inspiratory vital capacity (FIVC) is the maximal volume of air which can be inspired during forced inspiration from a position of full expiration [104].

\subsubsection{Timed forced inspiratory volume}

The timed forced inspiratory volume (FIV $)$ is the volume of air inhaled in a specified time during the performance of the forced inspiratory vital capacity, e.g. FIV, for the volume of air inhaled in the first second as defined above. Advantages claimed for FIV 1 are that it is little affected by low lung recoil, so that a low FEV, and a normal FIV, can be taken as evidence for low lung elastic recoil.

\subsubsection{Maximal inspiratory flow}

The maximal inspiratory flow $\left(\mathrm{MIF}_{\mathrm{x} \% \mathrm{FvC}}\right)$ is the maximal flow observed when a specified percentage $x$ of the FIVC has been inhaled.

\subsubsection{Peak inspiratory flow}

The peak inspiratory flow (PIF) is the maximal instantaneous flow achieved during a FIVC manoeuvre.

\subsection{Maximal voluntary ventilation}

The maximal breathing capacity (MBC) is the volume of air expired per minute during maximal breathing; the breathing can be by voluntary effort or driven by exercise or carbon dioxide. Maximal voluntary ventilation (MVV) is assessed during forced breathing. The breathing time is usually $15 \mathrm{~s}$ except for the sustained maximal voluntary ventilation when it can be up to $4 \mathrm{~min}$. In the latter case the inspired gas should contain carbon dioxide in order to prevent hypocapnia. The respiratory frequency (f) should be specified; for example, $M V V_{30}$ is MVV performed at 30 breaths per minute. The procedure can cause respiratory muscle fatigue which is some-times amenable to physical training. MVV is now superseded by FEV , with which it is highly correlated except during ressistance breathing. It remains an important functional dimension of the lung on account of its relationship to the maximal ventilation during exercise. Usually maximal exercise ventilation is less than MVV but can exceed it in the presence of severe airflow limitation.

\section{Methods}

\subsection{Introduction}

Volume changes of the lung are usually measured at the mouth, preferably by means of a spirometer or else a pneumotachometer and integrator, but other methods of measurement (e.g. rotating vane anemometer, hot wire anemometer) are gaining acceptance. Alternatively volume changes can be measured from the body surface by means of a volume displacement whole body plethysmograph, which also takes account of volume changes due to expansion or compression of gas [105]; it is mainly used for research purposes. These methods are suited to measure the vital capacity and its subdivisions. When lung volumes which include the residual volume are measured, this is done by gas dilution methods, whole body plethysmography or radiographic methods.

For sufficient accuracy as well as for comparability of measurements between laboratories and in longitudinal studies, it is imperative that the measurements and procedures are standardized; this includes frequent calibration of all equipment. Ventilatory manoeuvres should preferably be recorded and/or displayed in order to facilitate quality control.

\subsection{Measurement variability}

Instruments used to measure indices of ventilatory function should meet the requirements for accuracy delineated in $\S 6.4$. Laboratory personnel using the equipment need to be trained in its use and be familiar with its operation, so that problems can be easily detected and remedied promptly. 


\subsubsection{Accuracy and precision}

Measurements are subject to errors of accuracy and precision. The accuracy error is the systematic difference between the true and the measured value. For example, if exactly 3 litre is delivered to a spirometer, and the readings are $2.90,2.834,2.801,2.874,2.890$ (mean 2.860 ), the spirometer is inaccurate because the readings are systematically low by almost $5 \%$. The precision error, usually denoted reproducibility, is the numerical difference between successive measurements. In the case of many measurements this quantity is described by the standard deviation (SD). It can be computed as follows. Let $X_{1} \ldots . X_{n}$ be the value of $n$ measurements of the same quantity, then the mean $(\bar{x})$ is computed as the sum of all observations $(\Sigma \mathrm{X})$ divided by the number of observations:

$$
\overline{\mathrm{x}}=\Sigma \mathrm{X} / \mathrm{n}
$$

Each individual observation differs from the mean by an amount which is called the deviation. The standard deviation is the square root of the sum of all the deviations squared divided by $n$ which is the number of observations (or in the case of small numbers $\mathbf{n}-1$ ):

$$
\mathrm{SD}=\Sigma\left\{\Sigma \text { deviations }{ }^{2} /(\mathrm{n}-1)\right\}
$$

In the above example the mean is 2.860 litre, SD 0.041 ; hence the instrument deviates from the true value by on average $140 \mathrm{ml}$, and the standard deviation of 5 repeated measurements is 41 millilitre. The accuracy may be improved by calibrating the instrument, i.e. the act of checking the instrument against a known standard. In the above example, provided the inaccuracy is a proportional one, multiplying all readings by $3 / 2.860=1.049$ (calibration factor) would greatly improve the accuracy. The use of the factor would not improve the precision, which in this case could be expressed as a coefficient of variation $(100 \cdot \mathrm{SD} / \overline{\mathrm{x}})$. If the instrument is not precise but otherwise accurate, the estimate of the true value can be improved by repeating the measurements and reporting the mean. However, in measurements of FVC, $\mathrm{FEV}_{1}$, IVC and PEF it is recommended to report the largest rather than the mean of a number of measurements. Obviously this requires that every effort is made to produce results with a minimal precision error.

\subsubsection{Sources of variability}

In addition to the above instrumental errors, the measurements are subject to biological variability and to errors attributable to the observer. Biological variability is independent of errors due to the instrument or operator. In healthy persons such variability may be related to the time of the day, when it is often called diumal variation, exposure to tobacco smoke or other chemical or physical stimuli; also the respiratory system may be affected by the measurement procedure; for example deep inspiration can cause bronchodilation and a change in the elastic properties of the lung. Within subject variability in lung volumes and ventilatory flows may be due to variability in the activity of a disease process (infection, exposure to occupational inhalant and allergen), challenge testing, exercise or exposure to fog, cold air, tobacco smoke, or to environmental pollutants in subjects with hyperresponsive airways; obviously ventilatory function will also be influenced by drugs that affect airway calibre. Observer errors can be technical, for example from differences in the technique of reading charts, computational procedures, the handling or transferring of data, but also from differences in the way the subjects are approached and instructed.

\subsubsection{Reducing variability}

It is the objective of quality control to achieve maximal accuracy and precision. Biological variability is minimised by careful attention to the time and circumstances of the test (e.g. with respect to environmental conditions). Variability in the measurement is minimised by frequent checks of instrument performance, instrument maintenance, proper instrument use, adequate instruction of the person being tested, and well-trained personnel who can administer the test professionally and according to a standard protocol.

\subsection{Correcting to standard conditions}

All measurements of gas volumes should relate to conditions in the lung where the gas is at body temperature, pressure, saturated with water vapour (designated BTPS). They should not relate to conditions in the measuring equipment (ATP = ambient temperature, pressure; when saturated with water vapour designated ATPS). The correction from one set of conditions to the other will be dealt with for spirometers. Corrections for pneumotachometers are more complex: it is difficult to know the condition of the gas, which depends on how the instrument is heated, how close it is to the mouth, whether the gas is inspired or expired; a further complication is that the gain of the instrument varies with gas temperature. Corrections for pneumotachometers are dealt with in appendix A.

Spirometric recordings made at temperatures and water vapour pressures that differ from those in the lung should be corrected to BTPS conditions as follows:

$$
V_{\mathrm{BTPS}}=V_{\mathrm{ATP}} \cdot 310.2 \cdot\left(P_{\mathrm{B}}-P_{\mathrm{H}}\right) /\left[(273.2+t) \cdot\left(P_{\mathrm{B}}-6.3\right)\right]
$$

where $t=$ ambient temperature $\left({ }^{\circ} \mathrm{C}\right), P_{\mathrm{B}}=$ barometric pressure $(\mathrm{kPa})$ and $P_{\mathrm{H}}=$ water vapour pressure $(\mathrm{kPa})$ of the ambient gas. Note that «ambient» relates to the temperature and saturation of inspired gas or that attained by the gas when it is exhaled into an instrument; this condition may be that of room gas, but in all other circumstances it is the temperature and saturation of gas inhaled from or delivered into another system, such as a spirometer.

The relationship between temperature and water vapour pressure $\left(P_{\mathrm{H} 2 \mathrm{O}}\right)$ of fully saturated gas is shown in table 3. 
Between 16 and $37{ }^{\circ} \mathrm{C}$ it can be approximated as follows:

$$
P_{\mathrm{H} 2 \mathrm{O}}=1.63-0.071 \cdot t+0.0053 \cdot t^{2}(\mathrm{kPa})
$$

At sea level barometric pressure can be assumed to be $101.3 \mathrm{kPa}$, but with severe storms there may be significant deviations from this pressure. Under stable conditions at sea level the factor for converting volumes recorded at ATPS conditions to BTPS is as in table 3 . All spirometers should be equipped with a thermometer (see $\S 3.5 .1 .6$ ). Note that if «ambient» gas is not fully saturated with water, the actual $P_{\mathrm{H} 2 \mathrm{O}}$ rather than the one listed in table 3 must be substituted in the above equation. Occasionally it may not be feasible to assess ambient water vapour pressure. In such circumstances it is usually reasonable to assume a $50 \%$ saturation; the associated factor for conversion to BTPS is given in table 3 .

Table 3. - Relationship between water vapour pressure of fully saturated gas and Celsius temperature, and factor for correcting to BTPS at sea level.

\begin{tabular}{cccc}
\hline $\begin{array}{c}\text { Temperature } \\
\left({ }^{\circ} \mathrm{C}\right)\end{array}$ & $\begin{array}{c}\text { Water vapour } \\
\text { pressure }(\mathrm{kPa})\end{array}$ & \multicolumn{2}{c}{ Correction factor } \\
saturated* & $50 \%^{*}$ \\
\hline 16 & 1.817 & 1.123 & 1.133 \\
17 & 1.937 & 1.118 & 1.129 \\
18 & 2.063 & 1.113 & 1.124 \\
19 & 2.196 & 1.107 & 1.120 \\
20 & 2.337 & 1.102 & 1.115 \\
21 & 2.487 & 1.097 & 1.111 \\
22 & 2.643 & 1.091 & 1.106 \\
23 & 2.809 & 1.086 & 1.101 \\
24 & 2.984 & 1.080 & 1.097 \\
25 & 3.169 & 1.074 & 1.092 \\
26 & 3.361 & 1.069 & 1.087 \\
27 & 3.565 & 1.063 & 1.082 \\
28 & 3.780 & 1.057 & 1.078 \\
29 & 4.005 & 1.051 & 1.073 \\
30 & 4.244 & 1.045 & 1.068 \\
31 & 4.493 & 1.039 & 1.063 \\
32 & 4.756 & 1.033 & 1.058 \\
33 & 5.031 & 1.026 & 1.053 \\
34 & 5.320 & 1.020 & 1.048 \\
35 & 5.624 & 1.013 & 1.043 \\
36 & 5.943 & 1.007 & 1.038 \\
37 & 6.277 & 1.000 & 1.033 \\
\hline
\end{tabular}

* Saturation of «ambient» gas.

In practice gas delivered to volume displacement spirometers and their tubing does not attain a stable temperature immediately [106-108]; when operating at 3 ${ }^{\circ} \mathrm{C}$ errors occur in FEV, of 7.7 to $14 \%$ in spite of BTPS correction. It is recommended that gas temperatures in the spirometer should not be less than $17^{\circ} \mathrm{C}$ and not more than $40^{\circ} \mathrm{C}$ [109].

\subsection{Measurement procedures}

\subsubsection{General}

The subject should have been at rest 15 minutes prior to the test. The procedure should be carefully described to the subject with emphasis on the need of avoiding leaks round the mouthpiece, and where appropriate of making a maximal inspiratory and expiratory effort; the latter should be sustained until the expiration is complete. With inexperienced subjects the trained operator, whose performance should preferably have been validated against a practiced operator, should demonstrate the procedure using a detached mouthpiece, then allow two practice attempts which should be recorded.

Wher employing a spirometer without gas conditioning hypoxaemia and hypercapnia are prevented by flushing the spirometer with air after the subject has performed two vital capacity manoeuvres. During flushing the subject should be disconnected from the mouthpiece.

If the spirometer has an absorber for removing $\mathrm{CO}_{2}$ but no oxygen is added, the vital capacity delivered to the spirometer will be underestimated to a small amount (approximately 2-3\%).

A noseclip is mandatory for measurements made during normal breathing and maximal voluntary ventilation. Whilst it is difficult to exhale (partly) through the nose during a forced vital capacity manoeuvre the use of a noseclip is nevertheless recommended during such manoeuvres; it should be used if the forced expiratory time is greatly prolonged. It should also be used in children and in persons with blocked nasal passages. Dentures, unless fitting very badly so that they come loose and obstruct air flow, should not be removed, since the lips and cheeks then lose support, which promotes air leaks from the mouth. The mouthpiece should be inserted between the teeth and held by the lips. The use of disposable mouthpieces obviates the need for laborious disinfection.

\subsubsection{Body posture}

The measurements are to be made with the subject seated in an upright posture. This is because subdivisions of lung volumes are highly influenced by body position, being lower when supine than. when seated or standing [110-112]. The vital capacity is on average $70 \mathrm{ml}$ less in the sitting than the standing position in middle-aged persons [113] but not in younger persons [114]; it can drop markedly in the case of diaphragmatic paralysis when changing from the sitting to the recumbent position [115].

During the breathing manoeuvres the thorax should be free to move freely; hence tight clothing should be loosened. The practice of leaning forward as the expiration proceeds towards residual volume is undesirable, since it will compress the trachea and leads to saliva dripping into the mouthpiece assembly. The best position is achieved by using an adjustable stool and a rigid mouthpiece assembly or a flexible tube carrying the mouthpiece; this should be adjusted to suit the subject, so that the head is not tilted during measurements. 


\subsubsection{Volume history}

In tests which entail measuring forced expiratory flows and FEV, it is important that the volume history is standardised, i.e. that there is a smooth transition from inspiration to TLC, preferably about a $2 \mathrm{~s}$ pause at or near TLC and subsequent forced exhalation with minimal pause. This is because the effects of the inspiratory manoeuvre on airway and lung hysteresis are different; in addition stress relaxation of visco-elastic lung elements is time dependent, so that a forced expiration immediately after stretching the lung leads to higher expiratory flows than after some pause $[116,117]$, the latter being the most feasible in the majority of subjects. These phenomena lead to bronchodilator effects in healthy subects [118-123] except after administration of a bronchodilator drug. In asthmatics bronchoconstrictor [121, 124-131] as well as bronchodilator effects [127-132] have been neported; after induced bronchoconstriction there is usualiy a bronchodilator response to deep inspiration in asthmátics $[125,129,131-138]$. No such effects are observed in chronic obstructive pulmonary disease [119]. In order to circumvent bronchodilator or bronchoconstrictor effects partial expiratory flow-volume (PEFV) curves can be used, where the forced expiration is started after a normal inspiration [121, 139].

\subsubsection{Effort dependence of maximal expiratory flows}

The procedure of forced expiration causes compression of alveolar gas; on that account the lung volume, and hence the lung elastic recoil pressure (a determinant of maximal expiratory flow) diminishes. Thus the compression can reduce the rate of emptying of the lungs; this is particularly marked in subjects with airflow limitation ( $\$$ 1.2.2). Conversely submaximal effort, because it causes less alveolar gas compression, can be associated with unrepresentatively high values for most indices of forced expiratory flow. The principal exceptions are the peak expiratory flow and $\mathrm{MEF}_{75 \% \mathrm{FyC}}$, which are effortdependent. Expirations performed with submaximal effort are seldom reproduced exactly. For this reason, and to reduce breath-to-breath variations, the result is usually based on three blows which were performed correctly and with maximal effort (table 4).

\subsubsection{Required number of forced vital capacity man- oeuvres}

Each subject performs a minimum of three blows. In the event of the procedure being faulty, the defective blow should be repeated; if eight forced vital capacity manoeuvres have not led to a set of satisfactory blows, the test is best terminated since the results will be of little value [140]. Stress incontinence in elderly subjects may be an underrated problem leading to submaximal performance in tests which entail increasing the intra-abdominal pressure, such as FEV, and FVC.

\subsubsection{Acceptable forced vital capacity manoeuvres}

To achieve acceptable tracings the subject should follow all instructions, inspiratory efforts should be to total lung capacity and expiratory efforts to residual volume. Forced inspiratory and expiratory efforts should be performed with maximal effort and without hesitation, leading to smooth curves. Irregularities in the resulting curves may be due to the tongue obstructing the mouthpiece, coughs, leaks, pauses, and loose false teeth (table 4).

\subsubsection{Serial measurements}

Due to diumal variations in lung function, the time of the day at which measurements are made should ideally be fixed and repeat measurements preferably be made at the same time of the day. Ideally the subject should not have smoked $1 \mathrm{~h}$ prior to the measurements, and these should not be made shortly after meals. A record should be macle of the date, the time of day and at altitude, the barometric pressure; at sea level the pressure is unlikely to deviate much from normal except in relation to severe storms. It is also helpful to record the type and time of any recent medication, the extent to which the subject complied with the operator's instructions and any untoward reactions, for example coughing.

For serial measurements, the circumstances of the tests should preferably be similar on all occasions with respect to time of day, season of year, apparatus, and the test be administered by an experienced operator.

Table 4. - Common faults in performance of a forced ventilatory manoeuvre.

Inspiration not complete
Partial expiration before connecting to mouthpiece
Leak between lips and mouthpiece
Pursing the lips
Closing the teeth
Expiration not maximally forced and progressive to residual
volume
Coughing or premature inspiration

\subsubsection{Timing of forced vital capacity manoeuvre} When measuring timed volumes, such as FEV or FIV $_{1}$, the starting point of the forced ventilatory manoeuvre should be obtained by backward extrapolation to zero volume change of the steepest part of the volume-time curve $(\mathrm{d} V / \mathrm{d} t)$ [141-143]. This is illustrated in figure 4. In acceptable tracings the extrapolated volume should not exceed $100 \mathrm{ml}$ or $5 \%$ of the FVC, whichever is greater [109]. Alternatively, or when assessing the forced expiratory or inspiratory time, the starting point can be defined as that when the inspiratory or expiratory flow exceeds $0.5 l \cdot \mathrm{s}^{-1}$, and the end of the breath when the volume change in $0.5 \mathrm{~s}$ does not exceed $25 \mathrm{ml}$.

\subsubsection{Summary statistics of FVC manoeuvre}

The largest of the first three technically satisfactory vital capacities (be it the IVC, EVC or FVC) and of the first three technically acceptable FEV,s should be reported; the chosen value should not exceed the next highest one by more than $5 \%$ or $0.1 l$, whichever is greater. However, 
in some patients the manoeuvre may induce bronchoconstriction, so that consecutive measurements become less; this trend should be noted and the largest VC reported $[124,144]$. In addition variability in ventilatory indices is greater in subjects with obstructive airways disease [145] than in healthy subjects, so that patients are more likely to be unable to meet these reproducibility criteria. These criteria should not be applied to reject a patient's data but may lead to collecting more than the minimum of three technically acceptable manoeuvres. If even then the reproducibility criteria cannot be met, a note to that effect should accompany the best test results in the report form.

For indices taken from flow-volume curves the chosen curves should be of similar shape and have a peak which is representative and not flattened. To this end the curves should be available for inspection by the operator at the time of measurement. When curves are selected by the computer a useful criterion is that the PEF should be within $10 \%$ of the maximal value. Flow-volume indices should be obtained from three technically satisfactory FVC manoeuvres in either of two ways. The first one (envelope method, fig. 5) entails superimposing the curves from total lung capacity to form a composite maximal curve [146]; the largest FVC is used to delineate the highest instantaneous flows at specified lung volumes. The second method, which leads to equally reproducible results [146], is to take the highest instantaneous flow from three technically satisfactory FVC manoeuvres; the FVC from the chosen flow-volume curves should not differ from the largest FVC by more than $5 \%$. The two methods lead to equally reproducible results [146, 147]; with the latter method using the mean of 2 or 3 values improves the reproducibility. The practic of taking five definitive blows instead of three improves the reproducibility to a small extent, but the improvement is not usually cost-effective [147]. The Working Party has considered the recommendation to derive maximal expiratory flows from the «best curve», i.e. from the flowvolume curve with the highest sum of $\mathrm{FEV}_{1}$ and FVC $[109,141]$. Whilst on average the flows do not differ much from those obtained with the above procedures, the reproducibility of indices derived from the «best curve» compares unfavourably $[146,147]$, so that the method is not recommended.

\subsection{Spirometry}

Spirometers are the instruments of choice for measuring the vital capacity and its subdivisions. They can be divided into two broad categories which reflect their construction and measuring features [148], namely a) spirometers with facilities for gas conditioning: the conditioning relates primarily to facilities for controlling the concentrations of oxygen and carbon dioxide and to measures taken to ensure unidirectional gas flow; b) spirometers designed to have good dynamic properties. They are either of the wet type (such as the classical bell spirometer with a water seal) or dry type (bellows, piston, wedge or rolling seal spirometer).

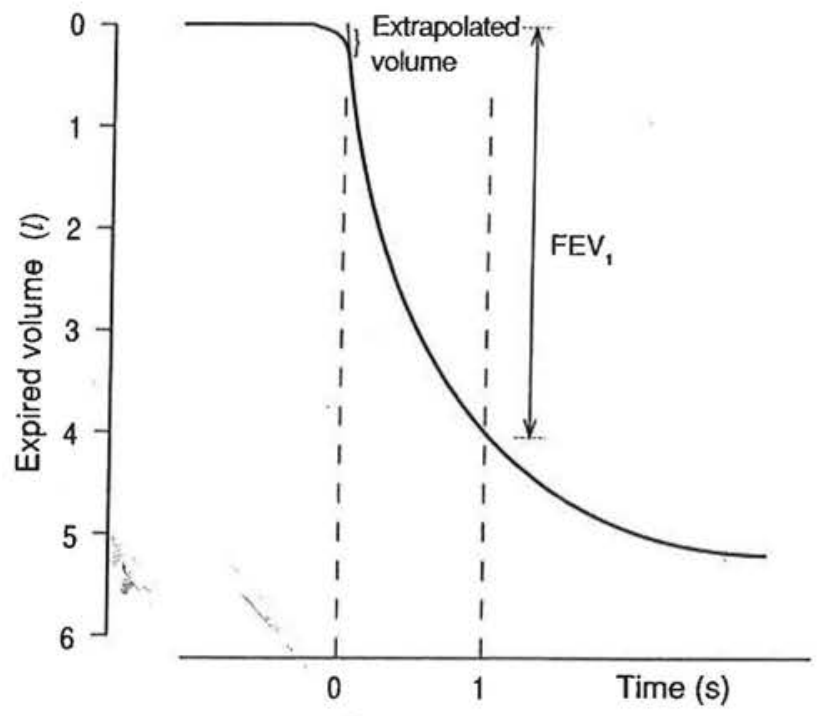

Fig. 4. - Use of the extrapolation procedure for determining the start of a forced expiration from a volume-time curve.

\subsubsection{Spirometers with facilities for gas conditioning} Spirometers with facilities for gas conditioning are suitable for investigations lasting from several minutes to many hours, depending on the conditioning of the gas in the spirometer. In a closed system, oxygen lack is the first and greatest danger, especially if the carbon dioxide concentration is kept very low.

\subsubsection{Capacity}

The spirometer should be capable of recording the full vital capacity (at leașt $8 l$ volume displacement) as a function of time. The smaller the volume of the spirometer circuit, the more attention needs to be paid to the conditioning of the gas. Gas circulation is produced preferably by a pump with an output at least ten times the volume of the spirometer per minute (minimal flow $180 \mathrm{l} \cdot \mathrm{min}^{-1}$ ) or alternatively by low-resistance one-way valves. The rationale for the recommended flow is as follows. In a valveless spirometer a flow of $3 l \cdot \mathrm{s}^{-1}$ suffices to prevent rebreathing of expired gas except during tests which entail maximal voluntary ventilation. In addition this flow ensures rapid gas mixing within the spirometer. The concentration $c$ of a substance at time $t$ which is made to mix in a gas container can be approximated by

$$
c_{t}=\mathrm{E} \cdot(\mathrm{n} \cdot V)^{-1} \cdot\left(1-\mathrm{e}^{-n}\right)
$$

where $\mathrm{E}$ is the substance added in $l \cdot \mathrm{min}^{-1}, V$ is the volume to which the substance is being added in litres, and $\mathrm{n}$ is the number of times the volume $V$ is being circulated per minute. If the spirometer volume is on average 6 litres, $\mathrm{n}$ comes to $180 / 6=30$ times per minute $=0.5$ times per second. The time constant for mixing is $1 / n=1 / 0.5=2 \mathrm{~s}$. This ensures both rapid gas mixing and a time constant which approximates or is better than the response time of most commercially available helium meters. 


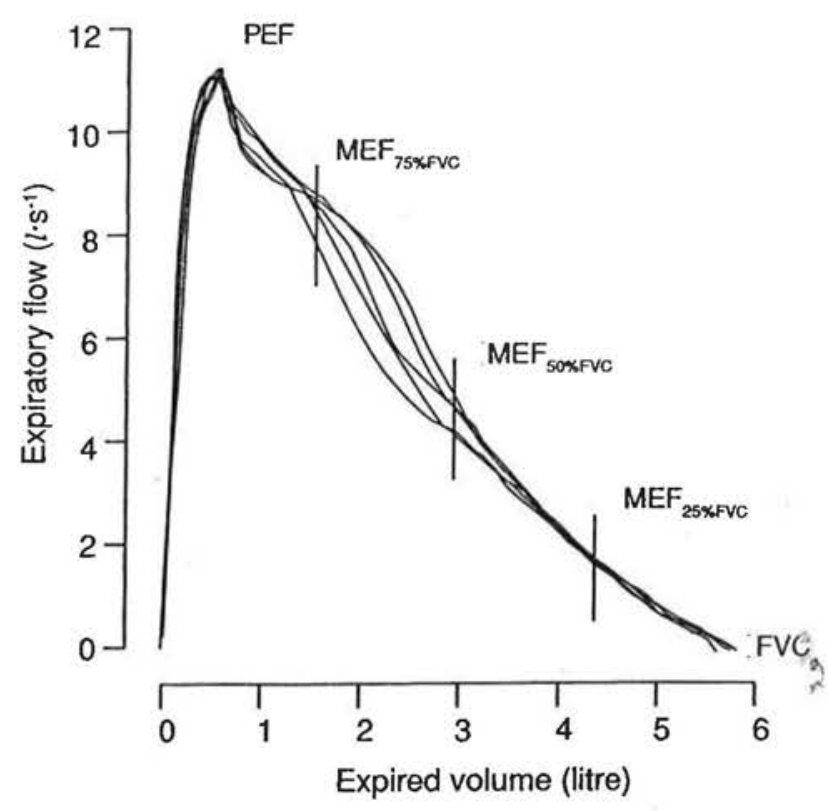

Fig. 5. - Using the «envelope method», a composite curve is obtained from a set of maximal expiratory flow-volume curves by superimposition at the level of total lung capacity and by reporting the largest flow values at given percentages of the largest FVC. Note that the variability in maximal flow shown here may arise from different flexion of the neck at each FVC manoeuvre.

\subsubsection{Construction}

A long-cylinder spirometer bell is the simplest in construction and mechanically the least vulnerable. For the measurement of static lung volumes, a bell crosssectional area of 300 to $400 \mathrm{~cm}^{2}$ and a moving mass of maximally $600 \mathrm{~g}$ is acceptable. A wide-cylinder bell (cross-sectional area 2000 to $3000 \mathrm{~cm}^{2}$ ) has considerably better dynamic properties for the same volume, weight and material. Such a bell requires a specially constructed suspension and electrical amplification of the displacement signal. A larger surface without the problems of suspension can be provided by a wedge-shaped spirometer.

\subsubsection{Connections}

The gas connections of the spirometer serve the following purposes:

1. Oxygen supply to compensate for $\mathrm{O}_{2}$-consumption and stabilization of the oxygen concentration in the spirometer;

2. Supply of indicator gas (usually helium) for determining the functional residual capacity;

3. The connections for the subject are usually provided by a two-way tap;

4. A connection to and from the spirometer should be available, so that the tracer gas concentration in the spirometer (for example helium) can be measured.

Carbon dioxide should be adsorbed by soda lime contained in a canister. The fractional $\mathrm{CO}_{2}$ concentration in the spirometer should be kept below 0.005 . The hose connecting the patient to the spirometer should be sufficiently stiff to prevent spurious volume deflections, such as may occur with concertina-hoses when handled during respiratory manoeuvres.

\subsubsection{Kymograph}

The paper speed should be $3 \mathrm{~cm} / \mathrm{min}$ for recording semistatic manoeuvres, and at least $120 \mathrm{~cm} / \mathrm{min}$ for recording dynamic lung volumes and ventilatory flows.

\subsubsection{Pressure, leaks}

The maximal pressure at the mouth during a forced expiratory ventilatory manoeuvre should not exceed $0.6 \mathrm{kPa}$. The driving pressure required to achieve a volume deflection should not exceed $0.03 \mathrm{kPa}$. The circuit should be free from leaks. These are looked for by placing a weight on the spirometer bell to raise the pressure by at least $0.2 \mathrm{kPa}$; the recording should remain level over at least a $1 \mathrm{~min}$ period. Tests for leaks should be performed each week.

\subsubsection{Temperature}

The spirometer should be equipped with a thermometer which should be carefully located. For correcting inspired gas to BTPS conditions the temperature may be measured at the inspiratory line near the mouthpiece. For expired gas the situation is more complex since temperature may rise considerably at the level of the soda lime when $\mathrm{CO}_{2}$ is adsorbed. In a water-seal spirometer the water temperature can be used for correcting inspiratory and expiratory gas volumes. In spirometers equipped with a gas circulation pump the gas temperature at the outlet of the spirometer, or under the spirometer bell, is an acceptable compromise; in spirometers with a common gas inlet and outlet the inspiratory temperature should be measured at that point; the site for expiratory temperature corrections should be carefully chosen within the spirometer [106, 149].

\subsubsection{Calibration}

The spirometer and recording equipment should be calibrated at least every three months by means of an airtight 3 litre calibrated syringe; the latter should be accurate within $25 \mathrm{ml}$. The displacement should be linear over the entire volume range and capable of being recorded with an accuracy of $\pm 3 \%$ of the reading or \pm $50 \mathrm{ml}$, whichever is greater, accounting for the potential error in the volume displacement from the calibrated syringe this implies that an error of up to $3.5 \%$ or 70 $\mathrm{ml}$, whichever is greater, is acceptable. A change in volume of $25 \mathrm{ml}$ should be detectable. Similarly the recorder speed should be checked at least quarterly with a stopwatch, and be accurate within $1 \%$. In spirometers where the time recording is initiated when the expired gas exceeds a certain volume, the acceleration of the electric motor is critical. This is difficult to check, but can be done with a calibrator based on explosive decompression $[150,151]$ or equipment which delivers precisely known flow patterns [152]. 


\subsubsection{Spirometers for recording forced ventilatory manoeuvres}

Spirometers with good dynamic properties are required to record rapid volume changes, and, by electronic or digital differentiation of the volume, flow during forced ventilatory manoeuvres. The characteristics of such spirometers should be the same as those for pneumotachometers which are described below. However, due to the differentiation procedure the signal to noise ratio of spirometers tends to be less than that of pneumotachometers.

\subsection{Pneumotachometry}

\subsubsection{Devices}

Numerous devices are available for measuring gas flow, of which the most widely used are Lilly and Fleisteh type pneumotachometers (screen and parallel capillary tubes respectively). They should be used in conjunction with an appropriate differential pressure transducer, amplifier and a DC-coupled analogue or a digital integrator. The present recommendations are limited to these two types only. Emphasis in the context of measuring lung volumes is put on the following features: linearity, stability and calibration.

\subsubsection{Linearity}

The gain of the system should not change with flow. This implies that the volume reading should be the same when a fixed volume of gas is administered from a calibrated syringe at varying flows. An accuracy of $3 \%$ of the reading or $50 \mathrm{ml}$, whichever is greater, (accounting for errors in the volume displacement of the syringe relaxes this to $3.5 \%$ or $70 \mathrm{ml}$, whichever is greater) is acceptable. Alinearity is a feature of some pneumotachometers; it should be corrected electronically or digitally prior to integration.

\subsubsection{Stability}

The volume signal often exhibits an unstable baseline «drift» for various reasons. The most important one is electric off-set of the flow signal, which is very often not constant over a prolonged period of time; it is usually minimized by allowing an appropriate warming-up period for the electronic equipment and by thermal isolation of the pressure transducer. In addition, inspired and expired gases are different because the respiratory exchange ratio is not unity, and because inspired and expired gas usually have a different temperature, water vapour content and gas composition, all of which affect the flow measurements (see appendix A). Finally the measuring device may give different signals for the same flow in opposite directions. For these reasons baseline «drift» of the volume signal is unavoidable. If it is minimal $\left(<100 \mathrm{ml} \cdot \mathrm{min}^{-1}\right)$ and constant, it does not interfere with measurements of static lung volumes provided that it is accounted for. Heating the pneumotachometer reduces variations in resistance to gas flow due to condensation and evaporation of water. However, the optimal temperature varies with the type and size of the pneumotachometer, the site of measurement and the temperature and composition of inhaled and exhaled gas (see appendix A). The pressure transducer should be positioned in such a way that secretions or water condensing in tubing cannot influence its performance.

\subsubsection{Calibration}

The device should be calibrated for volume daily by means of a 3 litre calibrated airtight gas syringe (see $\S 3.5 .1 .7$ ). The linearity of the device can be tested by delivering the gas rapidly and slowly; the volume readings should be independent of flow. In computeroperategd systems the flow can conveniently be derived from the volume calibration [153]. Electrical calibration is unsuitable because it does not test the pneumotachometer and differential pressure transducer, such calibrations, however, provide a useful check in between two physical calibrations and also for trouble shooting. When the device has been cleansed, it should be calibrated again. A correction factor may be necessary to take care of the differences in physical conditions of the gas between calibration and measurement. This factor may be different for inspiration and expiration (see appendix A).

The problems inherent in using Lilly and Fleisch type pneumotachometers for recording flows and volume displacements are discussed in appendix A. Thus it is common practice to calibrate the pneumotachometer with room air, and apply the calibrations without further corrections to inspired and expired gas. In the case of expired gas and a pneumotachometer heated to $30^{\circ} \mathrm{C}$, theoretically an error of up to $5.7 \%$ is made (see appendix A for further details).

\subsection{Gas dilution methods}

Gas dilution methods are applied for the measurement of lung volumes and capacities. They can be subdivided into those based on wash-in (usually helium) or washout (usually nitrogen) of an inert tracer gas, employing a closed or open system, and a multiple or single breath protocol.

\subsubsection{Multibreath helium equilibration method}

The most widely used method for the determination of functional residual capacity, which is recommended for routine use, is based on equilibration of gas in the lung with a known volume of gas containing helium [148, 154, 155]. To this end the spirometer should be equipped with a gas circulation pump, have facilities for carbon dioxide adsorption and oxygen supply, and gas inlet and outlet. The gas analyser is usually of the heat conductivity type. The helium meter should give a linear output up to the fractional helium concentration of 0.1 , with a resolution of $<0.05 \% \mathrm{He}$ and an accuracy of $0.1 \%$; the gas flow through the helium meter should be constant and be at least $200 \mathrm{ml} \cdot \mathrm{min}^{-1}$ to obtain an adequate response time 
for most analyzers. The $95 \%$ response (meter + spirometer) to a $2 \%$ step change should be $15 \mathrm{~s}$ or less. The gas line should contain absorbers which dry the gas and eliminate any $\mathrm{CO}_{2}$.

\subsubsection{Procedure and calculation}

The equipment should be used after sufficient time has passed for it to warm up and give a stable output; the warm-up time should be less than $10 \mathrm{~min}$. Prior to measurements the activity of the carbon dioxide absorber in the spirometer, and the $\mathrm{CO}_{2}$ and water absorbers in the helium meter line should be checked, and the absorbers changed when appropriate; in addition the water level should be checked in water sealed spirometers. The procedure for measuring lung volume entails:

1. Filling a water sealed spirometer from its minima volume with some extra oxygen, zeroing the helium meter, and subsequently adding helium; in the case of a rolling seal spirometer which can be completely emptied this should be preceded by filling the instrument with 1 litre room air.

2. When the helium reading is stable adding 2 or 3 litres of room air, preferably by a calibrated syringe.

3. When the helium reading is again stable assessing the patient's lung volume.

The minimal volume of the closed circuit varies with the amount of $\mathrm{CO}_{2}$-absorber, and with the water level in a water-sealed spirometer, however, with the proposed procedure this is taken into account. The first step is to flush the spirometer with ambient air, to place the bell in its lowest position and close the circuit. In rolling seal spirometers about $1 l$ air is added. Oxygen is subsequently added to raise the final oxygen concentration to about $25-30 \%$, and the helium meter reading adjusted to zero when a stable reading is obtained, and the volume added recorded; subsequently helium/ is added to raise the helium concentration to nearly full scale deflection (10\%) on the analyser. The initial helium concentration $F_{\text {sp. } \mathrm{H}}$ is noted, where $F$ is either the reading or the fractional concentration. Subsequently 2 or 3 litre room air is added (by a calibrated syringe) and the second meter reading $(F)$ noted when it is stable. Let $V_{\text {s }}$ be the volume of the spirometer prior to the addition of air, and $V_{\text {air }}$ the volume of air added during the last step, then $V_{s p}$ follows from:

$$
V_{s \mathrm{p}}=V_{\mathrm{air}} \cdot F_{\mathrm{sp}, \mathrm{He}, 2}\left(F_{\mathrm{sp}, \mathrm{He}, 1}-F_{\mathrm{sp}, \mathrm{He}, 2}\right)
$$

$V_{\text {sp }}$ need not be calculated for assessing FRC; its value is substituted by the right-hand part in computations (see below). If IVC measurements are made immediately after assessing the patient's lung volume, i.e. before the patient is connected to room air again, then for inspiring from FRC to TLC up to about 4 litre of gas should be added to the spirometer from the lowest bell position. A high initial helium concentration leads to a greater absolute change during measurements, so that random errors are small relative to the signal (see appendix B); hence it is recommended to start with a near full scale deflection in the linear range of the meter.
During measurements the subject should be seated and at rest, so that both the oxygen uptake and the FRC are stable. Dentures need not be removed, but a nose clip should be worn. The subject is placed on the mouthpiece and asked to breathe quietly for $30-60 \mathrm{~s}$, so as to become accustomed to the apparatus and attain a stable breathing pattern; subsequently the subject is connected to the closed system at the end of a normal expiration (fig. 6). Oxygen is added manually or automatically during the measurements in order to maintain a constant volume in the lung-spirometer system; the oxygen flow is adjusted by a needle valve to about $250-300 \mathrm{ml} \cdot \mathrm{min}^{-1}$ in adults.

The changes in helium concentration pass through two phases (fig. 6), namely:

a. A gas mixing period, during which helium becomes evenly distributed over the lung-spirometer system.

b. A period of constant change during which the helium concentration changes slowly on account of helium being taken up in body fluids and tissues $[60,155$, 156], as well as by imperfect balance between oxygen consumption and supply, so that the volume of the lung-spirometer system changes gradually.

The latter effect can in principle be eliminated graphically or arithmetically by extrapolation of the concentration-time curve to the beginning of the alteration in gas concentration [19]. The extrapolation method is valid in subjects in whom there is little evidence for impaired gas mixing; in such subjects the more or less constant change after a gas mixing phase can be attributed to helium rarefaction on account of imperfect oxygen supply and helium being dissolved in body fluids and tissues, and extrapolation redresses the problem. Indeed it was experimentally shown that the error in FRC determinations was effectively minimised by the extrapolation procedure when the (constant) oxygen supply was deliberately made far too large or far too small [155]. However, in patients with airways obstruction the helium-time tracing also drifts due to poorly mixing gas compartments; in such circumstances the extrapolation procedure leads to an underestimate of lung volume [19]. On that account, unlike a previous recommendation [19], the Working Party recommends that the extrapolation procedure be abandoned.

The helium concentration is noted every $15 \mathrm{~s}$ and gas mixing considered complete when the change in helium concentration has been constant and minimal over a 2 min period, or until $10 \mathrm{~min}$ after the beginning of the measurement. If the helium concentration can be read directly, or processed by computer, helium equilibration can be assumed when the change is less than $0.02 \%$ in $30 \mathrm{~s}$. The expiratory reserve volume is then measured in triplicate, after which the subject is disconnected from the closed system. The spirometer is then prepared for subsequent measurements of the IVC, which are performed in immediate succession, and the spirometer temperature noted. An acceptable alternative is to measure ERV, IC and IVC before disconnecting the patient, but this implies that the spirometer should have been sufficiently filled to allow up to 4 litre to be inhaled; the large spirometer volume adversely affects the accuracy with which the FRC is assessed (see appendix B). 

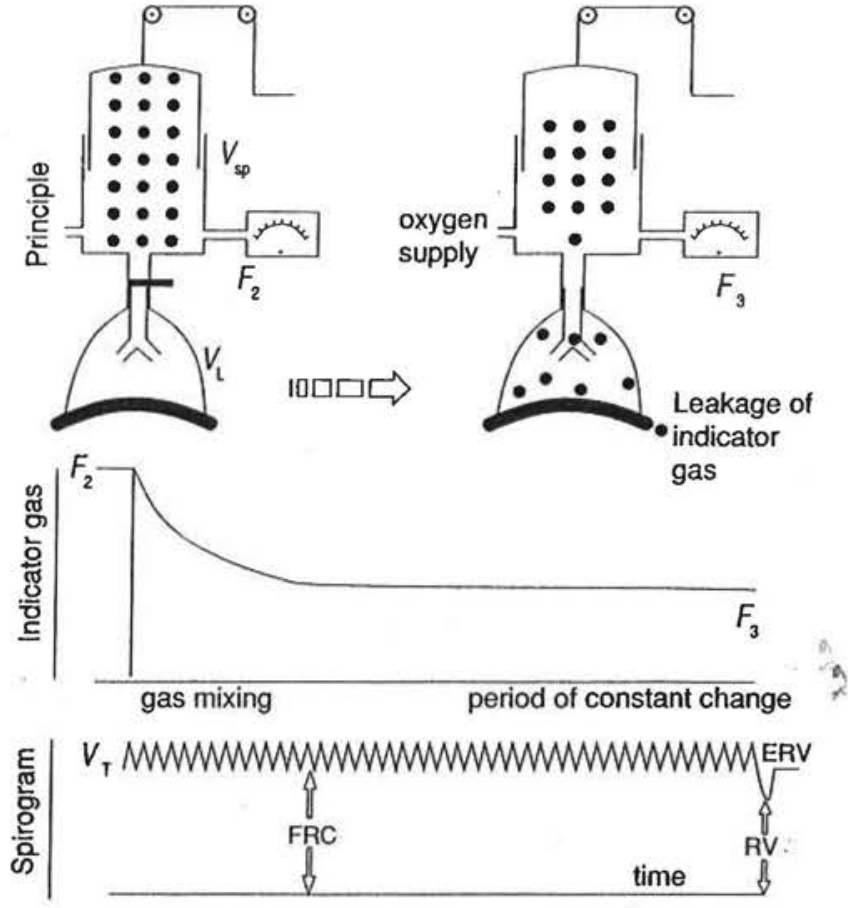

Fig. 6. - Principle of the measurement of the functional residual capacity by the closed circuit helium dilution method. Modified with permission from [148].

The lung volume $\left(V_{\mathrm{L}}\right)$ when the patient is connected to the spirometer is obtained as follows:

$V_{\mathrm{L}}=V_{\mathrm{air}} \cdot F_{\mathrm{sp}, \mathrm{He}, 1} \cdot\left(F_{\mathrm{sp}, \mathrm{He}, 2}-F_{\mathrm{sp}, \mathrm{He}, 3}\right) /\left\{F_{\mathrm{sp}, \mathrm{He}, 3} \cdot\left(F_{\mathrm{sp}, \mathrm{He}, 1}-F_{\mathrm{sp}, \mathrm{He}, 2}\right)\right\}-V_{\mathrm{dc}}$

where $F_{\mathrm{sp}, \mathrm{He}, 3}$ is the helium concentration at the end of the determination (see fig. 6), and $V_{\mathrm{ds}}$ is the instrumental dead space. The temperature and water vapour saturation of gas in the calibrating syringe should be used to convert the results to BTPS conditions; in the case of room air saturation is on average $50 \%$, when the last column in table 3 applies; however, the ERV, IC and IVC should be corrected according to the first column in table 3 .

In practice patients are not always switched into the spirometer circuit exactly at the mean resting endexpiratory level, so that $V_{L}$ is not equal to the FRC. Corrections for this need to be made when reporting the FRC, as shown in figure 7. In addition the volume of lung + spirometer may have changed during the test. This is possible if the patient was not at rest at the start of measurements, so that the FRC fell slowly; in that case this is inadvertently compensated by manipulating the oxygen supply to keep the end-tidal tracing level. Shortterm changes in end-expiratory level over a 7 to $10 \mathrm{~min}$ period are on average $110 \mathrm{ml}$ in (semi-recumbent) subjects without airways obstruction, and $376 \mathrm{ml}$ in patients with airflow limitation (mean FEV \%IVC 31\%) [155]; in addition there is a gradual shift of FRC over this period, so that ERV at the start of measurements is 114 (healthy) and $240 \mathrm{ml}$ (patients) larger respectively than at the end [155]. Such errors in oxygen supply can only be prevented by continuously measuring the oxygen concentration; such equipment is not generally available in lung function laboratories, so that its application cannot at this stage be recommended as standard procedure.

It is recommended to regard as FRC the representative end-expiratory level during the first 2-3 minutes of the measurements. RV and TLC are obtained as follows: RV $=$ FRC - ERV (where ERV is the largest of several efforts), and TLC = RV + IVC (the preferred method), but $\mathrm{TLC}=\mathrm{FRC}+\mathrm{IC}$ and RV $=$ TLC - IVC are also acceptable.

\subsubsection{Linearity}

To establish the linearity of the helium meter the spirometer is thoroughly flushed with air until the reading is stable. With the spirometer in its lowest position helium is added, and $F_{\text {sp.,He, }}$ read after mixing; after addition of a known volume of air with a syringe, the spirometer volume is calculated from the new concentration $F_{\text {sp, He, } 2}$, the known volume of added air and $F_{\text {sp He, }}$. Subsequently extra air is introduced with the syringe, and new computations are performed; this is repeated until the spirometer is full. The recorded and calculated volumes should agree within $3 \%$ and be linearly related with a regression coefficient of 1.00 [241].

\subsubsection{Calibration and quality check}

To validate the measurement of FRC, instead of connecting the patient to the spirometer $(\S 3.7 .1 .1)$ preferably a 3 litre calibrated syringe is employed. Three litres room air are added to the gas in the spirometer, filled with helium, extra oxygen and air as in 3.7.1.1. Care should be taken that the gas in the spirometer does not mix with the dead space of the syringe after emptying it into the spirometer. $F_{\mathrm{sp} \mathrm{He} 3}$ is recorded after $30 \mathrm{~s}$, when the meter reading is stable. The calculated volume (not corrected to BTPS conditions) is calculated from equation (1) above and should agree within $50 \mathrm{ml}$ with the added volume [241], otherwise the cause for the discrepancy should be diagnosed, repaired, documented, and a successful recheck be performed. Calibrations should be carried out weekly. After each change of soda lime and/ or change in water level the calibration should be repeated.

\subsubsection{Single breath helium dilution method}

The single breath method for determining lung volume, using helium as the inert tracer gas, is performed almost exclusively in conjunction with the determination of the transfer factor of the lung for CO [158]. This method of determination of alveolar volume underestimates the true lung volume in subjects with airflow limitation. The underestimation is less than with e.g. the single breath nitrogen test, possibly on account of mixing of helium by diffusion occurring during the breathholding period. The method is not recommended for routine use, unless in connection with the determination of the effective $T_{\text {LCOsb }}[19]$ when screening large numbers of subjects. 


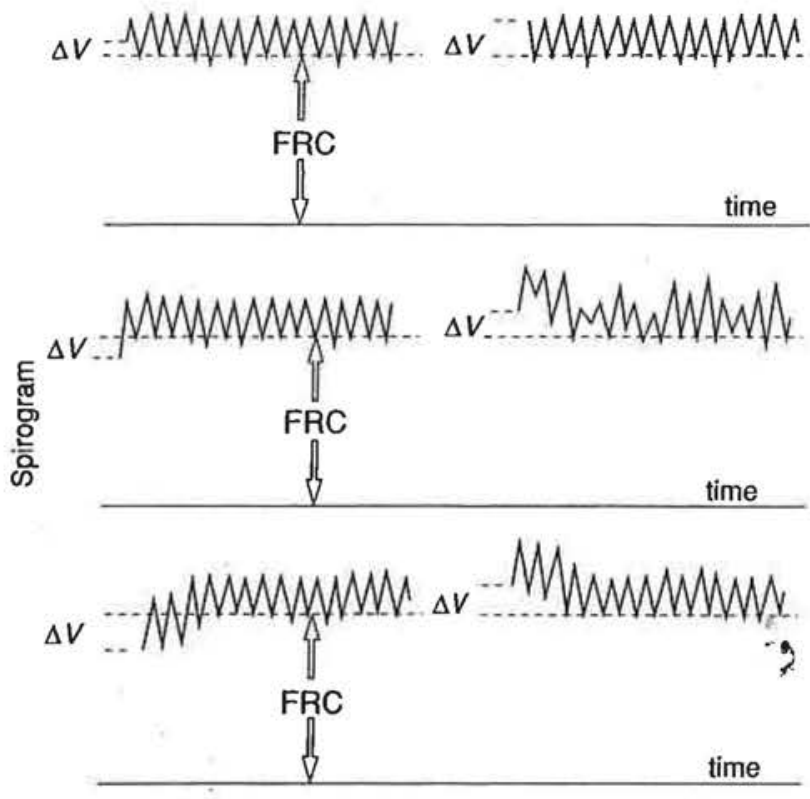

Fig. 7. - The subject is not connected to the spirometer at a representative end-expiratory volume. FRC is now the lung volume measured by gas dilution corrected by $\Delta V$.

\subsubsection{Other gas dilution methods}

\subsubsection{Multibreath nitrogen wash-out method}

With the open circuit method, most often nitrogen is washed out of the lung by the administration of oxygen via a valve system, the expired gas being collected in a Douglas bag until the nitrogen concentration falls below $1 \%$ [159]. The lung volume is calculated from the expired nitrogen volume, assuming an initial alveolar nitrogen concentration of $80 \%$. Alternatively the cumulative expired nitrogen volume is obtained by integrating the product of expiratory flow and nitrogen concentration and summing these over subsequent breaths. This method is technically demanding: it requires very careful dynamic synchronisation of flow and concentration signals, and linearisation of the nitrogen meter [160].

With both procedures errors can arise due to elimination of nitrogen from tissues and body fluids. This leads to the functional residual capacity in healthy subjects being considerably overestimated unless appropriate corrections are made.

\subsubsection{Single breath nitrogen method}

Residual volume and the total lung capacity can be estimated from the dilution of the nitrogen in the lungs caused by the inhalation of a vital capacity of oxygen. The measurement can be made in an open system using a pneumotachometer and integrator. However, difficulty arises because of the different viscosities of inspired and expired gas (oxygen, and oxygen in nitrogen respectively), and the correction procedures cannot be performed easily (see appendix A). Moreover alinearity of flow and concentration signals needs to be corrected; in addition the phase difference between flow and concentration signal may give rise to large errors unless are accounted for [160]. Therefore the use of a closed or semiclosed (bagin-bottle) system is more convenient. As regional RV/ TLC ratios vary, the mixed expired nitrogen concentration will underestimate the alveolar nitrogen concentration. On that account in apparently normal subjects this method underestimates the true volumes to a slight degree; in healthy subjects the intraindividual coefficient of variation is about $8 \%$ [71]. In subjects with airflow limitation, the underestimation of the true lung volume may become very large due to uneven distribution of inhaled gas; however, a partial correction for this can be made when the slope of the alveolar plateau (phase III) is recorded simultaneously $[71,84]$.

Othלs equally simple and more valid methods are available for the measurement of RV and TLC, so these single breath methods are not recommended for routine use.

\subsubsection{Forced rebreathing method}

The forced rebreathing technique $[51,69,71,161-170]$ has potential advantages over conventional gas dilution measurements:

a. Poorly ventilated compartments as well as air spaces which are not ventilated at resting functional residual capacity may be included in the measurements [52].

b. Gas mixing time is reduced to a maximum of 1 $\min$.

However, the instantaneous indicator gas concentration (usually nitrogen present in the lung at the start of the test) reflects not only gas mixing but also transfer of the gas between blood, tissues and alveolar gas, and in addition the respiratory exchange ratio; changes in this quantity during rebreathing significantly affect the computed lung volume. In healthy subjects the method gives valid results $[69,71,171]$, but in patients with airflow limitation the results are equivalent to those obtained with the multibreath helium dilution method [69, $170,171]$ and less than those obtained with the body plethysmographic technique [69]. The error due to continuous gas exchange can be circumvented by analysis of simultaneous wash-in and wash-out of two inert tracer gases [71, 172, 173]. This double-tracer method holds promise even in patients with uneven ventilation, but experience with it is limited and the required equipment not widely available in lung function laboratories.

\subsection{Whole body plethysmography}

\subsubsection{Principle}

Body plethysmography enables the determination of thoracic gas volume as well as the estimation of the resistance to airflow in the airways. This paragraph deals with the plethysmographic measurement of thoracic gas volume $[46,51,56,105,174-176]$.

The method is based on the relationship between pressure and volume at constant temperature of a fixed 
quantity of gas: $P \cdot V^{\gamma}=$ constant, where $\gamma$ varies between 1.4 (fully adiabatic compression, Poisson's law) and 1.0 (fully isothermal compression, Boyle's law). The gas laws applying to gas compression in the lung and whole body plethysmograph differ; however, we will develop the theory for Boyle's law, which states that the volume of a fixed quantity of gas at constant temperature varies inversely with the pressure:

$$
P \cdot V=(P+\Delta P) \cdot(V+\Delta V)
$$

and then address non-isothermal conditions. At limited pressure fluctuations $\Delta P \cdot \Delta V$ may be ignored, because it is very small. Applying Boyle's law to the lung, it follows that

$$
V_{\mathrm{L}}=-P_{\mathrm{A}} \cdot \Delta V_{\mathrm{L}} / \Delta P_{\mathrm{A}}
$$

where $V_{\mathrm{L}}=$ lung volume and $P_{\mathrm{A}}=$ alveolar pressure. Alveolar pressure is taken to be barometric pressure minus the water vapour pressure at $37{ }^{\circ} \mathrm{C}$ since it is assumed that when gas is saturated with water the volume of water vapour remains constant during pressure changes. When the airway is occluded at the mouth and pressure variations occur at frequencies $<1 \mathrm{~s}^{-1}$, alveolar and mouth pressure changes are the same : $\Delta P_{\mathrm{A}}=\Delta P_{\mathrm{m}}$

The change in lung volume $\left(\Delta V_{L}\right)$ as a result of a change in alveolar pressure $\left(\Delta P_{\mathrm{A}}\right)$ can be measured by a volume-displacement plethysmograph either by electronic integration of flow in and out of the plethysmograph (fig. 8 ) or directly by means of a spirometer; the frequency response of the equipment should be flat to $10 \mathrm{~Hz}[177$, 178].

The change in lung volume can also be measured indirectly in a volume-constant plethysmograph as a change in box pressure (fig. 8). In that case the change in box pressure, $\Delta P_{\text {box }}$, is measured instead of $\Delta V_{\mathrm{L}}$. As compression in the box is usually fully adiabatic at frequencies above $0.2 \mathrm{~Hz}[46,176,179,180]$, because its surface/ volume ratio is low, $\Delta P_{\text {box }}$ is related to $\Delta V_{\text {box }}$ by Poisson's law:

$$
P_{\text {box }} \cdot V_{\text {box }}^{1.4}=\left(P_{\text {box }}+\Delta P_{\text {box }}\right) \cdot\left(V_{\text {box }}+\Delta V_{b o x}\right)^{1.4}
$$

with $\mathrm{P}_{\text {box }}=$ barometric 'pressure. For small pressure changes

$$
\Delta V_{\text {box }}=-V_{\text {box }} \cdot \Delta P_{\text {box }} / 1 \cdot 4 \cdot P_{\text {box }}
$$

As $\Delta V_{\text {box }}$ and $\Delta V_{\mathrm{L}}$ are identical, combining eq. 4 and 6 provides

$$
V_{\mathrm{L}}=P_{\mathrm{A}} \cdot V_{\text {bax }} \cdot \Delta P_{\text {bax }} /\left(1.4 \cdot P_{\text {box }} \cdot \Delta P_{\mathrm{A}}\right)
$$

In practice the term $\mathrm{V}_{\mathrm{box}} /\left(1.4 \cdot \mathrm{P}_{\mathrm{box}}\right)$ is obtained by calibrating $\Delta P_{\text {box }}$ in terms of $\Delta V_{\text {box }}$ (eq. 6) by imposing sinusoidal volume changes with a reciprocating pump, at a frequency close to that of the panting manoeuvre.

In the volume-displacement or the flow plethysmograph $\Delta V$ is calibrated by entering and removing a known small volume into the plethysmograph by use of a piston pump. $\Delta V$ is commonly obtained by integration of flow into and out of the plethysmograph, and correction of this signal by adding a term proportional to $\Delta P_{\text {box }}[178,180]$. This fraction of $\Delta P_{\text {box }}$ increases with increasing resistance of the low-inertance screen across which flow is measured, and also increases with the volume of the plethysmograph adding a large capacity, both tending to increase the time constant of the plethysmograph.

The same calibration procedure applies to the volumeconstant plethysmograph, but here $\Delta P_{\text {box }}$ is proportional to $\Delta V$. As no air enters or leaves the plethysmograph during the cycling, the pressure signal for a given $\Delta V$ is larger than in the volume displacement plethysmograph. Whilst the signal is not subject to the drift of an integrator, it does drift with variations in plethysmograph temperature. Only small $\Delta V$ can be measured, and the volumeconstant plethysmograph is not suited for measuring thoracic gas compression during forced vital capacity manoeuvres.

\subsubsection{Technical requirements}

Since spontaneously occurring changes in barometric pressure and artifacts due e.g. to slamming doors are far larger than in plethysmograph pressure, the latter is best measured with reference to either:

a. A vessel connected via a small opening to the atmosphere, while the box is connected to the atmosphere via another small opening [51]; the mechanical timeconstant of volume-constant box and reference vessel should not be less than $5 \mathrm{~s}$ for measurements of thoracic gas volume.

b. A vessel in the airtight plethysmograph [46]. A small opening between vessel and plethysmograph should protect the differential pressure transducer against pressure build-up in the plethysmograph due to heating; for measurements of thoracic gas volume the mechanical time constant of the reference vessel should be $10 \mathrm{~s}$ at least.

It is desirable that the $\mathrm{X}-\mathrm{Y}$ recording of $\Delta P_{\mathrm{A}}$ and either $\Delta P_{\text {box }}$ or $\Delta V_{\mathrm{L}}$ are made at an angle of approximately $45^{\circ}$, as this leads to minimal errors.

It is required that the volume-constant plethysmograph can be vented to the atmosphere, so that pressure buildup due to heating of air by the subject can be dealt with. The time constant, including the thermal time constant in ventilated and non-ventilated volume-constant plethysmographs should be $>5$ s $[178,180]$; however, for measurements of airways resistance performed during quiet breathing the time constant should be $>15$ s $[19,178$, 180].

An intercom should be available for communication between patient and laboratory technician. Either type of plethysmograph should be equipped with either a piston pump or a loudspeaker system, with which a volume can be delivered of 10 to $100 \mathrm{ml}$ at a rate of 0.1 to $1 \mathrm{~s}^{-1}$. A shutter, which closes within $0.1 \mathrm{~s}$, should be present in the mouthpiece-flowmeter assembly; via a lateral tap in this assembly, mouth pressure is measured by a transducer which should be accurate to $0.01 \mathrm{kPa}$. 

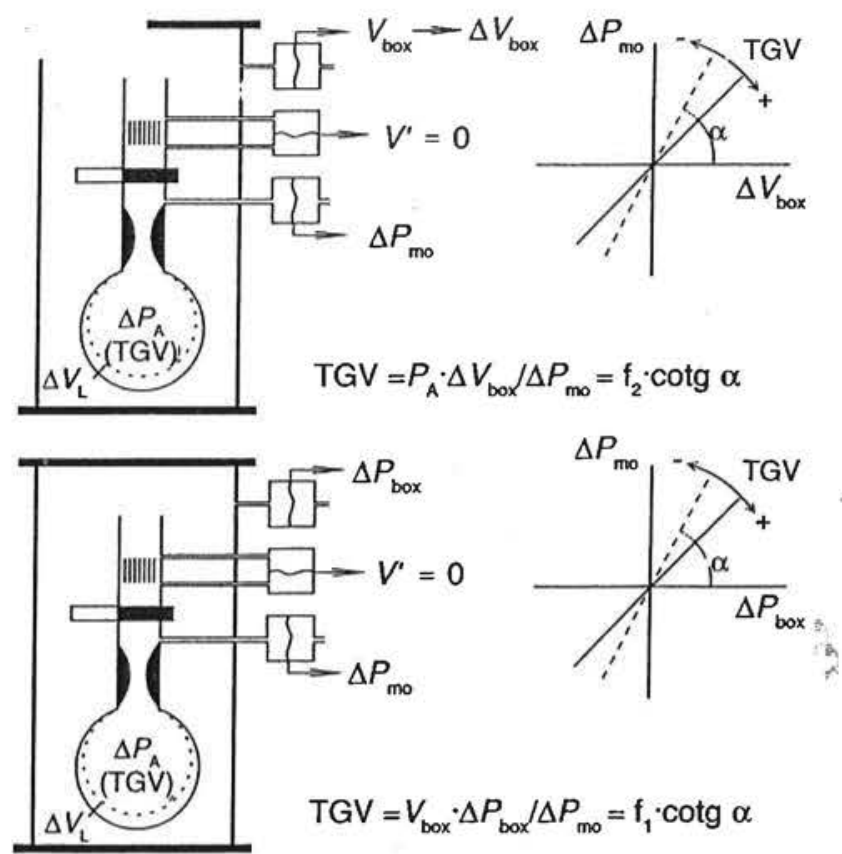

Fig. 8. - Schematic illustration of the measurement of thoracic gas volume by the flow-type volume-displacement (top) and the volumeconstant whole body plethysmograph. Modified with permission from [148].

Changes in mouth pressure should be recorded in phase with changes in either plethysmograph pressure or plethysmograph volume. The frequency response of all transducers and recording equipment should be flat to 10 $\mathrm{Hz}[177,178]$.

\subsubsection{Procedure}

Measurements of thoracic gas volume are started when the box pressure or volume are stable. The tidal volume, obtained by integration of air flow at the mouth, is recorded and preferably displayed. The subject is asked to support the cheeks with the hands while breathing through the mouthpiece-flowmeter assembly; a nose clip is mandatory. At the end of a normal expiration, the airways are closed by the shutter for $2-3$ seconds. During this time, the subject makes gentle breathing movements against the shutter at a rate of $<1 \mathrm{~s}^{-1}$; higher respiratory frequencies may lead to considerable overestimations of thoracic gas volume (see below) [63-65, 181-183]. After releasing the shutter the subject is instructed to perform either an ERV or an IC manoeuvre. The change in mouth pressure when the airway is occluded should not exceed $1 \mathrm{kPa}$, i.e. a $2 \mathrm{kPa}$ peak-to-peak pressure change. At the same time, the change in plethysmograph volume or pressure is recorded as a function of the change in pressure at the mouth. Unless the data are processed digitally and the software provides correction for a potential drift, such tracings are only accepted if two or more breathing cycles overlap (indicating that there is no drift) and if the X-Y recording is a straight line, indicating the absence of a substantial phase difference between the two signals. Looping in patients with airflow limitation is usually due to flabbiness of the cheeks and lips, occasionally also of the floor of the mouth; on that account the subject should always support the cheeks and floor of the mouth tightly with the hands. Flabbiness of the lips is promoted by removing dentures, which is hence not recommended. The (heated) pneumotachometer and integrator used for recording tidal volume is calibrated by a calibrated 3 litre syringe (see appendix A).

\subsubsection{Calibration of lung volume changes}

When at least three satisfactory tracings with a reproducible angle and no looping have been obtained volume changes are calibrated; to that end the subject is asked to hold the breath with open glottis while the piston pump or loudspeaker system is activated. The plethysmograph volume or pressure signal is recorded as a function of time during this procedure. Alternatively, the calibration is performed on an empty plethysmograph and corrected for the volume displacement of the subject. Preferably after each series of measurements, but at least weekly, the mouth pressure change is calibrated. This applies also to the calibration of the volume signal obtained from the pneumotachometer.

\subsubsection{Reproducibility}

The coefficient of variation of repeated measurements of thoracic gas volume made at the level of the functional residual capacity is about $5 \%$ in healthy subjects as well as in patients with obstructive lung disease [51, 56]. Even so the measurement of TGV and of either ERV or IC are preferably performed in immediate succession, as this minimises unnecessary sources of error [184]. The inspiratory vital capacity should be routinely determined at the end of the session, so that residual volume is also known. Corrections for not occluding the airway at a representative end-expiratory lung volume ( $c f$ fig. 7 ) need to be made to obtain FRC ${ }_{\text {box }}$ and IC.

\subsubsection{Summary statistics}

It is recommended to report as $\mathrm{FRC}_{\text {box }}$ the mean of three or more determinations which differ less than $5 \%$ from the mean, as TLC the mean FRC box plus the largest of the inspiratory capacities, but these should derive from a TGV which is within $5 \%$ of the mean. RV should be reported as TLC minus IVC [185].

\subsubsection{Body plethysmography vs gas dilution}

Both the gas dilution and body plethysmographic method are acceptable. The gas dilution method underestimates the lung volume in the presence of very poorly or nonventilated airspaces. Such spaces are included in the plethysmographic and radiographic lung volumes, and the plethysmographic technique is recommended in such circumstances. The plethysmographic determination of thoracic gas volume is the method of choice in patients with airflow limitation and air trapping. This is because changes in lung volume due to variations in gas pressure can be accurately measured (apart from small errors due 
to intra-abdominal gas) regardless of airway patency [186], and pressure swings at the mouth during airway occlusion are considered to be identical to those in mean alveolar pressure. However, in patients with a high airways resistance this only holds when respiratory efforts with an occluded airway are performed at a frequency of less than $1 \mathrm{~s}^{-1}$; at higher frequencies the change in mouth pressure lags behind that in alveolar pressure. This is because the compliant extrathoracic airways (mouth, pharynx, trachea) change in volume [187], permitting a small volume of air to flow between mouth and alveoli; in the presence of a normal airways resistance the pressure drop resulting from this flow is negligible, but in patients with severe airflow limitation the pressure drop and the phase lag between mouth and alveolar pressure changes may lead to very large errors in the measurement of thoracic gas volume. This error can be minimized by performing the respiratory manoeuvres at a frequency of $<1 s^{-1}[47,61,62]$. In infants overestimates of TGV may also be due to non-uniform alveolar pressure swings due to the very compliant thorax $[57,58,60]$, but this does not play a role in adults [186]. The combined use of body plethysmography and gas dilution methods gives information about the volume of «trapped gas», which may be clinically useful.

\subsection{Radiographic determination of lung volume}

Lung volumes can be determined from radiographs of the chest in the postero-anterior and lateral projections at full lung inflation $[48,50,52,59,188-196]$. The method gives values for total lung capacity which differ insignificantly from plethysmographically determined values even in subjects with airflow limitation $[43,47,49,50]$. More evidence is needed on accuracy in the presence of disorders of the lung interstitium.

The postero-anterior and lateral chest radiographs should be taken at the level of total lung capacity at a target-film distance of $185 \mathrm{~cm}$. The computational procedure should include corrections for non-gas containing structures within the thoracic cage $[43,48,50]$. The measurements can be performed both rapidly and easily [43, 197-199]. The within- and between-observer variabilities have been reported as $<1 \%$ and $<5 \%$ respectively, and the accuracy of the methods as $210 \mathrm{ml}$. Thus the method is recommended for use in healthy subjects, but not as the first choice due to ethical considerations with regard to exposure to radiation. The use of a standing posture should be noted since the volumes in this posture differ from those when the subject is seated [43].

More studies are required to assess the usefulness in patients with heart and lung disease. The radiographic method cannot be applied in subjects with an abnormal shape of the thorax and spinal column.

Detailed information about (regional) lung volumes and lung density can be obtained from computed tomography, single-photon emission computed tomography and magnetic resonance imaging [200-203], but these techniques for determining lung volumes are still at an experimental stage.

\section{Bronchodilator response and serial measurements}

\subsection{Assessment of the response to bronchodilator drugs}

The response to bronchodilator drugs is usually assessed in terms of a change in the $F_{E V}$, vital capacity or of airways resistance. The latter is standardized for lung volume by expressing the result as specific airways conductance. In some asthmatic subjects an acute response to a bronchodilator may be revealed only after a short course of steroids (possibly by restoring $\beta_{2}$-responsiveness in previously non-responsive asthmatics [204]), which may by itself change baseline lung function; this needs to be looked into further. Indices of forced expiratory flow can be in error if the lung volume changes during the assessment. For this reason MMEF, $\mathrm{MEF}_{50 \mathrm{FVC}_{\mathrm{C}}}$ and $\mathrm{MEF}_{25 \% \text { FvC }}$ should not be used; however, valid indices are obtained when the flows after administration of the drug are related to the same lung volumes as were used for the initial measurements, for example $\mathrm{MEF}_{\text {SOxinitial FvC }}$, etc. [205].

The observed response to a drug is dependent upon its pharmacological class, the route of administration and in the case of inhaled drugs the inhalation technique and aerosol delivery system; the response is influenced by the dose, the time after the administration when the measurement is made, the bronchial lability at the time of assessment, the mean level of lung function, the reproducibility of the index used for the measurement and the likelihood that any slight bias in the measurement will not be the same on the two occasions (hence regression towards the mean, which can be eliminated by relating the change to the mean level (i.e. $\Delta \mathrm{x} / \overline{\mathrm{x}})[206,207])$.

An unambiguous bronchodilator response should exceed spontaneous variability and the response observed in healthy individuals. Amongst the latter the standard deviations of repeated measurements of FVC and FEV, are on average 148 and $183 \mathrm{ml}$ respectively (weighted averages from [33]; these data also comprise variability between different days), and the upper $95 \%$ confidence limit of the bronchodilator response in $\mathrm{FEV}_{1}$ has been reported as $7.7 \%$ to $10.5 \%(220-315 \mathrm{ml})$ [208-211]; corresponding figures for FVC are $5.2 \%$ to $10.7 \%$ [208, 209].

The long-term variability in ventilatory function in patients with lung disease is larger than in healthy subjects. However, in patients in a stable condition the short-term variability in FEV, is very similar (upper $95 \%$ confidence limit $0.19 l$ ) $[210,212]$. The common practice of reporting the change relative to the initial value $\left(\Delta \mathrm{x} / \mathrm{x}_{1}\right)$ has disadvantages that contribute towards controversies about the diagnostic and prognostic value of bronchodilator responses [206, 212-216]. First, the change in FEV is only weakly related or unrelated to the level of FEV,$[205,212-214,217-221]$, whether expressed in absolute value or as percent predicted. Hence the method yields high values in persons with «poon initial values and lower ones in those with «good» initial values. 
On this account the changes should be reported as a difference in absolute units and, standardised for age and size, as a percentage of the reference value. An unambiguous bronchodilator response is obtained when the improvement in $\mathrm{FEV}_{1}$ and/or FVC is both larger than $12 \%$ predicted and exceeds $200 \mathrm{ml}$. This approach allows better discrimination between bronchodilator responses in patients with asthma and with COPD [213, 218]. In adults an increase in PEF of $60 \mathrm{l} \cdot \mathrm{min}^{-1}$ after administration of a bronchodilator drug indicates a clinically significant improvement [222].

Whether an unambiguous bronchodilator response is closely related to a clinical benefit has not been established. Some patients with COPD and with poorly reversible airflow limitation $\left(\triangle \mathrm{FEV}_{1}<10 \%\right.$ predicted after inhalation of $800 \mathrm{mg}$ terbutaline) report bronchodilator induced relief of shortness of breath; subjective improve ment correlated with IVC, $\mathrm{MIF}_{50 \% \mathrm{vc}}$ and specific airways resistance [223].

\subsection{Serial measurements}

For many applications, the results of tests of lung function are interpreted on the basis of serial measurements in which the initial and/or the final values themselves constitute the reference value. Changes well in excess of the measurement error occur in clinical medicine and are easily detected; annual changes due to smoking or occupational air pollution can be very small, of the order of $10-25 \mathrm{ml}$ and yet be of long term significance. The accurate estimation of such changes requires large numbers of subjects, several years follow-up and meticulous attention to the details of the measurement. For FEV, a sample size of 100 , a follow up time of 5 years and duplicate measurements on two separate occasions at each end of that time have been recommended [224]. However, a smaller scale study can be adequate if conditions are optimal. To this end the same observers and equipment should be used throughout, and for each subject the observations should be made at the same time of day and season of the year. Six weeks should be allowed after any viral infection of the respiratory tract. In addition the measurements should preferably be repeated at intervals during the follow-up period, as this will identify systematic deviations within the study which might otherwise not be detectable [225].

In studies in which the effect of intervention is of prime interest, a power analysis prior to the start of the study is recommended [226]. This can be illustrated by an example. If in a group of control subjects $\mathrm{FEV}_{1}$ declines $50 \mathrm{ml}$ annually, SD $45 \mathrm{ml}$, and one wishes to detect whether intervention can slow the decline to $20 \mathrm{ml}$ per year, then the group size $\mathrm{n}$ can be estimated as follows:

$$
\mathbf{n}=2 \cdot \mathrm{SD}^{2} \cdot\left(\overline{\mathrm{x}}_{1}-\overline{\mathrm{x}}_{2}\right)^{-2} \cdot \mathrm{f}(\mathrm{a}, \mathrm{b})
$$

where $\tilde{x}_{1}$ and $\bar{x}_{2}$ are the means of the control and treatment group respectively; $\mathrm{f}(\mathrm{a}, \mathrm{b})$ is a factor (see table 5) in which account is taken of the likelihood that differences are erroneously accepted or rejected (a is the type I error, i.e. the risk of a false-positive result, often taken to be $0.05 ; 1-b$ is the power of detecting a difference $\bar{x}_{1}-\bar{x}_{2}$, where $b$ is the risk of a false-negative result, often taken to be $0.05,0.1$ or even 0.2 ). Applying $\mathrm{a}=0.05$ and $\mathrm{b}=0.05$, $\mathrm{n}$ comes to $2 \cdot 45^{2} \cdot 30^{-2} \cdot 13.0=58.5$. This implies that the treatment and the control group should minimally have 59 subjects each. Further examples are given in [226].

Longitudinal reference cannot be obtained from crosssectional studies. The latter are inevitably biased by selective mortality of subjects with inferior lung function [227] and by cohort effects which lead to systematic differences in lung function between persons born and brought, up in different economic circumstances and environmental conditions [228-231]. In addition for Caucasian men there is now good evidence that the annual decline in lung function is related to the mean level of lung function [232]. There is as yet no similar information for women or for other ethnic groups. Short term longitudinal studies over periods of 5 to 7 years can provide much useful information, and more research is needed.

Table 5. - Values of $f(a, b)$ to be used in computing required number of patients.

\begin{tabular}{rlrrr}
\hline & & \multicolumn{3}{c}{ (type II error) } \\
& & 0.05 & 0.1 & 0.2 \\
\hline$\alpha$ (type I & 0.1 & 10.8 & 8.6 & 6.2 \\
error) & 0.05 & 13.0 & 10.5 & 7.9 \\
& 0.02 & 15.8 & 13.0 & 10.0 \\
& 0.01 & 17.8 & 14.9 & 11.7 \\
\hline
\end{tabular}

\section{$5 \quad$ Reference values}

\subsection{Predictions for adults of Caucasian descent}

Reference values for lung volumes and forced ventilatory flows for adults of European descent are given in table 6. They derive from studies carried out on subjects who were nonsmokers without (previous) disease which could compromise their ventilatory function; in addition the studies were performed with equipment and methods which seemed to be compatible with present standards. For PEF, RV, FRC and TLC the situation is not satisfactory; this is because smokers and ex-smokers in published studies have not been consistently excluded; in addition the number of published studies is small, and the results disparate particularly for FRC. A detailed account of how summary equations were derived from published reference values is given in the previous ECSC report [233]. The equations apply to men and women of European descent, aged $18-70 \mathrm{yr}$, between 18 and $25 \mathrm{yr}$ an age of $25 \mathrm{yr}$ is to be entered into the various equations since in cross-sectional studies there is little if any change in ventilatory function in this age range. The equations were derived from a height range of $1.55-1.95 \mathrm{~m}$ in men, and $1.45-1.80 \mathrm{~m}$ in women. Since its publication [19] the values predicted for $\mathrm{FEV}_{1}$ and FVC [234-239] and those for TLC [239] have been shown to agree well with 
those observed in various populations of nonsmokers without a history of respiratory symptoms in various European countries. Values for neonates, children and adolescents have been recently reviewed [240].

Reference values for indices derived from flow-volume curves during air breathing for adults of European descent are not entirely concordant but more so than formerly [233]. Some of the variation is due to the use of instruments with different physical characteristics, but in addition mathematical treatment of the results may not always have been appropriate. Thus there is need for more information.

It is recommended not to put too much reliance on «abnormal» or «normal» test results for instantaneous forced expiratory flows derived from maximal expiratory flow-volume curves and the FVC manoeuvre, in particular if the $\mathrm{FEV}_{1}$ is within normal limits. MEF $\mathrm{XsFvC}$ and MMEF are determined at a fixed percentage of the FVC and over the middle half of the FVC respectively; hence alterations in the FVC and in RV due to restrictive or obstructive lung disease imply that flows may deviate from predictions not only on account of an underlying disease process, but also because they are not measured at the same lung volume as in healthy subjects. Conversely the $\mathrm{FEV}_{1}$, which is the integrated flow over the first second of the forced expiration, is less sensitive to changes in the level of lung inflation; except in patients with gross abnormalities in their TLC, the FEV is usually delivered starting from a level of lung inflation which is comparable to that in the healthy subjects from whom the prediction equations were derived.

\subsection{Other ethnic groups and other factors}

The size of the lungs relative to body size varies with age (for example, in young men during the latter part of adolescence). It also varies with ethnic group [241, 242]. Some of the variability is due to ethnic differences in trunk length relative to standing height. This factor provides part of the explanation for black people having smaller lungs with lower values for $\mathrm{FEV}_{1}$ and FVC (but not necessarily for PEF and other indices) compared with white people. But trunk length does not account for all of the difference, nor does it explain why many Asian Indian, Polynesian and Mongoloid people also have relatively small lungs; differences in fat free mass, chest dimensions and the pressure that can be generated by respiratory muscles may all contribute, whilst ethnic differences in alveolar size [243] or airway dimensions [242] are less likely. The differences can be allowed for by taking ethnic group into account. Either reference values for the appropriate ethnic group can be consulted or a correction factor can be applied to the corresponding reference values for white people. Some correction factors in current use are given in table 7.

Difficulty can arise on account of:

1 Differences in methodology; not all studies meet present day criteria.

2 Migration. This does not of itself affect the lung function, so the reference values need not be based on information in the country of residence.
Table 6. - Summary equations for lung volumes and ventilatory flows for adults aged $18-70 \mathrm{yr}^{\text {s. }}$. The lower 5 or upper 95 percentiles are obtained by subtracting or adding the figure in the last column from the predicted mean.

\begin{tabular}{|c|c|c|c|c|}
\hline Variable & Unit & Regression equation & \multicolumn{2}{|c|}{ RSD 1.64RSD } \\
\hline \multicolumn{5}{|c|}{ Men } \\
\hline IVC & 1 & $6.10 \mathrm{H}-0.028 \mathrm{~A}-4.65$ & 0.56 & 0.92 \\
\hline FVC & $l$ & $5.76 \mathrm{H}-0.026 \mathrm{~A}-4.34$ & 0.61 & 1.00 \\
\hline TLC & $l$ & $7.99 \mathrm{H}-7.08$ & 0.70 & 1.15 \\
\hline RV & $l$ & $1.31 \mathrm{H}+0.022 \mathrm{~A}-1.23$ & 0.41 & 0.67 \\
\hline FRC & $l$ & $2.34 \mathrm{H}+0.009 \mathrm{~A}-1.09$ & 0.6 & 0.99 \\
\hline RV/TLC & $\%$ & $0.39 A+13.96$ & 5.46 & 9.0 \\
\hline FRC/TLC & $\%$ & $0.21 \mathrm{~A}+43.8$ & 6.74 & 11.1 \\
\hline $\mathrm{FEV}_{\mathrm{i}}$ & $l \cdot \mathrm{s}^{-1}$ & $4.30 \mathrm{H}-0.029 \mathrm{~A}-2.49$ & 0.51 & 0.84 \\
\hline $\mathrm{FEV}_{1} / \mathrm{VC}$ & $\%$ & $-0.18 \mathrm{~A}+87.21$ & 7.17 & 11.8 \\
\hline $\mathrm{FEF}_{25-75 \%}$ & $1 . s^{2}$ & $1.94 \mathrm{H}-0.043 \mathrm{~A}+2.70$ & 1.04 & 1.71 \\
\hline $\mathrm{PEF}_{\xi}$ & $l \cdot \mathrm{s}^{-1}$ & $6.14 \mathrm{H}-0.043 \mathrm{~A}+0.15$ & 1.21 & 1.99 \\
\hline $\mathrm{MEF}_{75}$ & $l \cdot \mathrm{s}^{-1}$ & $5.46 \mathrm{H}-0.029 \mathrm{~A}-0.47$ & 1.71 & 2.81 \\
\hline $\mathrm{MEF}_{\text {so }}^{\prime \prime}$ & $l \cdot \mathrm{s}^{-1}$ & $3.79 \mathrm{H}-0.031 \mathrm{~A}-0.35$ & 1.32 & 2.17 \\
\hline $\mathrm{MEF}_{25}$ & $l \cdot \mathrm{s}^{-1}$ & $2.61 \mathrm{H}-0.026 \mathrm{~A}-1.34$ & 0.78 & 1.28 \\
\hline \multicolumn{5}{|c|}{ Women } \\
\hline IVC & $l$ & $4.66 \mathrm{H}-0.026 \mathrm{~A}-3.28$ & 0.42 & 0.69 \\
\hline FVC & $l$ & $4.43 \mathrm{H}-0.026 \mathrm{~A}-2.89$ & 0.43 & 0.71 \\
\hline TLC & $l$ & $6.60 \mathrm{H}-5.79$ & 0.60 & 0.99 \\
\hline RV & $l$ & $1.81 \mathrm{H}+0.016 \mathrm{~A}-2.00$ & 0.35 & 0.58 \\
\hline FRC & $l$ & $2.24 \mathrm{H}+0.001 \mathrm{~A}-1.00$ & 0.50 & 0.82 \\
\hline RV/TLC & $\%$ & $0.34 \mathrm{~A}+18.96$ & 5.83 & 9.6 \\
\hline FRC/TLC & $\%$ & $0.16 \mathrm{~A}+45.1$ & 5.93 & 9.8 \\
\hline FEV, & $l$ & $3.95 \mathrm{H}-0.025 \mathrm{~A}-2.60$ & 0.38 & 0.62 \\
\hline $\mathrm{FEV}_{1} / \mathrm{FVC}$ & $\%$ & $-0.19 A+89.10$ & 6.51 & 10.7 \\
\hline $\mathrm{FEF}_{25.75 \%}$ & $l \cdot \mathrm{s}^{-1}$ & $1.25 \mathrm{H}-0.034 \mathrm{~A}+2.92$ & 0.85 & 1.40 \\
\hline $\mathrm{PEF}_{1}$ & $l \cdot \mathrm{s}^{-1}$ & $5.50 \mathrm{H}-0.030 \mathrm{~A}-1.11$ & 0.90 & 1.48 \\
\hline $\mathrm{MEF}_{75}$ & $l \cdot \mathrm{s}^{-1}$ & $3.22 \mathrm{H}-0.025 \mathrm{~A}+1.60$ & 1.35 & 2.22 \\
\hline $\mathrm{MEF}_{50}$ & $l \cdot \mathrm{s}^{-1}$ & $2.45 \mathrm{H}-0.025 \mathrm{~A}+1.16$ & 1.10 & 1.81 \\
\hline $\mathrm{MEF}_{25}$ & $l \cdot \mathrm{s}^{-1}$ & $1.05 \mathrm{H}-0.025 \mathrm{~A}+1.11$ & 0.69 & 1.13 \\
\hline
\end{tabular}

$\mathrm{H}$ : standing height $(\mathrm{m}) ; \mathrm{A}$ : age (yr); RSD: residual standard deviation. 'Between 18 and $25 \mathrm{yr}$ substitute $25 \mathrm{yr}$ in the equations. ^Mixture from (mini-)Wright peak flowmeter and pneumotachometer: more work is needed.

3 Inter-marrying. The lung size of a person of mixed racial origin is intermediate between that of the parents [244]. Migrants interbreed with persons in their adopted country, so the white admixture can be important. In the case of black people in the USA, the average admixture is currently in excess of $22 \%$ [245], and appears to be increasing. The extent of the inter-breeding can best be estimated by noting the ethnic groups of a person's grandparents.

4 Nutrition. A low protein diet during childhood can stunt growth and result in a failure to achieve optimal lung size. Thus a traditional diet contributed to the small lungs of previous generations in Japan. This dietary factor still operates in many parts of the world, including South India where women appear to be affected more than men.

5 Other environmental factors. A high level of habitual activity during childhood contributes to above average lung function, as does residence at high altitude. Physical exercise which develops the muscles of the shoulder girdle (for example navvying, rowing, deep sea diving) can have a similar effect. 
6 Many of the factors which influence lung function operate concurrently, so no single set of referenc values or conversion factors is likely to be satisfactory. The values which are used should be appropriate to the circumstances.

An estimate of the proportional variability in FVC attributable to various factors is as as follows: sex $\pm 30 \%$, age $8 \%$, stature $20 \%$, ethnic group $10 \%$, weight $2 \%$, technical factors $3 \%$, leaving about $30 \%$ to be explained by smoking, past respiratory disease, etc. [246].

\subsection{Expression of results}

It is common practice to express results as percent predicted, i.e. 100.observed/predicted, and regard $80 \%$ predicted as the lower limit of normal. However, this sis only valid if the scatter is proportional to the level of lung function, as is the case in children [253, 254]. The assumption is invalid in adults, where the scatter is independent of the level [255-260], hence the residual standard deviation about the prediction equation is a constant and not a proportionality. The assumption of a proportionality where none exists can lead to major errors in interpretation. Error can also arise if a fixed lower limit is assumed without regard to the age or other relevant attribute of the subject (for example the height, gender or ethnic group). Thus, when in an elderly and short individual as well as in a tall and young individual the FEV, is one RSD below the predicted value, their $\mathrm{FEV}_{1}$ is comparable albeit numerically different; expressing the results in percent predicted would falsely suggest that ventilatory function is worse in the elderly subject.

Table 7. - Approximate conversion factors for adjusting European reference values for application to men of other ethnic groups.

\begin{tabular}{llll}
\hline Population & FEV, & FVC & Reference \\
\hline Orientals & & & \\
$\quad$ Hong Kong Chinese & 1.0 & 1.0 & {$[247]$} \\
$\quad$ Japanese American & 0.89 & - & {$[248]$} \\
Polynesians & 0.9 & 0.9 & {$[249]$} \\
N. Indians \& Pakistanis & 0.9 & 0.9 & {$[250]$} \\
S. Indians, see Africans & & & {$[251]$} \\
African descent & 0.87 & 0.87 & {$[252]$} \\
$\quad$ or subtract $(l)$ & $0.45^{*}$ or & $0.70^{*}$ & {$[241]$} \\
\hline
\end{tabular}

* The corresponding volumes for women are $0.4 l$ and $0.6 l$.

When comparing actual to predicted values the use of standardised residuals is recommended [19, 254]:

$$
\text { standardised residual }=\frac{\text { observed }- \text { predicted }}{\text { RSD }}
$$

One thus obtains a dimensionless index which indicates how far the observed value is removed from the predicted one, and therefore how likely it is that the observed value occurs in a reference population; the probability can be computed or taken from tables (e.g. pp. 28-30 in [261] or p. 44 in [262]). For example a standardised residual of 0 indicates that the observed value is equal to the reference value (hence is at the 50th percentile). Standardised residuals of -1.64 or 1.96 indicate the results are at the 5 th percentile and at the 97 th percentile respectively. Table 8 shows how various values of the standardised residual relate to confidence limits.

\section{Summary of recommendations}

\subsection{Measuring conditions}

Before measurements are made the subject should be carefully instructed in the procedure, which should be demonstrated. In tests over the full vital capacity range the importance of full inspiration and expiration, and when assessing forced ventilatory flows the need for maximal effort throughout the respiratory manoeuvre, should be emphasized.

The subject should be at rest and comfortable: tight clothing should be loosened, the height of the mouthpiece assembly adjusted to suit the subject. Measurements are made with the subject seated upright; other postures should be noted, as they affect lung volumes.

Table 8. - Value of standardised residual in relation to confidence interval in the case of normally distributed data.

\begin{tabular}{llllll}
\hline $99 \%$ CI & 2.576 & $95 \%$ CI & 1.960 & $60 \%$ CI & 0.842 \\
$98 \%$ CI & 2.326 & $90 \%$ CI & 1.644 & $50 \%$ CI & 0.674 \\
$97 \%$ CI & 2.170 & $80 \%$ CI & 1.282 & $40 \%$ CI & 0.524 \\
$96 \%$ CI & 2.054 & $70 \%$ CI & 1.036 & $30 \%$ CI & 0.385 \\
\hline
\end{tabular}

The removal of dentures is not recommended, because it enhances flabbiness of cheeks and lips, promoting leaks and spuriously high values for thoracic volume; it may, however, be necessary to remove badly fitting dentures in tests which entail forced ventilatory manoeuvres. A noseclip is mandatory for measurements made at low flows, such as during normal tidal breathing, and is recommended when determining forced ventilatory flows. The mouthpiece should be inserted between the teeth and held by the lips.

Ventilatory manoeuvres should preferably be displayed and recorded to facilitate quality control. Two practice attempts may precede determinations of lung volumes and forced ventilatory flows; this is particularly appropriate with inexperienced subjects. Failure to obtain reproducible results should lead to collecting more than the minimum number of technically acceptable manoeuvres. If even then reproducibility criteria cannot be met, a note to that effect should accompany the best test results in the report form. In some patients vital capacity manoeuvres induce bronchoconstriction, so that consecutive measurements of the VC and forced ventilatory flows become less; this trend should be noted.

Measurements should normally be made during normal working hours by a well-trained operator. Ideally the subject should have been at rest for 15 minutes, and should not have smoked at least one hour before the 
measurements; these should not be made shortly after meals. The time of the day and the season of the year should be noted, as diurnal variations are larger in subjects with lung disease than in healthy subjects. On that account repeat measurements should ideally be made at the same time of the day. It is also helpful to record the time of the last cigarette and of medication used, the extent to which the subject complied with the operator's instructions and any untoward reactions, e.g. coughing.

Measurements of volumes and ventilatory flows are corrected to BTPS conditions. For this purpose the temperature of the flow or volume recorder should be noted, and a record made of barometric and water vapour pressure.

For serial measurements the circumstances of the test should be similar on all occasions with respect to time of the day, season of year, apparatus and the operator. The latter should be well trained and his or her performance should preferably have been validated against a practiced operator.

Measurements of absolute lung volumes (i.e. including residual volume) may be made by gas dilution methods (preferably by helium dilution) and by whole body plethysmography. The latter is the preferred method in patients with obstructive airways disease, when respiratory movements against the closed shutter should be made at a frequency of less than $1 \mathrm{~s}^{-1}$; at higher frequencies lung volumes may be overestimated with this method. Measurements of TLC (or static lung compliance [19]) should form the basis for diagnosing a restrictive ventilatory defect. Such measurements are also recommended when interpreting volume dependent indices, such as instantaneous flows, lung elastic recoil and airways resistance.

Where a measurement of VC is used, it shall normally be the IVC; when facilities for measuring the IVC are not available the relaxed expiratory $\mathrm{VC}$ is an acceptable altemative. Similarly in size-correcting the FEV, by expressing it as a percentage of the vital capacity (Tiffeneau index) the IVC or EVC should preferably be used in the denominator to provide an index of airflow limitation. When comparing actual with predicted values, in adults the difference should be expressed in standardised residuals ([observed - predicted]/RSD), which provide a measure how far the value is removed from the predicted value.

Measurements of MMEF and maximal flows at a defined percentage of the FVC are not suitable for monitoring changes in airflow limitation, such as those induced by a bronchodilator or bronchoconstrictor drug, because they may be assessed at different lung volumes before and after bronchodilation due to changes in FVC. An unambiguous bronchodilator response in $\mathrm{FEV}$, or FVC should be both larger than $12 \%$ of the predicted value and exceed $200 \mathrm{ml}$.

\subsection{Indices}

The priority indices are, for ventilatory capacity: FEV and FVC, and for lung volumes: IVC, FRC, TLC and
RV. If only a spirometer is available, the latter three indices will be omitted. MMEF is also recommended, as are maximal expiratory flow-volume curves, from which in addition to FVC and FEV, forced expiratory flows at different lung volumes can be derived. A logical extension is to combine spirometry with a gas dilution method for determining FRC, RV and TLC, preferably using helium, or a body plethysmograph. Measurement of FRC in patients with obstructive lung disease is preferably performed in a body plethysmograph at a respiratory frequency less than $1 \mathrm{~s}^{-1}$; in that case, the IVC and IC are also determined in the plethysmograph by integration of airflow at the mouth.

IVC Inspiratory vital capacity. The largest value from the first three technically satisfactory determinations. The chosen value should not exceed the next highest one by more than $5 \%$ or $100 \mathrm{ml}$, whichever is gieater. If the difference is larger up to 8 measurements are made and the largest value reported, if appropriate with a note that reproducible measurements could not be obtained.

FVC Forced (expiratory) vital capacity. The criteria are the same as for IVC.

TLC Total lung capacity. When assessed by helium dilution TLC $=$ FRC + IC or TLC $=$ RV + IVC. When assessed by whole body plethysmography TLC = FRC + IC, where FRC is the mean of at least three determinations agreeing within $10 \%$ of the largest value, and IC is the largest value associated with any of the accepted FRC measurements. Whilst ideally the mean of 2 or more measurements should be used, in practice this will seldom be done with the helium dilution method, so that one measurement of FRC suffices; with the body plethysmograph at least three determinations should be made (number to be specified).

RV Residual volume. With the helium dilution method RV = FRC - ERV, where ERV is the largest of 3 determinations, but RV = TLC - IVC is equally acceptable. When measured by body plethysmography: RV = TLC - IVC.

FEV, Forced expiratory volume in 1 second. The highest value from the first three technically satisfactory attempts. The start of the forced expiration is obtained by linear extrapolation of the steepest part of the volume-time curve of a spirogram; the extrapolated volume should not exceed $5 \%$ of the FVC or $100 \mathrm{ml}$, whichever is greater. The chosen FEV, should not exceed the next highest one by more than $5 \%$ or $100 \mathrm{ml}$, whichever is greater. If the difference is larger up to 8 measurements are made and the largest value reported, if appropriate with a note that reproducible measurements could not be obtained.

MMEF: Maximal mid-expiratory flow. The largest value from the first three technically satisfactory forced expirations; the reported value should be from a forced vital capacity manoeuvre which 
differs less than $5 \%$ from the largest FVC.

PEF Peak expiratory flow. The largest value from the first three technically satisfactory blows.

$\mathrm{MEF}_{\mathrm{x} \text { FFC }}$ : Maximal expiratory flow when $\mathrm{x} \%$ of the FVC remains in the lung. The value is taken from an envelope of at least three technically satisfactory MEFV curves, which are super-imposed from total lung capacity. Alternatively the highest value is taken from a set of three curves; the FVC of the chosen curve(s) should differ less than $5 \%$ from the largest FVC. The three MEFV curves should be of similar shape and have a peak which is representative and not flattened, with a peak expiratory flow which differs less than $10 \%$ from the largest one.

\subsection{Reference values}

2

The set of reference values given in table $6(\S 5.1)$ is recommended for use in Caucasian males and females. The equations apply to people aged $18-70 \mathrm{yr}$, height range $1.55-1.95 \mathrm{~m}$ in men, and $1.45-1.80 \mathrm{~m}$ in women; however, in subjects aged 18-25 yr the predicted mean is the same as for a subject aged $25 \mathrm{yr}$, so that $25 \mathrm{yr}$ should be substituted in the prediction equations.

The upper 95 per cent or lower 5 per cent limit of predicted normal values is obtained by adding or subtracting 1.64.RSD from the predicted mean (table 6). This is the preferred method of delineating a reference limit, as these limits are not age dependent, unlike per cent predicted.

\subsection{Equipment}

A summary of recommendations is given in tables 9-11. The apparatus should accurately indicate volume with respect to time, and flow with respect to both time and volume. These variables should be available for inspection by the operator at the time of measurement in the form of an accurate graphical output and preferably also a digital display. If a spirometer is used, its capacity should be at least $8 l$; the displacement of the spirometer or the output from a pneumotachometer and integrator should be linear and capable of being recorded with an accuracy of $\pm 3 \%$ or $\pm 50 \mathrm{ml}$, whichever is greater. Volume displacements should be calibrated with a calibrated, airtight 3 litre syringe, which should be accurate within $25 \mathrm{ml}$; thus the combined error in volume calibrations is acceptable up to $3.5 \%$ or $70 \mathrm{ml}$, whichever is larger. The timing should be accurate to $1 \%$; for measurements which entail the subject performing a forced vital capacity manoeuvre, the equipment should be capable of registering over a minimal duration of $15 \mathrm{~s}$. A change in volume of $25 \mathrm{ml}$ should be detectable.

Temperature sensors should be checked weekly. They should be accurate to within $0.5^{\circ} \mathrm{C}$. This can be assessed by comparing its reading at ambient temperature to that of a mercury thermometer with a known accuracy of $0.1^{\circ} \mathrm{C}$.
Table 9. - Specifications applying to spirometers used for measuring static and dynamic lung volumes.

\begin{tabular}{|c|c|}
\hline Item & Specification \\
\hline Volume range & at least $8 l$ volume displacement \\
\hline accuracy & $\pm 3 \%$ or $\pm 50 \mathrm{ml}$, whichever is greater \\
\hline resolution' & $25 \mathrm{ml}$ \\
\hline Gas circulation $^{2}$ & at least $180 l \cdot \mathrm{min}^{-1}$ \\
\hline Timing accuracy & $\pm 1 \%$ \\
\hline Mouth pressure & $<0.6 \mathrm{kPa}$ \\
\hline $\mathrm{CO}_{2}$ level $^{2}$ & less than $0.5 \%$ \\
\hline Gas connections $^{2}$ & $\begin{array}{l}\text { oxygen supply } \\
\text { indicator gas supply } \\
\text { gas analyser connections }\end{array}$ \\
\hline Driving pressure ${ }^{3}$ & less than $0.03 \mathrm{kPa}$ \\
\hline Temperature & measurement in spirometer \\
\hline Calibration & calibrated syringe (3 litre) \\
\hline
\end{tabular}

The minimal change that can be detected. ${ }^{2}$ Applies to FRCdeterminations and inspiratory manoeuvres. ${ }^{3}$ Pressure at the mouthpiece below which there is no excursion of the spirometer.

Table 10. - Specification of equipment used in the plethysmographic assessment of lung volume.

\begin{tabular}{ll}
\hline Item & Specification \\
\hline $\begin{array}{l}\text { Mouth pressure range } \\
\text { accuracy* }\end{array}$ & -2 to $+2 \mathrm{kPa}$ \\
$\begin{array}{l}\text { Plethysmograph } \\
\quad \text { pressure range }\end{array}$ & $\pm 0.01 \mathrm{kPa}$ \\
$\quad$ accuracy* & $\begin{array}{l}\text { at least } \pm 2 \cdot 10^{-2} \mathrm{kPa} \\
\text { Volume deflection }\end{array}$ \\
& -200 to $+200 \mathrm{ml}$ (due to gas com- \\
$\quad$ accuracy* & $\pm 0.5 \mathrm{ml}$ \\
$\Delta P$ and $\Delta V$ & in phase up to $10 \mathrm{~Hz}$ \\
*The minimal change that can be detected.
\end{tabular}

For healthy subjects breathing air, the equipment should be capable of registering flows over the range 0 to 15 $l \cdot \mathrm{s}^{-1}$ (accuracy $\pm 3.5 \%$ or $0.07 \mathrm{l} \cdot \mathrm{s}^{-1}$, whichever is the greatest). The dynamic resistance should be less than 0.05 $\mathrm{kPa} \cdot l^{-1} \cdot \mathrm{s}$, and the inertia less than $0.001 \mathrm{kPa} \cdot l^{-1} \cdot \mathrm{s}^{2}$. The dynamic response of the instrument should be flat within $5 \%$ up to at least $3 \mathrm{~Hz}$ for measuring FEV, MMEF and $\mathrm{MEF}_{25}, 5 \mathrm{~Hz}$ for $\mathrm{MEF}_{50}$ and $20 \mathrm{~Hz}$ for PEF and $\mathrm{MEF}_{75}$ [263-268]. These recommendations are summarised in tables 9-11. They differ in some respects from those from other sources $[109,141,269]$. The calibration of peak flow meters, which may not meet all of the above criteria, is currently under review.

Calibration with respect to volume should be made using a gas syringe or by water displacement with the gas at constant pressure, temperature and humidity. Calibration with respect to time should be done using an electric motor or crystal oscillator. With a view to assessing the frequency response, calibration with respect to flow should preferably be made during conditions of fluctuating flow, for example with a pump which generates a sine wave, or with a computer-driven servocontrolled pump $[109,152]$. It should also be done during conditions of steady flow using a rotameter or 
Table 11. - Specification of helium meters used for measuring functional residual capacity.

\begin{tabular}{ll}
\hline Item & Specification \\
\hline Linearity & $0-10 \%$ helium \\
Accuracy & $\pm 1 \%$ of initial deflection \\
Resolution & $<0.05 \% \mathrm{He}$ \\
Gas flow & constant $>200 \mathrm{ml} \cdot \mathrm{min}^{-1}$, gas to be free of \\
& $\mathrm{CO}_{2}$ and $\mathrm{H}_{2} \mathrm{O}$ \\
Response time & $95 \%$ response time $<15 \mathrm{~s}$ (meter + \\
& spirometer) \\
\hline
\end{tabular}

piston which has itself been calibrated for the conditions of the measurement. Calibration of an integrator with its attendant recorder should be made using a gas syringe, or by delivering known steady flows for a precisely measured perod of time, or a flow-volume generator, the latter should be capable of delivering a range of volumes and flow profiles over the physiological range [150, 151]. The constancy of the calibration should be checked at the start and end of each session of measurement.

\subsection{Hygiene}

The working party is unaware of reports that disease has been transmitted via lung function equipment. However, hygienic measures should form part of the daily routine in lung function laboratories. It is impossible to provide detailed generally applicable recommendations in this respect, since there is such great variety in equipment used, component parts and materials applied, each of which may be advesely affected by one or the other cleaning or disinfection procedure. In the European Community it is compulsory that manufacturers provide recommendations about the cleaning and disinfection of their equipment.

In general bacteria and fungi thrive in a moist environment; hence equipment, hoses and other connections should be kept dry. Secretions should be trapped and disposed of. After testing a patient the breathing circuit should be opened to room air and the system blower run for ten minutes to remove condensation. In addition the breathing valve should be mechanically cleaned and disinfected with an appropriate disinfectant. Spirometers should bi opened at the end of the day, cleaned mechanically and with an appropriate disinfectant, and dried. Hoses should similarly be cleaned and disinfected or sterilised, and dried subsequently by first slinging them around and then hanging them to dry; their interior surface should be smooth. Where feasible disposable articles (e.g. mouthpiece, which may be fitted with a bacterial filter [270]) should be used; noseclips should be applied with tissue. Rubber mouthpieces and noseclips should be washed with a detergent, soaked in a disinfectant, rinsed, and hung to dry; the technician should wear protective rubber gloves during cleaning. At the end of the week the water should be drained from water sealed spirometers, which should be allowed to dry. In addition $2 \%$ glutaraldehyde can be used to sterilise the apparatus [270].

\section{APPENDIX}

\section{A Factors affecting measurements of gas flow by pneumotachometer ${ }^{1}$}

\section{A.1 Introduction}

This appendix is meant to illustrate the complexities of measurements of gas flow by pneumotachometry. The results of computations should not be used indiscriminately to correct calibrations or flow readings, since most of them are based on the application of gas laws and not on experimental data. For example the heat transfer of Fleisch and Lilly pneumotachometers is different, and the assumption of immediate temperature equilibration is naive. Thus there is need for further studies.

\section{A.2 Temperature, viscosity and volume}

The pneumotachometer is extensively used in measurements of ventilatory function and gas exchange. Yet it

\footnotetext{
'The section on pneumotachometry has benefitted greatly from contributions by Dr. M.R. Miller.
}

is a complex instrument if we want to take proper account of all the factors that influence its reading [271279]. In the following we shall address some of the problems.

The influence of gas temperature at constant pressure is twofold, namely an influence on gas volume and on gas viscosity.

The volume $(V)$ of a quantity of gas varies with the thermodynamic temperature $(T)$ and the pressure $(P)$ :

$$
P \cdot V=n \cdot R \cdot T
$$

where $n=$ number of moles and $R=$ gas constant. For a constant quantity of gas this reduces to

$$
P \cdot V / T=C
$$

where $\mathrm{C}=n \cdot R=$ constant. As long as the gas is saturated with water vapour, so that the quantity of gas varies with the temperature (variable number of water moles in the gas phase), the gas law will only be applied to the dry quantity: 


$$
V_{1} \cdot V_{2}^{-1}=\left(P_{2}-P_{T 2, \mathrm{H} 2 O}\right) \cdot T_{1} \cdot\left(P_{1}-P_{T 1, \mathrm{H} 2 O}\right)^{-1} \cdot T_{2}^{-1}
$$

where $P_{T \text { H2O }}$ is the partial water vapour pressure at temperature $T$. If gas cools before it is being measured, its initial volume will be underestimated.

Gas viscosity increases with temperature. The temperature coefficient is not the same for each gas [274]. The greater the gas viscosity, the larger the pressure drop across a pneumotachometer of fixed flow resistance. The viscosity of ambient air at different temperatures can be calculated by Sutherland's formula [280, 281], and for a gas mixture by Wilke's [282] or Turner's equation [283]. The following is a worked example taken from [279] (see table 12, data reproduced with permission from [279]). In the example the concentrations in air are: $\mathrm{N}_{2}$ $78.09 \%, \mathrm{O}_{2} 20.95 \%, \mathrm{CO}_{2} 0.03 \%$, Ar $0.93 \%, \mathrm{H}_{2} \mathrm{O} 50 \%$ saturation, in expired gas: $\mathrm{N}_{2} 78.49 \%, \mathrm{O}_{2} 16.52 \%, \mathrm{CO}_{2}$ 。 $4.06 \%$, Ar $0.93 \%, \mathrm{H}_{2} \mathrm{O} 100 \%$ saturated; barometric pressure is $101.3 \mathrm{kPa}$.

Gas which is being inhaled and exhaled passes through a pneumotachometer and attendant connections, which all influence the gas temperature. The temperature of exhaled gas at the mouth is about $33-35^{\circ} \mathrm{C}$ [284-286]; it is likely to become cooler on its way to the pneumotachometer unless the connecting tubing is heated, which is rarely done. It has been recommended [278, 279] that the pneumotachometer itself be heated to $30^{\circ} \mathrm{C}$; this is sufficient to prevent condensation of water vapour. One can compute how the changes in temperature and viscosity affect the volume calibrations and the measurements of flow using an unheated pneumotachometer at $20^{\circ} \mathrm{C}$, and one heated at $30^{\circ} \mathrm{C}$.

\section{A.2.1 Pneumotachometer not heated}

A calibration with 1 litre of ambient air at $20^{\circ} \mathrm{C}$ (viscosity $181.5 \mathrm{kPa} \cdot \mathrm{s}, c f$ table 12) is recorded as 1 litre. One litre of gas expired from the lungs at $37^{\circ} \mathrm{C}$, if it cools to $20^{\circ} \mathrm{C}$, would on that account be recorded as $1 / 1.102=0.9074$ $l$ (cf table 3), while the relative change in viscosity is $177.62 / 181.50=0.9786(c f$ table 12$)$. The combined effect is that $1 l$ expired gas is recorded as 0.9074.0.9786 $=0.8880 \mathrm{l}$. If one applies a BTPS correction factor from $20^{\circ} \mathrm{C}$ to $37^{\circ} \mathrm{C}$, the recorded volume becomes 0.9786 $l$, so that the true volume change is underestimated by $2.1 \%$. The total correction factor should be 1.125 and not 1.102 , which was based on the BTPS correction alone.

Under the same circumstances inspiratory flows and volumes would be correctly recorded, since the gas condition during calibration and during inspiration would be the same.

\section{A.2.2 Pneumotachometer heated}

In the case of a pneumotachometer heated to $30^{\circ} \mathrm{C}$, and assuming that gas passes through it immediately and completely assumes that temperature (an erroneous assumption), the 1 litre of room air at $20^{\circ} \mathrm{C}$ delivered during calibration expands to $273+30) /(273+20)=$
Table 12. - Viscosity (in kPa.s) of ambient air and expired gas at various temperatures.

\begin{tabular}{lcc}
\hline & Inspired & Expired \\
\hline $20^{\circ} \mathrm{C}$ & 181.50 & 177.62 \\
$30^{\circ} \mathrm{C}$ & 185.43 & 180.73 \\
$34^{\circ} \mathrm{C}$ & 186.83 & 181.68 \\
$37^{\circ} \mathrm{C}$ & 187.81 & 182.24 \\
\hline
\end{tabular}

$1.034 l$, because no change in water vapour pressure does occur. However, it is equated to $1.0 \mathrm{l}$, so that a true delivery of $1 l$ at $30^{\circ} \mathrm{C}$ would be recorded as $1 / 1.034$ $=0.9671 \mathrm{l}$. One litre exhaled from the lungs at $37^{\circ} \mathrm{C}$ becomes $1 / 1.044=0.9579 l$ at $30^{\circ} \mathrm{C}(c f$ table 3$)$ and is recorded as $0.9579 \cdot 180.73 / 185.43=0.9336 l(c f$ table 12$)$, due to combined effects of cooling and changes in gas viscosity. Since a true litre at $20^{\circ} \mathrm{C}$ is recorded as 0.9671 $l$, the net reading would be $0.9336 \cdot 0.9671=0.9029 l$, and when corrected with the BTPS factor only it would be $0.9029 \cdot 1.044=0.9426 l$, i.e. an underestimation by $5.7 \%$. The true correction factor would be $1 / 0.9029=$ 1.108 .

If on inspiration we consider room air $50 \%$ saturated with water vapour at $20^{\circ} \mathrm{C}$, application of the gas law gives a correction factor of 1.115 as shown in table 3 . The temperature of the pneumotachometer plays no role in the calculations.

\section{A.3 Conclusions}

Using an unheated pneumotachometer would seem the best solution if it were not for the temperature changes which occur in the meter during inspiration and expiration, and the condensation of water vapour which affects its airflow resistance and hence the reading. In practice it is a good compromise to heat the pneumotachometer to $30^{\circ} \mathrm{C}$ employing a temperature feedback controller [278, 279]; the Fleisch type pneumotachometer has an advantage in this respect because of a better heat transfer than is obtained with a Lilly type meter. Ideally the calibration is performed with room air fully saturated with water vapour at $30^{\circ} \mathrm{C}$ (viscosity $185.43 \mathrm{kPa} \cdot \mathrm{s}$ ), so that a correction need only be made for the different viscosity of exhaled gas $\left(180.73 \mathrm{kPa} \cdot \mathrm{s}\right.$ at $\left.30^{\circ} \mathrm{C}\right)$ : correction factor 0.975 .

The above computations for a heated pneumotachometer all assume instantaneous temperature equilibration, which is unrealistic; hence more experimental work is required to establish how appropriate corrections are made for different types of pneumotachometers. For tests which do not entail continuous measurement of ventilatory flow it is acceptable to use an unheated pneumotachometer which receives a resting flow of room air in between blows [278, 279]. Expired gas readings should then be increased by $2 \%$ if ambient temperature is $20^{\circ} \mathrm{C}$, and appropriate corrections of inspiratory and expiratory readings made for other temperatures. However, these suggestions need to be tested experimentally using different types and sizes of pneumotachometers. 
Table 13. - Thermal conductivities of various gases relative to $\mathrm{CO}_{2}$.

\begin{tabular}{cc}
\hline Gas & Conductivity relative to $\mathrm{CO}_{2}$ \\
\hline $\mathrm{CO}_{2}$ & 1.00 \\
$\mathrm{Ar}$ & 1.27 \\
$\mathrm{~N}_{2}$ & 1.71 \\
$\mathrm{O}_{2}$ & 1.83 \\
$\mathrm{He}$ & 11.04 \\
\hline
\end{tabular}

Table 14. - Computed thermal conductivities of gas mixtures in spirometer relative to dry 'air' $\left(79 \% \mathrm{~N}_{2}\right.$ and $21 \%$ $\left.\mathrm{O}_{2}\right)$.

\begin{tabular}{lllc}
\hline \multicolumn{4}{l}{ Gas concentrations (\%) } \\
$\mathrm{O}_{2}$ & $\mathrm{He}$ & $\mathrm{N}_{2}$ & conductivity/air \\
\hline 30 & 3 & 67 & 1.1675 \\
24.56 & 3 & 72.44 & 1.1638 \\
24.84 & 1.91 & 73.25 & 1.1054 \\
& & & \\
30 & 10 & 60 & 1.5439 \\
23.88 & 10 & 66.12 & 1.5397 \\
24.84 & 6.37 & 68.79 & 1.3452 \\
\hline
\end{tabular}

\section{B Measuring lung volume by helium dilution method}

\section{B.1 Sources of error}

Random and systematic errors in the concentration reading affect the computations; such errors should be small relative to the change in helium concentration arising from gas mixing. Errors may also arise from helium dissolving into body fluids and tissues, and from errors in the oxygen supply. The net error in the measurement of lung volume is affected by the sum of all individual errors.

\section{B.2 Heat conductivity meter}

The thermal conductivities of various gases vary ( $c f$ [287]); in table 13 they are expressed relative to $\mathrm{CO}_{2}$. We can estimate how the sensitivity of the helium meter to various gases works out in a $\mathrm{He}-\mathrm{O}_{2}-\mathrm{N}_{2}$ mixture (air being $21 \% \mathrm{O}_{2}$ and $79 \% \mathrm{~N}_{2}$ ); however, this is an approximation, since the heat conductivities of gas mixtures differ somewhat from the values computed algebraically from the properties of each gas [288]. We start with a 3 or $10 \%$ He concentration in $30 \%$ oxygen, $\mathrm{N}_{2}$ balance, in the spirometer. We compute (table 13) the mean concentrations of $\mathrm{N}_{2}$ and $\mathrm{O}_{2}$ which would be obtained by mixing alveolar and spirometer gas $\left(V_{\mathrm{l}}=3 l, V_{\mathrm{sp}}=5 l\right.$, assuming alveolar $\mathrm{N}_{2}=80 \%$, alveolar $\mathrm{CO}_{2}=5 \%$, and alveolar $\mathrm{O}_{2}$ $=15 \%$ respectively); first keeping the helium concentration in the spirometer constant, and then we compute average concentrations for all three gases when they are made to mix between lung and spirometer, always maintaining $5 \% \mathrm{CO}_{2}$ in the lung.
Table 14 illustrates that concomitant changes in the $\mathrm{O}_{2}-\mathrm{N}_{2}$ ratio when $[\mathrm{He}]$ is unaltered have only a very small effect on the katapherometer reading. The relative changes in heat conductivity relative to air due to gas mixing between lung and spirometer are $5.3 \%$ when the starting concentration is $3 \%$, and $12.9 \%$ when the initial $\mathrm{He}$ concentration is $10 \%$. In the latter case reading errors will have a smaller effect, leading to a more favourable signal/noise ratio.

The influence of errors in gas concentrations, be it due to the measurement instrument itself (alinearity, or interaction between helium and oxygen, nitrogen, water vapour) or reading errors can be approximated numerically as follows. Let $V_{\mathrm{L}}$ be the lung volume, $V_{\mathrm{sp}}$ the spirometer volume, and $F_{\mathrm{sp}, \mathrm{He}, 1}$ and $F_{\mathrm{sp} \mathrm{He}, 2}$ be the fractional helium concentrations at the start and the completion of gas mixing respectively, then if measured without errors

$$
V_{\mathrm{L}}=V_{\mathrm{sp}}\left(F_{\mathrm{sp}, \mathrm{He}, \mathrm{I}} / F_{\mathrm{sp}, \mathrm{He}, 2}-1\right)
$$

We define the accuracy of the measurement in terms of a fraction $\mathrm{p}$ of the initial helium reading ( $c f$ the recommendations), so that in the worst case the first reading is $F_{\mathrm{sp}, \mathrm{He}, 1}+\mathrm{p}$, and the second reading is $F_{\mathrm{sp}, \mathrm{He}, 2}-\mathrm{p}$. The equation then transforms to

$$
V_{\mathrm{L}}=V_{\mathrm{sp}} \cdot\left[\left(F_{\mathrm{sp}, \mathrm{He}, \mathrm{l}} \pm \mathrm{p}\right) /\left(F_{\mathrm{sp}, \mathrm{He}, 2} \pm \mathrm{p}\right)-1\right]
$$

From this it follows that the relative error $\mathrm{E}_{\mathrm{vol}}$ in the assessment of lung volume comes to

$\mathrm{E}_{\mathrm{vol}}=\left[\left(F_{\mathrm{sp}, \mathrm{He}, 1} \pm \mathrm{p}\right) /\left(F_{\mathrm{sp}, \mathrm{He}, 2} \pm \mathrm{p}\right)-1\right] /\left(F_{\mathrm{sp}, \mathrm{He}, \mathrm{l}} / F_{\mathrm{sp}, \mathrm{He}, 2}-1\right)$

In the worst case the error arising from accuracy enrors is as depicted in figure 9, where p varies between 0.5 and $3 \%$ of the initial helium concentration. Note that the error increases the smaller $V_{L}$ is relative to $V_{\text {sps }}$; arbitrarily a ratio $>0.3$ should form the lower limit, as the errors in lung volume increase rapidly when the ratio is less than this (fig. 9).

\section{B.3 Solubility of helium}

If gas mixing is continued long enough, then helium will not only mix between spirometer and lung, but will also equilibrate with the blood and subsequently with body water and fat. The helium uptake has been estimated at $0.3 \mathrm{ml} \cdot \mathrm{min}^{-1}$ per per cent helium in alveolar gas [155], i.e. $0.5 \mathrm{ml} \cdot \mathrm{s}^{-1}$ per unit fractional helium concentration. This does not take into account that body fluids and fat become saturated with helium, so that its uptake ultimately diminishes. Therefore the error will be approximated as follows. Let us assume that $V_{\mathrm{L}}=0.043 \cdot \mathrm{W}$, where $V_{\mathrm{L}}$ is in litre and $\mathrm{W}=$ body mass in $\mathrm{kg}$; in addition we assume that total body water is $0.6 \mathrm{~W}$ and body fat $0.1 \mathrm{~W}$; for a person of $70 \mathrm{~kg} V_{\mathrm{L}}$ comes to 3 litre. The blood/gas partition coefficient for helium is 0.0088 , that for oil/water 1.7 [ $c f 289$ ]. Hence body fluids and body fat are equivalent to a gas compartment of 


$$
(0.6+0.1 \cdot 1.7) \cdot \mathrm{W} \cdot 0.0088=0.006776 \cdot \mathrm{W} \text { litre }
$$

In this example, if gas mixing is continued long enough to achieve equilibration between gas, body fluids and body tissues, the helium equilibration will lead to an overestimate of $V_{\mathrm{L}}$ by

$$
(0.043+0.006776) / 0.043-1=0.1576
$$

or nearly $16 \%$. More soluble tracer gases, such as $\mathrm{N}_{2}$, lead to an even greater overestimate of $V_{L}$. In patients with a high FRC due to airways obstruction and/or emphysema the fluid and tissue compartments lead to a smaller relative error, in those with restrictive lung disease the relative error will be larger.

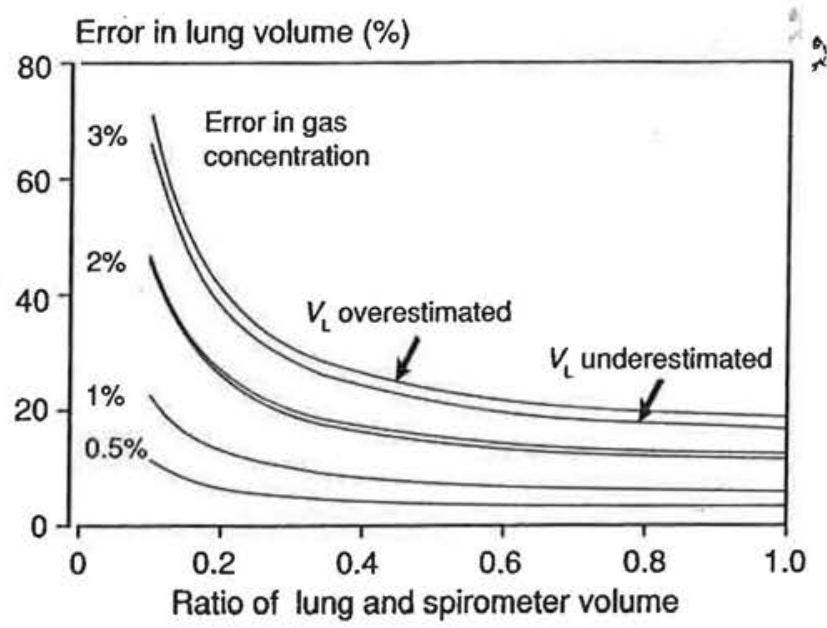

Fig. 9. - Maximal errors in measurements of lung volume if the helium concentrations at the start and the end of measurements of FRC differ by $\mathrm{x} \%$ from the initial helium concentration (modified from [290]).

\section{B.4 Imperfect oxygen supply}

Gas concentrations are not only influenced by the gas mixing process and helium uptake, but also by the continuous oxygen consumption not being perfectly matched by oxygen supply. From $V_{\mathrm{L}}, V_{\mathrm{sp}}, F_{\mathrm{sp}, \mathrm{He}, 1}$ and $F_{\text {sp.He, } 2}$ as defined above, we obtain:

$$
V_{\text {sp }} \cdot F_{\text {sp.He, }}=\left(V_{\text {sp }}+V_{L}\right) \cdot F_{\text {spHe } 2}
$$

Disregarding any influence of changes in oxygen and nitrogen concentration on the measuring device the error can be approximated as follows. Let the volumetric error $V_{\text {er }}$ in oxygen supply at any time $t$ be

$$
V_{t, \text { err }}=\text { oxygen supply - oxygen consumption }
$$

then the above equation transforms to

$$
V_{\mathrm{sp}} \cdot F_{\mathrm{sp}, \mathrm{He}, 1}=\left(V_{\mathrm{sp}}+V_{\mathrm{L}}+V_{\mathrm{t}, \mathrm{en}}\right) \cdot F_{\mathrm{sp}, \mathrm{He}, 2}
$$

and the relative error in lung volume comes to

$$
\left(V_{\mathrm{L}}+V_{t, \mathrm{etr}}\right) / V_{\mathrm{L}}-1
$$

Note that when the volumetric error in oxygen supply is small relative to the spirometer volume, this will safeguard against a dangerous drop in inspired oxygen concentration in the case of prolonged measurements.

\section{References}

1. Hyatt RF, Okeson GC, Rodarte JR. - Influence of expiratory flow limitation on the pattern of lung emptying in man. J Appl Physiol 1973; 35: 411-419.

2. Rodarte JR, Hyatt RE, Cortese DA. - Influence of expiratory flow on closing capacity at low expiratory flow rates. J Appl Physiol 1975; 39: 60-65.

3. Gueríy-Force ML, Müller NL, Wright JL, Wiggs B, Coppin C, Paré PD, Hogg JC. - A comparison of bronchitis obliterans with organizing pneumonia, usual interstitial pneumonia, and small airways disease. Am Rev Respir Dis 1987; 135: 705-712.

4. Ries AL, Sosa G, Prewitt L, Friedman PJ, Harwood IR. - Restricted pulmonary function in cystic fibrosis. Chest 1988; 94: 575-579.

5. Denolin H, Arhirii M. - Nomenclature and definitions in respiratory physiology and clinical aspects of chronic lung diseases. Bull Physiopath Respir 1975; 11: 937-959.

6. Bégin P, Grassino A. - Inspiratory muscle dysfunction and chronic hypercapnia in chronic obstructive pulmonary disease. Am Rev Respir Dis 1991; 143: 905-912.

7. Dawson SV, Elliott EA. - Wave-speed limitation on expirtory flow - a unifying concept. J Appl Physiol 1977; 43: 498-515.

8. Melissinos CG, Mead J. - Maximum expiratory flow changes induced by longitudinal tension on trachea in normal subjects. I Appl Physiol 1977; 43: 537-544.

9. Ingram RH, Schilder DP. - Effect of thoracic gas compression on the flow-volume curve of the forced vital capacity. Am Rev Respir Dis 1966;. 94: 56-63.

10. Sadoul P. - Mesure de la capacité vitale et des débits maximaux. In: Denolin H, Sadoul P, Orie NGM eds. L'exploration fonctionnelle pulmonaire, 2 me partie. Flammarion, Paris 1971.

11. Van de Woestijne KP, Afschrift M. - Airway dynamics during forced expiration in patients with chronic obstructive lung disease. In: Orie NGM, Van der Lende R eds. Bronchitis III. Royal Van Gorcum, Assen 1970; pp. 195-206.

12. Krowka MJ, Enright PL, Rodarte JR, Hyatt RE. - Effect of effort on measurement of forced expiratory volume in one second. Am Rev Respir Dis 1987; 136: 829-833.

13. Macklem PT, Wilson NJ. - Measurement of intrabronchial pressure in man. J Appl Physiol 1965; 20: 653-663.

14. Macklem PT, Fraser RG, Bates DV. - Bronchial pressures and dimensions in health and obstructive airway disease. J Appl Physiol 1963; 18: 699-706.

15. Teculescu DB. - Density dependence of forced expiratory flows. Methodological aspects. Bull Europ Physiopath Respir 1985; 21: 193-204.

16. Teculescu DB, Prefaut C. - Why did density dependence of maximal expiratory flows not become a useful epidemiological tool? Bull Europ Physiopath Respir 1987; 23: 639-648.

17. Castile RG, Pedersen OF, Drazen JM, Ingram JH Jr. Density dependence of maximal flow in dogs with central and peripheral obstruction. J Appl Physiol 1983; 55: 717-725.

18. Estenne E, Ketelbant P, Primo G, Yemault JC. - Human heart-lung transplantation: physiologic aspects of the denervated 
lung and post-transplant obliterative bronchiolitis. Am Rev Respir Dis 1987; 135: 976-978.

19. Quanjer $\mathrm{PhH}$ (ed). - Standardized lung function testing. Report Working Party Standardization of Lung Function Tests, European Community for Coal and Steel. Bull Europ Physiopath Respir 1983; 19, suppl 5: 1-95.

20. Council directive of 20 December 1979 on the approximation of the laws of the Member States relating to units of measurement and on the repeal of Directive 71/354/EEC; 80/ 181/EEC. Official Journal of the European Communities L39, 1980; 23: 40-50.

21. Matthys H. - Clinical Respiratory Physiology, Abbreviations, symbols and units, definitions. Working document of the European Society for Clinical Respiratory Physiology, Literae Medicinales Thomae 1978,

22. Kommission der Deutschen Gesellschaft für Innere Medizin zur Normung der Nomenklatur und der Symbole von Atmungsgrössen. Kongresszentralblatt Ges. Innere Medizin 1958; 192: $1-6$.

23. Units, symbols and abbreviations. A guide for biologieal and medical editors and authors. The Royal Society for Medicine, 1977.

24. Van Assendelft OW, Mook GA, Zijlstra WG. - International system of units (SI) in physiology. Pfluegers Arch 1973; 339: 265-272.

25. SI units and recommendations for the use of their multiples and certain other units. International Standard ISO 1000. International Organization for Standardization, 1973.

26. Symbols, units and nomenclature in physics. Intemational Union of Pure and Applied Physics, document UIP 11 (SUN 65-3), 1965.

27. The SI for the health professions. World Health Organization, Geneva, 1977.

28. Cotes JE. - SI units in respiratory medicine. Am Rev Respir Dis 1975; 112: 753-755.

29. Douma JH, Jacquemin C, Kamburoff PL, Peslin R, Visser BF. - Quantities and units in respiratory mechanics. Bull Physiopath Respir 1973; 9: 1242-1243.

30. Kamburoff PL. - Standardization of units and nomenclature in lung mechanics. Bull Physiopath Respir 1972; 8: 873. 31. Peslin R. - Units, symbols, abbreviations. Report presented at the WHO-SEPCR meeting in Sirmione, 1975.

32. Visser BF. - Quantities and units in respiratory physiology. Bull Physiopath Respir 1973; 9: 513-514.

33. Becklake MR, Permutt S. - Evaluation of tests of lung function for «screening» for early detection of chronic obstructive lung disease. In: The lung in the transition between health and disease, Macklem PT and Permutt S (ed.). Marcel Dekker, New York, 1979, pp. 345-387.

34. Hansen LM, Pedersen OF, Lyager S, Naeraa N. - Differences in vital capacity due to the methods employed (in Danish). Ugerkr Laeger, 1983; 145: 2752-2756.

35. Bedell GN, Wilson WR, Seebohm DM. - Pulmonary function in obese persons. J Clin Invest 1958; 37: 1049-1060. 36. Barrera F, Reidenberg MM, Winters WL. - Pulmonary function in the obese patient. Am J Med Sci, 1967; 785796.

37. Gilbert R, Sipple JH, Auchincloss JH. - Respiratory work and control of breathing in obese subjects. J Appl Physiol 1961; 16: 21-26.

38. Emirgil C, Sobol BJ. - The effects of weight reduction on pulmonary function and the sensitivity of the respiratory center in obesity. Am Rev Respir Dis 1973; 108: 831-842.

39. Ray CS, Sue DY, Bray G, Hansen JE, Wasserman K. Effects of obesity on respiratory function. Am Rev Respir Dis 1983; 128: 501-506.

40. Thomas PS, Owen ERTC, Hulands G, Milledge JS.
- Respiratory function in the morbidly obese before and after weight loss. Thorax 1989; 44: 382-386.

41. Naimark A, Cherniack RM. - Compliance of the respiratory system and its components in health and obesity. $J$ Appl Physiol 1960; 15: 377-382.

42. Brulot N, Kadas V, Grassino A, Milic-Emili J. - Positional variation in lung volumes in COPD. Am Rev Respir Dis 1992; 145: A764.

43. Pierce RJ, Brown DJ, Holmes M, Cumming G, Denison DM. - Estimation of lung volumes from chest radiographs using shape information. Thorax, 1979; 34: 726-734.

44. Ross JC, Copher DE, Teays JD, Lord TJ. - Functional residual capacity in patients with pulmonary emphysema. Ann Int Med 1962; 57: 18-28.

45. Tierney DF, Nadel JA. - Concurrent measurements of functional residual capacity by three methods. $J$ Appl Physiol 1962; 17: 871-873.

46. Woitowitz HJ, Buchheim FW, Woitowitz R. - Zur Theorie und Praxis der Ganzkörperplethysmographie in der Lungenfunktionsanalyse. Prax Pneumol 1967; 8: 449-471.

47. Paré PD, Wiggs BJ, Coppin CA. - Errors in the measurement of total lung capacity in chronic obstructive lung disease. Thorax 1983; 38: 468-471.

48. Bush A, Denison DM: Use of different magnification factors to calculate radiological lung volumes. Thorax 1986; 41: $158-159$.

49. Rodenstein DO, Sopwith TA, Stanescu DC, Denison DM. - Re-evaluation of the radiographic method for measurement of total lung capacity. Bull Europ Physiopath Respir 1985; 21: $521-525$.

50. Pierce RJ, Brown DJ, Denison DM. - Radiographic, scintigraphic and gas dilution estimates of individual lung and blood volumes in man. Thorax 1980; 35: 777-780.

51. Quanjer PhH, de Pater L, Tammeling GJ. - Plethysmographic evaluation of airway obstruction. Netherlands Asthma Foundation, Leusden, 1971.

52. Corbeel LJ. - Comparison of measurements of functional residual capacity and thoracic gas volume in chronic obstructive pulmonary disease. In: Prog Resp Res, vol 4 (Body plethysmography), DuBois $\mathrm{AB}$ and Van de Woestijne KP eds., pp. 199-204. Karger, Basel/New York, 1969.

53. Labadie H, Van Eenige MJ. - The routine assessment of residual volume by body plethysmography (in Dutch). Ned Tijdschr Geneeskd 1968; 115: 938-940.

54. Bedell GN, Marshall R, DuBois AB, Harris JH. Measurement of the volume of gas in the gastro-intestinal tract. Values in normal subjects and ambulatory patients. $J$ Clin Invest 1956; 35: 336-345.

55. Brown R, Hoppin FG Jr, Ingram JH Jr, Saunders NA, McFadden E Jr. - Influence of abdominal gas on the Boyle's law determination of thoracic gas volume. J Appl Physiol 1978; 44: 469-473.

56. DuBois AB, Botelho SY, Bedell GN, Marshall R, Comroe JH Jr. - A rapid plethysmographic method for measuring thoracic gas volume; a comparison with a nitrogen wash-out method for measuring functional residual capacity. $J$ Clin Invest 1956; 35: 322-326.

57. Brown R, Ingram JH Jr, McFadden ER Jr. - Problems in the plethysmographic assessment of changes in total lung capacity in asthma. Am Rev Respir Dis, 1978; 118: 685-692. 58. Brown R, Scharf S, Ingram JH Jr. - Nonhomogeneous alveolar pressure swings in the presence of airway closure. $J$ Appl Physiol 1980; 49: 398-402.

59. Demedts M, Van de Woestijne KP. - Which technique for total lung capacity measurement? Bull Europ Physiopath Respir 1980; 16: 705-709.

60. Habib MP, Engel LA. - Influence of panting technique 
on the plethysmographic measurement of thoracic gas volume. Am Rev Respir Dis 1978; 117: 265-271.

61. Rodenstein DO, Stanescu DC. - Reassessment of lung volume measurement by helium dilution and body plethysmography in chronic airflow obstruction. Am Rev Respir Dis 1982; 126: 1040-1044.

62. Shore S, Milic-Emili J, Martin JG. - Reassessment of body plethysmographic technique for the measurement of thoracic gas volume in asthmatics. Am Rev Respir Dis 1982; 126: $515-520$.

63. Shore SA, Huk O, Mannix S, Martin JG. - Effect of panting frequency on the plethysmographic determination of thoracic gas volume in chronic obstructive pulmonary disease. Am Rev Respir Dis 1983; 128: 54-59.

64. Rodenstein DO, Stanescu DC. - Demonstration of failure of body plethysmography in airway obstruction. $J$ Appl Physiol 1982; 52: 949-954.

65. Rodenstein DO, Stanescu DC. - Frequency dependence of plethysmographic volume in healthy and asthmatic subjetts. $J$ Appl Physiol 1982; 52: 159-165.

66. Beardsmore CS, Stocks J, Silverman M. - Problems in measurement of thoracic gas volume in infancy. $J$ Appl Physiol 1982; 52: 995-999.

67. Helms P. - Problems with plethysmographic estimation of lung volume in infants and small children. $J$ Appl Physiol 1982; 52: 698-702.

68. Stanescu DC, Rodenstein D, Cauberghs M, Van de Woestijne KP. - Failure of body plethysmography in bronchial asthma. J Appl Physiol 1982; 52: 939-948.

69. Mashalla YJS. - Measurement of lung volumes in healthy subjects and in subjects with airflow limitation. Emphasis on patients with airways obstruction resulting in gas mixing disorders. PhD Thesis, Dar-Es-Salaam, Tanzania, 1987.

70. Sharp JT, Henry JP, Sweany SK, Meadows WR, Pietras RJ. - Effects of mass loading the respiratory system in man. J Appl Physiol 1964; 19: 959-966.

71. Sterk PJ, Quanjer PhH, Van der Maas LLJ, Wise ME, Van der Lende R. - The validity of the single breath nitrogen determination of residual volume. Bull Europ Physiopath Respir 1980; 16: 195-213.

72. Lanier RC, Olsen GN. - Can concomitant restriction be detected in adult men with airflow obstruction? Chest 1991; 99: 826-830.

73. Wiggins J, Strickland B, Turner-Warwick M. - Combined cryptogenic fibrosing alveolitis and emphysema: the value of high resolution computed tomography in assessment. Respir Med 1990; 84: 365-369.

74. Owens MW, Kinasewitz GT, Anderson WM. - Clinical significance of an isolated reduction in residual volume. $A m$ Rev Respir Dis 1987; 136: 1377-1380.

75. Bradwik I, Wollmer P, Simonsson B, Albrechtsson U, Lyttkens K, Jonson B. - Lung mechanics and their relationship to lung volumes in pulmonary sarcoidosis. Eur Respir $J$ 1989; 2: 643-651.

76. Schwartz DA, Merchant RK, Helmers RA, Gilbert SR, Dayton CS, Hunninghake GW. - The influence of cigarette smoking on lung function in patients with idiopathic pulmonary fibrosis. Am Rev Respir Dis 1991; 144: 504-506.

77. Lindmark BE, Arborelius M Jr, Eriksson SG. Pul-monary function in middle-aged women with heterozygous deficiency of the serine protease inhibitor alphaantichymotrypsin. Am Rev Respir Dis 1990; 141: 884-888.

78. De Troyer A, Yernault JC, Rodenstein D, Englert M, De Coster A. - Pulmonary function in patients with primary spontaneous pneumothorax. Bull Eur Physiopathol Respir 1978; 14: $31-39$.
79. Lesur O, Delorme N, Fromaget JM, Bernadac P, Polu JM. - Computed tomography in the etiologic assessment of idiopathic spontaneous pneumothorax. Chest 1990; 98: 341347.

80. Colebatch HJH, Ng CKY. - Rate of increase in pulmonary distensibility in a longitudinal study of smokers. Thorax 1988; 43: 175-182.

81. Sériès F, Cormier Y, La Forge J. - Role of lung volumes in sleep apnoea-related oxygen desaturation. Eur Respir J 1989; 2: 26-30.

82. Derveaux L, Ivanoff I, Rochette F, Demedts M. Mechanism of pulmonary function changes after surgical correction for funnel chest. Eur Respir J 1988; 1: 823-825.

83. Yernault JC, Gibson GJ. - Interactions between lung and chest wall in restrictive ventilatory defects. Bull Eur Physiopathol Respir 1982; 18: 395-401.

84. Loiseau A, Loiseau P, Saumon G. - A simple method for correting single breath total lung capacity for underestimation. Thorax 1990; 45: 873-877.

85. Roberts CM, MacRae KD, Seed WA. - Multi-breath and single breath helium dilution lung volumes as a test of airway obstruction. Eur Respir J 1990; 3: 515-520.

86. Wade JF, Mortenson R, Irwin CG. - Physiologic evaluation of bullous emphysema. Chest 1991; 100: 1151-1154.

87. Nickoladze GD. - Functional results of surgery for bullous emphysema. Chest 1992; 101: 119-122.

88. Tiffeneau R, Pinelli A. - Régulation bronchique de la ventilation pulmonaire. J Fr Méd Chir Thorac 1948; 2: 221244.

89. Leuallen EC, Fowler WS. - Maximal mid-expiratory flow. Am Rev Tuberc Pulm Dis 1953; 72: 783-800.

90. Fisher J, Shaw J. - Calibration of some Wright peak flow meters. Br J Anaesth 1980; 52: 461-464.

91. Fry DL, Hyatt RE. - Pulmonary mechanics: a unified analysis of the relationship between pressure, volume and gas flow in the lungs of normal and diseased human subjects. Am $J$ Med 1960; 29: 672-689.

92. McDonald JB, Cole TJ. - The flow-volume loop: reproducibility of air and helium-based tests in normal subjects. Thorax 1980; 35: 64-69.

93. Lapp NL, Hyatt RE. - Some factors affecting the relationship of maximal expiratory flow to lung volume in health and in disease. Dis Chest 1967; 51: 475-481.

94. Pedersen OF, Ingram RH Jr. - Configuration of maximum expiratory flow-volume curve: model experiments with physiological implications. J Appl Physiol 1985; 58: 13051313.

95. Neuburger N, Levison H, Kruger K. - Transit time analysis of the forced expiratory vital capacity in cystic fibrosis. Am Rev Respir Dis 1976; 114: 753-759.

96. Miller MR, Pincock AC. - Repeatability of the moments of the truncated forced expiratory spirogram. Thorax 1982; 37: 205-211.

97. Chinn DJ, Cotes JE. - Transit time analysis of spirograms: which blow is best? Bull Europ Physiopath Respir 1986; 22: $461-466$.

98. Harrison BDW. - Upper airway obstruction - a report on sixteen patients. Quart J Med 1976; 45: 625-645.

99. Labadie H. - Proc Europ Acad Allergy, Barcelona 1960, pp. 83-112. Stenfert Kroese, Leiden 1960.

100. Jones JSR, Renzetti AD Jr, Mitchell MM. - The maximal breathing capacity in extrathoracic airway obstruction. Am Rev Respir Dis 1972; 106: 925-927.

101. Miller RD, Hyatt RE. - Evaluation of obstructing lesions of the trachea and larynx by flow-volume loops. Am Rev Respir Dis 1973; 108: 475-481.

102. Rotman HH, Liss HP, Weg JG. - Diagnosis of upper 
airway obstruction by pulmonary function testing. Chest 1975; 68: 796-799.

103. Kryger M, Bode F, Antic R, Anthonisen N. - Diagnosis of obstruction of the upper and central airways. Am J Med 1976; 61: 85-93.

104. Fletcher C, Peto R, Tinker C, Speizer FE. - The natural history of chronic bronchitis and emphysema. Oxford University Press, Oxford, 1976.

105. Mead J. - Volume displacement body plethysmograph for measurements on human subjects. J Appl Physiol 1960; 15: 736-740.

106. Pincock AC, Miller MR. - The effect of temperature on recording spirograms. Am Rev Respir Dis 1983; 128: 894 898.

107. Hankinson JL, Viola DO. - BTPS correction factors for spirometric data. J Appl Physiol 1983; 44: 1354.

108. Hankinson JL, Castellan RM, Kinsley KB, Keimig DG. Effects of spirometer temperature on $\mathrm{FEV}_{1}$ shift changes. $J$ Occup Med 1986; 28: 1222-1225.

109. ATS Statement. Standardization of spirometry - 198 update. Am Rev Respir Dis 1987; 136: 1285-1298.

110. Laval P, Feliciano JM, Fondarai J, Kleisbauer JP, Poirier R. - Variations de la capacité respiratoire fonction-nelle et des résistances des voies aériennes chez des sujets normaux en position assise puis couché. Bull Physiopath Respir 1971; 7: 743-764.

111. Burki NK. - The effects of changes in functional residual capacity with posture on mouth occlusion pressure and ventilatory pattern. Am Rev Respir Dis 1977; 116: 895-900.

112. Parot S, Chaudun E, Jacquemin E. - The origin of postural variations of human lung volumes as explained by the effects of age. Respiration 1970; 27: 254-260.

113. Townsend MC. - Spirometric forced expiratory volumes measured in standing versus the sitting posture. Am Rev Respir Dis 1984; 130: 123-124.

114. Pierson DJ, Dick NP, Petty TL. - A comparison of spirometric values with subjects in standing and sitting positions. Chest 1976; 70: 17-20.

115. Bates DV, Macklem PT, Christie RV. - Respiratory function in disease. 2nd ed. WB Saunders, Philadelphia, 1971. 116. D'Angelo E, Robatto FM, Calderini E, Tavola M, Bono D, Torri G, Milic-Emili E. - Pulmonary and chest wall mechanics in anesthetized paralyzed humans. J Appl Physiol 1991; 70: 2602-2610.

117. D'Angelo E, Prandi E, Milic-Emili J. - Dependence of maximal flow-volume curves on time-course of preceeding inspiration (abstract). Am Rev Respir Dis 1992; 145: A28.

118. Nadel JA, Tiemey DF. - Effect of previous deep inspiration on airway resistance in man. J Appl Physiol 1961; 16: 717-719.

119. Fairshter RD. - Effect of deep inspiration on expiratory flow in nomals and patients with chronic obstructive pulmonary disease. Bull Europ Physiopathol Respir 1986; 22: 119-125.

120. Fairshter RD. - Airway hysteresis in normal subjects and individuals with chronic airflow obstruction. $J$ Appl Physiol 1985; 58: 1505-1510.

121. Zamel N. - Partial flow-volume curves. Bull Europ Physiopathol Respir 1984; 20: 471-475.

122. Mialon P, Barthélémy L, Sébert P. - Effects of maximal breath holding on maximal expiratory flows. Eur Respir $J$ 1989; 2 : 340-343.

123. Duggan CJ, Chan J, Whelan AJ, Berend N. - Bronchodilation induced by deep breaths in relation to transpulmonary pressure and lung volume. Thorax 1990; 45: 930-934.

124. Gayrard P, Orehek J, Grimaud C, Charpin J. - Mechanism of the bronchoconstrictor effects of deep inspiration in asthmatic patients. Thorax 1979; 34: 234-240.
125. Fish JE, Peterman VI, Cugell DW. - Effect of deep inspiration on airway conduction in subjects with allergic rhinitis and allergic asthma. J Allergy Clinical Immunol 1977; 60: $41-46$.

126. Fish JE, Ankin MG, Kelly JF, Peterman VL. - Regulation of bronchomotor tone by lung inflation in asthmatic and non-asthmatic subjects. $J$ Appl Physiol 1981; 50: 1079-1086.

127. Zamel N, Hughes D, Levison H, Fairshter RD, Gelb AF - Partial and complete maximum expiratory flow-volume curves in asthmatic patients with spontaneous bronchospasm. Chest 1983; 83: 35-39.

128. Berry RB, Fairshter RD. - Partial and maximal expiratory flow-volume curves in normal and asthmatic subjects before and after inhalation of metaproterenol. Chest 1985; 88: 697-702.

129. Gayrard P, Orehek J, Grimaud C, Charpin J. - Bronchoconsfrictor effect of a deep inspiration in patients with asthma. Am Rev Respir Dis 1975; 111: 443-449.

130. Orehek J, Charpin J, Velardocchio JM, Grimaud C. Bronchomotor effect of bronchoconstriction-induced deep inspirations in asthmatics. Am Rev Respir Dis 1980; 121: 297305.

131. Lim TK, Pride NB, Ingram JH Jr. - Effects of volume history during spontaneous and acutely induced airway obstruction in asthma. Am Rev Respir Dis 1987; 135: 591-596.

132. Beaupré A, Orehek J. - Factors influencing the bronchodilator effect of a deep inspiration in asthmatic patients with provoked bronchoconstriction. Thorax 1982; 37: 124-128.

133. Bums CB, Taylor WR, Ingram RH. - Effects of deep inhalation in asthma: relative airway and parenchymal hysteresis. J Appl Physiol 1985; 59: 1590-1596.

134. Hida W, Arai M, Shindoh C, Liu Y-N, Sasaki H, Takishima T. - Effect of inspiratory flow rate on bronchomotor tone in normal and asthmatic subjects. Thorax 1984; 39: 86-92.

135. Orehek J, Nicoli MM, Delpierre S, Beaupré A. Influence of the previous deep inspiration on the spirometric measurement of provoked bronchoconstriction in asthma. Am Rev Respir Dis 1981; 123: 269-272.

136. Pichurko BM, Ingram RH. - Effects of airway tone and volume history on maximal expiratory flow in asthma. $J$ Appl Physiol 1987; 62: 1133-1140.

137. Malo J, L'Archevèque J, Cartier A. - Comparative effects of volume history on bronchoconstriction induced by hyperventilation and methacholine in asthmatic subjects. Eur Respir J 1990; 3: 639-643.

138. Wheatley JR, Paré PD, Engel LA. - Reversibility of induced bronchoconstriction by deep inspiration in asthmatic and normal subjects. Eur Respir J 1989; 2: 331-339.

139. Sterk PJ, Daniel EE, Zamel N, Hargreave FE. - Limited bronchoconstriction to methacholine using partial flow-volume curves in non-asthmatic subjects. Am Rev Respir Dis 1985; 132: 272-277.

140. Ferris BG Jr, Speizer FE, Bishop Y, Prang G, Weener J. - Spirometry for an epidemiologic study: deriving optimum summary statistics for each subject. Bull Europ Physiopathol Respir 1978; 14: 145-166.

141. ATS Statement - Snowbird workshop on standardization of spirometry. Am Rev Respir Dis 1979; 119: 831-838.

142. Knudson RJ, Lebowitz MD, Slatin RC. - The timing of the forced vital capacity. Am Rev Respir Dis 1979; 119: 315318.

143. Kory RC, Callahan R, Boren HG, Syner HC. - The Veterans Administration - Army co-operative study of pulmonary function. 1. Clinical spirometry in normal men. Am J Med 1961; 30: 243-258.

144. Gimeno F, Berg WC, Sluiter HJ, Tammeling GJ. 
- Spirometry-induced bronchial obstruction. Am Rev Respir Dis 1972; 105: 68-74.

145. Pennock BE, Rogers RM, McCaffee DR. - Changes in measured spirometric indices - what is significant. Chest 1981; 80: 97-99.

146. Peslin R, Bohadana A, Hannhart B, Jardin P. Comparison of various methods for reading maximal expiratory flow-volume curves. Am Rev Respir Dis 1979; 119: 271-278. 147. Schrader PC, Quanjer PhH, Van Zomeren BC, DeGroodt EG, Wever AMJ, Wise ME. - Selection of variables from maximum expiratory flow-volume curves. Bull Europ Physiopathol Respir 1978; 14: 43-49.

148. Tammeling GJ, Quanjer PhH. - Contours of breathing 1. CH Boehringer Sohn, Ingelheim am Rhein, 1979.

149. Perks WH, Sopwith T, Brown D, Jones CH, Green M. Effects of temperature on Vitalograph spirometer readings. Thorax 1983; 58: 592-594.

150. Pedersen OF, Naeraa N, Lyager S, Hilberg C, Larsen L. - A device for evaluation of flow recording equipment. Bull Europ Physiopathol Respir 1983; 19: 515-520.

151. Petusevsky ML, Lyons LD, Smith AA, Epler GR, Gaensler EA. - Calibration of time derivatives of forced vital capacity by explosive decompression. Am Rev Respir Dis 1980; 121: 343-350.

152. Hankinson JL, Gardner RM. - Standard wave forms for spirometer testing. Am Rev Respir Dis 1982; 126: 362-364.

153. Varène $P$, Vieillefond $H$, Saumon $G$, Lafosse JE. Étalonnage des pneumotachographes par méthode intégrale. Bull Physiopathol Respir 1974; 10: 340-360.

154. Hathirat S, Renzetti AD Jr, Mitchell M. - Measurement of the total lung capacity by helium dilution in a constant volume system. Am Rev Respir Dis 1970; 102: 760-770.

155. Tammeling GJ. - Residual volume and the functional residual capacity (in Dutch). PhD Thesis, Groningen, 1958.

156. Birath G, Swenson EW. - A correction factor for helium absorption in lung volume determinations. Scand J Clin Lab Invest 1956; 8: 155-158.

157. Ferris BG (principal investigator). - Epidemiology standardization project. Am Rev Respir Dis 1978; 118 (vol 6, part 2): $55-58$.

158. Cotes JE. - Transfer factor (diffusing capacity). In: Standardized lung function testing, $\mathrm{PhH}$ Quanjer, ed. Bull Europ Physiopathol Respir 1983; 19 (suppl. 5): 39-44.

159. Darling RC, Cournand A, Richards DW Jr. - Studies on intrapulmonary mixture of gases. III. Open circuit methods for measuring residual air. J Clin Invest 1940; 19: 609-618. 160. Brunner JX, Wolff G, Cumming G, Langenstein H. Accurate measurement of $\mathrm{N}_{2}$ volumes during $\mathrm{N}_{2}$ washout requires dynamic adjustment of delay time. $J$ Appl Physiol 1985; 59: 1008-1012.

161. Kowalski J, Quanjer PhH, Laros CD, Foest KA, Visser BF. - Resultate einer Methode zur schnellen Bestimmung des Residualvolumens. Pneumonologie, 1973; 149: 199-204.

162. Visser BF, Kowalski JJ. - Helium rebreathing method for the determination of functional residual capacity and residual volume. Bull Physiopath Respir 1972; 8: 132-134.

163. DeGroodt EG, Quanjer PhH, Wise ME. - Short and long term variability of indices from the single and multibreath nitrogen test. Bull Europ Physiopath Respir 1984; 20: 217-277. 164. DeGroodt EG, Quanjer PhH, Wise ME. - Influence of external resistance and minor flow variations in single breath nitrogen test and residual volume. Bull Europ Physiopath Respir 1983; 19: 267-272.

165. Rodarte JR, Hyatt RE, Westbrook PR. - Determination of lung volume by single and multiple breath nitrogen washout. Am Rev Respir Dis 1976; 114: 131-136.

166. Bründler JP, Lewis CM. - Estimation of lung volume from nitrogen washout curves. Bull Europ Physiopath Respir 1982; 18: 281-289.

167. Lundsgaard C, Van Slyke DD. - Studies of lung volumes: 1. Relation between thorax size and lung volume in normal adults. J Exp Med 1918; 27: 65-86.

168. Rahn H, Fenn O, Otis AB. - Daily variations of vital capacity, residual air and expiratory reserve including a study of the residual air method. $J$ Appl Physiol 1949; 1: 725736:

169. Wilmore JH. - A simplified method for determination of residual lung volume. J Appl Physiol 1969; 27: 96-100.

170. Demedts M, Sniderman A, Utz G, Palmer WH, Becklake MR. - Lung volumes including closing volume, and arterial blood gas measurements in acute ischaemic left heart failure. Bull Europ Physiopath Respir 1974; 10: 11-25.

171. Merkus PJFM, Verver S, Van Essen-Zandvliet EEM, Duiverman EJ, Kerrebijn KF, Quanjer PhH. - Lung volumes measured by the forced rebreathing technique in children with airways obstruction Eur Respir J 1992; 5: 879-886.

172. Nunneley SA, Flynn ET Jr, Camporesi EM. - Two tracer method for rapid determination of residual volume. $J$ Appl Physiol 1974; 37: 286-289.

173. Jones HA, Davies EE, Hughes JM. - A rapid rebreathing method for measurement of pulmonary gas volume in humans. J Appl Physiol 1986; 60: 311-316.

174. Matthys H. - Lungenfunktionsdiagnostik mittels Ganzkörperplethysmographie. Schattauer Verlag, Stuttgart/New York, 1972.

175. Nolte D, Reif E, Ulmer WT. - Die Ganzkörperplethysmographie. Methodische Probleme und Praxis der Bestimmung des intrathorakalen Gasvolumens und der Resistance-Messung bei Spontanatmung. Respiration 1968; 25: 14-34.

176. Smidt U, Muysers K. - Kritische Betrachtungen zu den methodischen Grundlagen der Ganzkörperplethysmographie. Respiration 1968; 25: 116-139.

177. Bernstein L, Shephard RH Jr. - High resolution display for variables in volume-displacement body plethysmography. $J$ Appl Physiol 1966; 21: 721-724.

178. Van de Woestijne KP, Bouhuys A. - Spirometer response and pressure correction in body plethysmography. In: Prog Resp Res, vol 4 (Body plethysmography), DuBois AB and Van de Woestijne KP eds., pp. 64-74. Karger, Basel/New York, 1969.

179. Nolte D. - Experimental studies on the existence of isothermal conditions in the human lung. In: Body Plethysmography, pp. 102-108, DuBois AB and Van de Woestijne KP eds. S Karger, Basel/New York, 1969.

180. Bargeton D, Barrès G. - Time characteristics and frequency response of body plethysmograph. In: Prog Resp Res, vol 4 (Body plethysmography), DuBois $A B$ and Van de Woestijne KP eds., pp. 2-23. Karger, Basel/New York, 1969. 181. Bohadana AB, Peslin R, Hannhart B, Teculescu D. Influence of panting frequency on plethysmographic measurement of thoracic gas volume. J Appl Physiol 1982; 52: 739747.

182. Brown R, Slutsky AS. - Frequency dependence of plethysmographic measurement of thoracic gas volume. $J$ Appl Physiol 1984; 57: 1865-1871.

183. Bégin P, Peslin R. - Influence of panting frequency on thoracic gas volume measurements in chronic obstructive pulmonary disease. Am Rev Respir Dis 1984; 130: 121123.

184. Williams JH Jr, Bencowitz HZ. - Differences in plethysmographic lung volumes. Effects of linked $v s$ unlinked spirometry. Chest 1989; 95: 117-23.

185. Bohadana AB, Teculescu D, Peslin R, Jansen da Silva JM, Pino J. - Comparison of four methods for calculating the total 
lung capacity measured by body plethysmography. Bull Europ Physiopathol Respir 1980; 16: 769-776.

186. Rodenstein DO, Francis C, Stanescu DC. - Airway closure in humans does not result in overestimation of plethysmographic lung volume. J Appl Physiol 1983; 55: 1784-1789. 187. Rodenstein DO, Goncette L, Stanescu DC. - Extrahoracic airway changes during plethysmographic measurements of lung volume. Respir Physiol 1983; 52: 217-222.

188. Barnhard HJ, Pierce JA, Joyce JW, Bates JH. - Roentgenographic determination of total lung capacity. Am J Med 1960; 28: 51-60.

189. Dull WL, Bonnassis JB, Teculescu D, Sadoul P. - Place de la radiographie thoracique dans l'estimation de la capacité pulmonaire totale. Bull Europ Physiopathol Respir 1980; 16: 777-784.

190. Loyd HM, String TI, DuBois AB. - Radiographic and plethysmographic determination of total lung capacity. Radiology 1966; 86: 7-14.

191. Nicklaus TM, Watanabe S, Mitchell MM, Renzetti AD Jr. - Roentgenologic, physiologic and structural estimations of the total lung capacity in normal and emphysematous subjects. Am $J$ Med 1967; 12: 547-553.

192. Ries AL, Clausen JL, Friedman PJ. - Measurement of lung volumes from supine portable chest radiographs. $J$ Appl Physiol 1979; 47: 1332-1335.

193. O'Shea NC, Lapp AD, Rossakoff R, Morgan WKC. Determination of lung volumes from chest films. Thorax 1970; 25: 544-549.

194. Reger RB, Young A, Morgan WKC. - An accurate and rapid radiographic method for determining total lung capacity. Thorax 1972; 27: 163-168.

195. Pratt PC, Klugh GH. - A method for the determination of total lung capacity from postero-anterior and lateral chest roentgenograms. Am Rev Respir Dis 1967; 96: 548-552.

196. Harris TR, Pratt PC, Kilburn KH. - Total lung capacity measured by roentgenogram. Am J Med 1971; 50: 756-763.

197. Barrett WA, Clayton WD, Lambson CR, Morris AH. Computerized roentgenographic determination of total lung capacity. Am Rev Respir Dis 1976; 113: 239-244.

198. Glenn WV Jr, Greene R. - Rapid computer-aided radiographic calculation of total lung capacity (TLC). Radiology 1975; 117: 269-273.

199. Paul J, Levine MD, Fraser RG, Laszlo CA. - The measurement of total lung capacity based on a computer analysis of anterior and lateral radiographic chest images. IEEE Trans Biomed Eng 1974; 21: 444-451.

200. Millar AB, Fromson B, Strickland BA, Denison DM. Computed tomography based estimates of regional gas and tissue volume of the lung in supine subjects with chronic airflow limitation or fibrosing alveolitis. Thorax 1986; 41: 932-939.

201. Denison DM, Morgan MD, Millar AB. - Estimation of regional gas and tissue volumes of the lung in supine man using computed tomography. Thorax 1986; 41: 620-628.

202. Chapman B, O'Callaghan C, Coxon R, Glover P, Jaroszkiewicz G, Howseman A, Mansfield P, Small P, Milner $\mathrm{AD}$, Coupland RE. - Estimation of lung volume in infants by echo planar imaging and total body plethysmography. Arch Dis Child 1990; 65: 168-170.

203. Zwijnenburg A, Klumper A, Roos CM, Jansen HM, Van der Schoot JB, Van Zandwijk N, Marcuse HR. - Lung volume calculations from ${ }^{81} \mathrm{Km}$ SPECT for the quantitation of regional ventilation. Clin Physiol Meas 1988; 9: 147-154.

204. Ellul-Micallef R, Fenech FF. - Effects of intravenous prednisolone in asthmatics with diminished adrenergic responses. Lancet 1975; ii: 1269-1271.

205. Afschrift M, Clément J, Peeters R, Van de Woestijne KP. - Maximal expiratory and inspiratory flows in patients with chronic obstructive pulmonary disease. Influence of bronchodilation. Am Rev Respir Dis 1969; 100: 147-152.

206. Demedts M. - The assessment of reversibility: what physiological test? Eur Respir J 1990; 3: 1084-1087.

207. Oldham PD. - A note on the analysis of repeated measurements of the same subjects. J Chron Dis 1962; 15: 969 977.

208. Watanabe S, Renzetti AD, Begin R, Bigler AH. - Airway responsiveness to a bronchodilator aerosol. Am Rev Respir Dis 1974; 109: 530-537.

209. Lorber DB, Kaltenborn W, Burrows B. - Responses to isoproterenol in a general population sample. Am Rev Respir Dis 1978; 118: 855-861.

210. Sourk RL, Nugent KM. - Bronchodilator testing: confidence intervals derived from placebo inhalations. Am Rev Respir Dis 1983; 128: 153-157.

211. Dales RE, Spitzer WO, Tousignant P, Schechter M, Suissa S. - Clinical interpretation of airway response to a bronchodilator: epidemiologic considerations. Am Rev Respir Dis 1988; 138: $317-320$.

212. Tweeddale PM, Alexander F, McHardy GJR. - Short term variability in $\mathrm{FEV}$, and bronchodilator responsiveness in patients with obstructive ventilatory defects. Thorax 1987; 42: 487-490.

213. Eliasson O, Degraff AC. - The use of criteria for reversibility and obstruction to define patient groups for bronchodilator trials. Influence of clinical diagnosis, spirometric, and anthropometric variables. Am Rev Respir Dis 1985; 132: 858864.

214. Kabondo P, Orehek J. - Réversibilité de l'obstruction bronchique dans l'asthme et la bronchite chronique. Bull Europ Physiopathol Respir 1977; 13: 826-836.

215. Rossiter C. - Contribution to discussion. Scand J Respir Dis 1976; 57: 315-316.

216. Brand PLP, Quanjer PhH, Postma DS, Kerstjens HAM, Koëter GH, Dekhuyzen PNR, et al. - Interpretation of bronchodilator response in patients with obstructive airways disease. Thorax 1992; 47: 429-436.

217. Tweeddale PM, Alexander F, McHardy GJR. - Short term variability in $\mathrm{FEV}_{\text {, }}$ : relation to pretest activity, level of $\mathrm{FEV}_{1}$, and smoking habits. Thorax 1984; 39: 928-932.

218. Meslier N, Racineux JL. - Tests of reversibility of airflow obstruction. Eur Respir Rev 1991; 1: 34-40.

219. Weir DC. - Measures of reversibility in response to bronchodilators in chronic airflow obstruction: relation to airway calibre. Thorax, 1991; 46: 43-45.

220. Harf A. - How to express the reversibility of bronchial obstruction? Editorial. Eur Respir J 1992; 5: 919-920.

221. Dompeling E, van Schayck CP, Molema J, Akkermans R, Folgering $\mathrm{H}$, van Grunsven PM, van Weel C. - A comparison of six different ways of expressing bronchodilating response in asthma and COPD; reproducibility and dependence of prebronchodilator FEV . Eur Respir J 1992; 5: 975-981.

222. Dekker FW, Schrier AC, Sterk PJ, Dijkman JH. - Validity of peak expiratory flow measurement in assessing reversibility of airflow obstruction. Thorax 1992; 47: 162-166.

223. Noseda A, Schmerber J, Prigogine T, Yernault JC. Perceived effect on shortness of breath of an acute inhalation of saline or terbutaline: variability and sensitivity of a visual analogue scale in patients with asthma or COPD. Eur Respir $J$ 1992; 5: 1043-1053.

224. Berry G. - Longitudinal observations, their usefulness and limitations with special reference to the forced expiratory volume. Bull Physiopathol Respir 1974; 10: 643655.

225. Diem JE, Jones RN, Hendrick DJ, et al. - Five-year longitudinal study of workers employed in new toluene 
diisocyanate manufacturing plant. Am Rev Respir Dis 1982; 126: $420-428$.

226. Pocock S. - Clinical trials. A practical approach. 266 pages. John Wiley and Sons, Chichester, 1983.

227. Carpenter L, Beral V, Strachan D, Ebi-Kryston KL, Inskip H. - Respiratory symptoms as predictors of 27 year mortality in a representative sample of British adults. Brit Med J 1989; 299: 357-361.

228. Burrows B, Lebowitz MD, Camilli AE, Knudson RJ. Longitudinal changes in forced expiratory volume in one second in adults. Methodologic considerations and findings in healthy nonsmokers. Am Rev Respir Dis 1986; 133: 974-980.

229. Louis TA, Robins J, Dockery DW, Spiro A III, Ware JH. - Explaining discrepancies between longitudinal and crosssectional models. J Chronic Dis 1986; 39: 831-839.

230. Vollmer WM, Johnson LR, McCamant LE, Buist AS. Longitudinal versus cross-sectional estimation of lung function decline: further insights. Stat Med 1988; 7: 685-696.

231. Van Pelt W, Quanjer PhH, Borsboom GJJM, Rijcken B, Schouten J. - Cohort effects in ventilatory function and chronic respiratory symptoms in a 12-year follow-up study (abstract). Am Rev Respir Dis 1990; 141: A326.

232. Cole TJ. - Linear and proportional regression models in the prediction of ventilatory function. J Roy Stat Soc A, 1975; 138: 297-328.

233. Quanjer PhH, Dalhuijsen A, Van Zomeren BC. - Summary equations of reference values. Bull Europ Physiopathol Respir 1983; 19 (suppl. 5): 45-51.

234. Quanjer $\mathrm{PhH}$. - Interpretation of tests of ventilatory function. In: The ECSC in technological and social research, p. 407-425, Gijón, 1989.

235. Smolej-Narancic N, Pavlovic M, Rudan P. - Ventilatory parameters in healthy nonsmoking adults of Adriatic island (Yugoslavia). Eur Respir J 1991; 4: 955-964.

236. Van Pelt W, Quanjer PhH, Borsboom G, Paoletti P, Di Pede F, Viegi G, Rijcken B, Schouten J. - Comparability of reference populations from Holland and Italy (abstract). Eur Respir J 1990; 3: P485.

237. Roca J, Sanchis J, Agusti-Vidal A, Segarra F, Navajas D, Rodriguez-Roisin R, Casan P, Sans S. - Spirometric reference values from a Meditteranean population. Bull Europ Physiopathol Respir 1986; 22: 217-224.

238. Paoletti P, Pistelli G, Viegi G et al. - Reference values for vital capacity and flow-volume curves from a general population study. Bull Europ Physiopathol Respir 1986; 22: 451-459.

239. Roberts CM, MacRae KD, Winning AJ, Adams L, Seed WA. - Reference values and prediction equations for normal lung function in a non-smoking white urban population. Thorax 1991; 46: 643-650.

240. Quanjer PhH, Helms P, Bjure J, Gaultier Cl, eds. Standardization of lung function tests in paediatrics. Eur Respir $J$ 1989; 2 (suppl. 4): 121s-264s.

241. Cotes JE. - Lung function: Assessment and application in medicine, 5th edition. Blackwell Scientific Publications, Oxford, 1993.

242. Yang T-S, Peat J, Keena V, Donnelly P, Unger W, Woolcock A. - A review of the racial differences in the lung function of normal Caucasian, Chinese and Indian subjects. Eur Respir J 1991; 4: 872-880.

243. Donnelly PM, Yang T-S, Peat JK, Woolcock AJ. What factors explain racial differences in lung volumes? Eur Respir J 1991; 4: 829-838.

244. Miller GJ, Saunders MJ, Gilson RJC, Ashcroft MT. Lung function of healthy boys and girls in Jamaica in relation to ethnic composition and habitual physical activity. Thorax 1977; 32: 486-496.
245. Reed TE. - Caucasian genes in American negroes. Science 1969; 165: 762-768.

246. Becklake MR. - Concepts of normality applied to the measurement of lung function. Am J Med 1986; 80: 11581164.

247. Lam K-K, Pang S-C, Allan WGL, et al. - A survey of ventilatory capacity in Chinese subjects in Hong Kong. Ann Hum Biol 1982; 9: 459-472.

248. Marcus BE, Maclean CJ, Curb JD, et al. - Reference values for FEV, in Japanese-American men from 45 to 68 years of age. Am Rev Respir Dis 1988; 138: 1393-1397.

249. De Hamel FA, Welford B. - Lung function in Maoris and Samoans working in New Zealand. NZ Med J 1983; 96: 560-562.

250. Malik MA, Moss E, Lee WR. - Prediction values for the ventilatory capacity in male West Pakistani workers in the United Kingdom. Thorax 1972; 27: 611-619.

251. Kamát SR, Tyahi NK, Rashid SSA. - Lung function in Indian adult subjects. Eung India 1982; 1: 11-21.

252. Rossiter CE, Weill H. - Ethnic difference in lung function; evidence for proportional differences. Internat $J$ Epidemiol 1974; 3: 55-61.

253. Quanjer $\mathrm{PhH}$. - Predicted values: how should we use them (letter). Thorax 1988; 43: 663-664.

254. Quanjer PhH, Stocks J, Polgar G, Wise M, Karlberg J, Borsboom G. - Compilation of reference values for lung function measurements in children. Eur Respir $J$ 1989; 2, Suppl. 4: $184 \mathrm{~s}-261 \mathrm{~s}$.

255. Miller MR, Pincock AC. - Predicted values: how should we use them? Thorax 1988; 43: 265-267.

256. Sobol BJ, Weinheimer B. - Assessment of ventilatory abnormality in the asymptomatic subject: an exercise in futility. Thorax 1966; 21: 445-449.

257. Oldham PD. - Percent of predicted as the limit of normal in pulmonary function testing: a statistically valid approach. Thorax 1979; 34: 569.

258. Crapo RO, Morris AH, Gardner RM. - Reference spirometric values using techniques and equipment that meet ATS recommendations. Am Rev Respir Dis 1981; 123: 659664.

259. Miller A. - Prediction equations and "normal values". In: Miller A, ed. Pulmonary function tests in clinical and occupational lung disease. New York, Grune \& Stratton, 1986; 197-213.

260. ATS Statement. - Lung function testing: selection of reference values and interpretative strategies. Am Rev Respir Dis 1991; 144: 1202-1218.

261. Documenta Geigy: Wissenschaftliche Tabellen, 7th ed. Diem K, Lentner C, eds. JR Geigy AG, Basel, 1968.

262. Fisher KA, Yates F. - Statistical tables for biological, agricultural and medical research, 6th ed. Oliver and Boyd, Edinburgh, 1963.

263. Peslin R. - Frequency response of pneumotachographs. Bull Physiopathol Respir 1972; 8: 1363-1376.

264. Lemen RJ, Gerdes CB, Wegmann MJ, Perrin KJ. - Frequency spectra of flow and volume events for forced vital capacity. J Appl Physiol 1982; 53: 977-984.

265. Peslin R, Jardin P, Bohadana A, Hannhart B. - Harmonic content of the flow signal during forced expiration in normal man. Bull Europ Physiopathol Respir 1982; 18: 491-500. 266. Van Hartevelt JH, Kruyt EW, Van Zomeren BC. On-line assessment of flow-volume curves (in Dutch). Proceedings Medisch Informatica Congres 79, pp. 229-232. J.L. Willems, Antwerpen 1979.

267. Peslin R, Jardin P. - Influence of second-order data filtering on common forced expiration indices. Clinical Physiology 1983; 3: 123-130. 
268. Kruyt EW, Van Hartevelt JH, Quanjer PhH, Douma JH. - Frequency requirements for pneumotachometers for recording maximum expiratory flow-volume curves. Bull Europ Physiopathol Respir 1982; 18: 42p-43p.

269. Gardner R (chaiman). - Report of Snowbird workshop on standardization of spirometry. ATS News 1977; 3: 20-25.

270. Mitchell DM, Fleming J, Pinching AJ, Harris JRW, Moss FM, Veale D, Shaw RJ. - Pulmonary function in human immunodeficiency virus infection. A prospective 18-month study of serial lung function in 474 patients. Am Rev Respir Dis 1992, 146: $745-751$.

271. Blumenfeld W, Tumey S, Cowley RA. - Mathematical model for flow on the heated Fleisch pneumotachometer. Med Biol Eng 1973; 11: 546-551.

272. Douma JH. - Reynolds similarity law applied to airway resistance. Bull Physiopathol Respir 1969; 5: 385-395.

273. Finucane KE, Egan BA, Dawson SV. - Linearity and frequency response of pneumotachographs. J Appl Physiol 1972; 32: 121-126.

274. Hodgeman CD, West RC, Shankland RS, Selby SM ẹds. - Handbook of Chemistry and Physics, 44th ed. Chemical Rubber Co., Cleveland, Ohio 1962.

275. McCall ChB, Hyatt RE, Noble FW, Fry DL. Harmonic content of certain respiratory flow phenomena of normal individuals. J Appl Physiol 1957; 10: 215218.

276. Sterk W. - Respiratory mechanics of diver and diving apparatus. $\mathrm{PhD}$ Thesis, Utrecht, 1973.

277. Tumey SZ, Blumenfeld W. - Heated Fleisch pneumotacho- meter: a calibration procedure. J Appl Physiol 1973; 34: 117-121.

278. Miller MR, Pincock AC. - Linearity and temperature control of the Fleisch pneumotachograph. J Appl Physiol 1986; 60: 710-715.

279. Miller MR, Pedersen OF. - The characteristics and calibration of devices for recording peak expiratory flow. Eur Respir $J$ in the press.

280. Sutherland W. - The viscosity of gases and molecular force. Philos Mag 1893; 36: 507-531.

281. Kaye GWC, Laby TH (editors). - Physical and chemical constants, 9th ed. Longmans Green, London 1941.

282. Wilke CR. - Viscosity equation for gas mixtures. $J$ Chem Phys 1950; 18: 517-519.

283. Tumer MJ, MacLeod IM, Rothberg AD. - Effects of temperature and composition on the viscosity of respiratory gases. J Appl Physiol 1989; 67: 472-477.

284. Liese W, Warwick WJ, Cumming G. - Water vapour pressure in expired air. Respiration 1974; 31: 252-261.

285. Cole P. - Recordings of respiratory air temperature. $J$ Laryngbl. 1954; 68: 295-307.

286. Madan I, Bright P, Miller MR. - Expired air temperature during a maximal forced expiratory manoeuvre. In the press. 287. Hodgeman CD. - Handbook of Chemistry and Physics, ed. 33. Chemical Rubber Publ Comp, 1951-1952.

288. Visser BF. - Clinical gas analysis based on thermal conductivity. Thesis, Utrecht, 1957.

289. Biological Handbooks: Respiration and Circulation, pp. 19 and 20. Ed. PL Altman and DS Dittmer. Federation of American Societies for Experimental Biology, Bethesda, Md, 1971.

290. Merth IT, Verschragen GJ, Olievier ICW, de Winter PJ, Quanjer PhH. - Water-sealed spirometer for measurements in newborns and infants. J Appl Physiol 1993; 74: 470475 . 